\title{
Examining internal programmatic assessments implemented by physician assistant educators
}

Donald G. Shipman

West Virginia University

Follow this and additional works at: https://researchrepository.wvu.edu/etd

\section{Recommended Citation}

Shipman, Donald G., "Examining internal programmatic assessments implemented by physician assistant educators" (2004). Graduate Theses, Dissertations, and Problem Reports. 2575.

https://researchrepository.wvu.edu/etd/2575

This Dissertation is protected by copyright and/or related rights. It has been brought to you by the The Research Repository @ WVU with permission from the rights-holder(s). You are free to use this Dissertation in any way that is permitted by the copyright and related rights legislation that applies to your use. For other uses you must obtain permission from the rights-holder(s) directly, unless additional rights are indicated by a Creative Commons license in the record and/ or on the work itself. This Dissertation has been accepted for inclusion in WVU Graduate Theses, Dissertations, and Problem Reports collection by an authorized administrator of The Research Repository @ WVU.

For more information, please contact researchrepository@mail.wvu.edu. 

Examining Internal Programmatic Assessments
Implemented by
Physician Assistant Educators

Donald G. Shipman

\begin{abstract}
Dissertation submitted to the College of Human Resources and Education

at West Virginia University in partial fulfillment of the requirements

for the degree of
\end{abstract}

Doctor of Education

in

Educational Leadership Studies

Elizabeth Jones, $\mathrm{PhD}$, Chair

Ernest Goeres, $\mathrm{PhD}$

Patricia Obenauf, $\mathrm{PhD}$

Jacki Webb-Dempsey, PhD

Steven Yevich, MD

Department of Advanced Educational Studies

Morgantown, West Virginia
2004

Keywords: Assessment, Student, Learning, Outcomes

Copyright 2004 Donald G. Shipman 


\author{
ABSTRACT \\ Examining Internal Programmatic Assessments \\ Implemented by \\ Physician Assistant Educators
}

Donald G. Shipman

Programmatic student learning outcomes assessment is the process of collecting and analyzing data from a myriad of differing sources in order to develop deeper understandings of what students know, understand, and can do with their knowledge as a result of their educational experiences; this cyclic process then utilizes assessment results to improve teaching, learning, and programs (Huba \& Freed, 2000). In examining the assessments implemented by Physician Assistant (PA) educators today, a mixed-methods study (i.e., Concurrent Nested Design) utilizing survey research and document analysis was used to conduct a census of all 133 PA program directors in the nation. The results of this descriptive study indicate that PA educators are crafting well-developed programmatic and course-level student learning outcomes. The results also indicate that areas such as resource acquisition for assessment activities and the dissemination of assessment results continue to progress. The synthesis of this data appears to indicate that PA programs are early in the assessment movement. A number of recommendations for practice emerge from this research such as a need for greater levels of assessment-related faculty development and the need for more formalized assessment planning and implementation. This investigation also identifies areas for future research such as the development of guiding principles and best practices to assist PA educators in making evidence-based decisions about student learning. 


\section{Dedication}

I dedicate this study to the assessment scholars and practitioners in higher education who continually strive toward a more learned citizenry. Among this group specifically, I note Trudy Banta, Jann Freed, Mary Huba, Elizabeth Jones, and Catherine Palomba. Thank you for the essentials and a student-centered approach.

\section{And}

To the Physician Assistant educators across the nation who work so diligently to deliver competent healthcare providers to our society. Among this group in particular, I note Richard Dehn, Michael Holt, Roderick Hooker, Anthony Miller, Donald Pedersen, and William Tozier. Your support and encouragement has been invaluable.

$$
\text { And lastly, }
$$

To my father, Donald Shipman. You were the first to teach me assessment and its value in personal, professional, and organizational growth. 


\section{Acknowledgements}

I wish to acknowledge the two mentors who are most responsible for my being here today. I thank Colonels Brian Commons and Steve Yevich who urged me, rather firmly, to pursue this doctorate. They were right...

Next, I want to extend my gratitude to the members of my doctoral committee for their individual strengths and our collective synergy. My thanks to: my Chair, Dr. Elizabeth Jones, for keeping me on course and demanding high standards; to Dr. Ernie Goeres for your commonsense approaches and consistent accessibility; to Dr. Jaci WebbDempsey for your wellspring of enthusiasm and expertise; to Dr. Pat Obenauf for gnosis; and to Dr. Steve Yevich for the push that started this journey. Thank you all for this warm welcome into the Community of Scholars...

Lastly, there is no way I can adequately express my deep and eternal gratitude to my wife, Diane, and our children, Ike and Samantha, for their steadfast support during this chapter in our lives together. You are my most cherished blessing...

\section{De Oppresso Liber}

Don Shipman

West Virginia University

Spring, 2004 
Chapter One: Introduction 1

$\begin{array}{ll}\text { The Problem } & 1\end{array}$

Purpose and Significance of the Study 5

$\begin{array}{ll}\text { Research Questions } & 6\end{array}$

$\begin{array}{ll}\text { Structure of the Study } & 7\end{array}$

Chapter Two: Review of the Literature $\quad 8$

$\begin{array}{lr}\text { Conceptual Framework } & 9\end{array}$

$\begin{array}{ll}\text { Gaining Institutional Resources for Assessment } & 10\end{array}$

$\begin{array}{ll}\text { Faculty Development in Assessment } & 15\end{array}$

$\begin{array}{ll}\text { Programmatic Student Learning Outcomes } & 27\end{array}$

Student Learning Outcomes and Course Integration 30

Measurement Instruments in Assessment $\quad 35$

Using Assessment Results to make Program Improvement 45

Communicating Assessment Results to Specific Audiences 52

Definitions of Key Terms $\quad 56$

$\begin{array}{ll}\text { Chapter Three: Methodology } & 62\end{array}$

$\begin{array}{ll}\text { Research Design } & 62\end{array}$

$\begin{array}{ll}\text { Type } & 62\end{array}$

$\begin{array}{ll}\text { Rationale } & 68\end{array}$

$\begin{array}{ll}\text { Strengths and Limitations } & 69\end{array}$

$\begin{array}{ll}\text { Research Methods } & 71\end{array}$

$\begin{array}{ll}\text { Site Selection } & 71\end{array}$

$\begin{array}{ll}\text { Sampling Procedures } & 71\end{array}$ 
Data Analysis

Trustworthiness

Researcher's Background

Timeframe

Conclusion

Demographic Characteristics of Physician Assistant Program Directors

Demographic Characteristics of Physician Assistant Programs

Research Finding by Research Question

Gaining Institutional Resources for Assessment Activities

Faculty Development in the Assessment Process

Programmatic Student Learning Outcomes

Student Learning Outcome Integration

Measuring Student Learning Outcomes

Using Assessment Results to Make Program Improvements

Introduction

Interpretation of Findings and Relationship to Previous Research 
Refereneces

Appendices

Appendix A, Survey Instrument 210

Appendix B, Carnegie Classification of Physician Assistant Programs 219

Appendix C, Pilot Study Advanced Mailing 226

Appendix D, Pilot Study Cover Letter 228

Appendix E, Survey Cover Letter $\quad 231$

Appendix F, Program Document Protocol 234 


\section{List of Tables}

Table 1, Data Collection and Sources $\quad 66$

Table 2, Physician Assistant Programs by Carnegie Classification (Census) 72

Table 3, Program Directors' Demographics by Gender and Education 84

Table 4, Program Directors' Demographics by Geographical Distribution $\quad 84$

Table 5, Physician Assistant Programs by Carnegie Classification (Respondents) 86

Table 6, Faculty Status at Physician Assistant Programs $\quad 87$

Table 7, Current Student Enrollments at Physician Assistant Programs $\quad 88$

Table 8, Annual Number of Graduates from Physician Assistant Programs $\quad 89$

Table 9, Number of Years Physician Assistant Programs Accredited 90

Table 10, Current Accreditation of Physician Assistant Programs 91

Table 11, Development and Implementation of Assessment Plans at Physician Assistant Programs $\quad 92$

Table 12, Leadership Factors in a Culture of Assessment 94

Table 13, Acquisition of Institutional Resources for Assessment Activities 95

Table 14, Human Resources and the Use of Assessment Experts 96

Table 15, Type and Frequency of Assessment Sessions 98

Table 16, Assessment Topics at Faculty Development Sessions 99

Table 17, Faculty Incentives to Participate in the Assessment Process 101

Table 18, Faculty Reward System (Intrinsic) 102

Table 19, Faculty Reward System (Extrinsic) 103

Table 20, Programmatic Student Learning Outcomes (Survey) 105

Table 21, Programmatic Student Learning Outcomes (Documents) 106 
Table 22, Selected Programmatic Mission Statements, Goals, $\begin{array}{ll}\text { and Student Learning Outcomes } & 107\end{array}$

Table 23, Selected Programmatic Mission Statements, Goals, and Student Learning Outcomes 108

Table 24, Characteristics of Effective Student Learning Outcomes in Physician Assistant Courses (Survey)

Table 25, Characteristics of Effective Student Learning Outcomes in Physician Assistant Courses (Documents)

Table 26, Characteristics of Effective Student Learning Outcomes in Physician Assistant Courses (Samples)

Table 27, Characteristics of Effective Student Learning Outcomes in Physician Assistant Courses (Samples)

Table 28, Effective Integration of Bloom's Taxonomy in Course-Level Student Learning Outcomes (Documents)

Table 29, Effective Integration of Bloom's Taxonomy in Course-Level Student Learning Outcomes (Samples)

Table 30, Effective Integration of Bloom's Taxonomy in Course-Level Student Learning Outcomes (Samples)

Table 31, Use of Commercially and Locally-Developed Instruments by Physician Assistant Educators

Table 32, Use of Direct, Course-Embedded Instruments by Physician Assistant Educators 
Table 33, Use of Indirect Instruments

by Physician Assistant Educators

125

$\begin{array}{ll}\text { Table 34, Measurement Demographics } & 127\end{array}$

Table 35, Using Assessment Results to Make Program Improvements 128

Table 36, Assessment Reporting Formats 129

Table 37, Internal Audiences Receiving Assessment Reports 130

Table 38, External Audiences Receiving Assessment Reports 131

Table 39, Dissemination Plan for Assessment Results

at Physician Assistant Programs

132 


\section{List of Figures}

$\begin{array}{lr}\text { Figure 1, Conceptual Framework } & 9\end{array}$

Figure 2, Concurrent Mixed Model Design $\quad 63$

Figure 3, Concurrent Nested Design $\quad 64$

Figure 4, Triangulation of Research Questions $\quad 67$ 


\section{CHAPTER ONE. INTRODUCTION}

The Problem

"What have our students learned and how well have they learned it" (Huba \&

Freed, 2000, p. 8). Today, educators, and Physician Assistant (PA) educators specifically, continue to ask themselves this centuries-old question. During the 1980 s, educators in the United States initiated the current assessment movement in response to external, organizational, and internal influences that sought the answer to this question (Ewell, 1987, 2002; Jones, 2002; Stark \& Lattuca, 1997). What, however, is assessment and how can it help answer this question? Huba and Freed (2000) define assessment in the following way:

Assessment is the process of gathering and discussing information from multiple and diverse sources in order to develop a deep understanding of what students know, understand, and can do with their knowledge as a result of their educational experiences; the process culminates when assessment results are used to improve subsequent learning (p. 80).

The planning and implementation of institutional and programmatic assessment to ascertain what students have learned and how well they have learned it encompasses a number of challenges. Some of these challenges are, for example, acquisition of institutional resources, faculty development, student learning outcomes, measurement of outcomes, change based upon assessment results, and the dissemination of those results.

One of the earliest challenges facing those involved in assessment is that of a definitional nature (Terenzini, 1989). Specifically, what are the similarities and differences between programmatic evaluation and programmatic assessment? The 
responsive evaluation model developed by Robert Stake (1973), for example, focuses on a program's stakeholders, scope, data, and reporting much like programmatic assessment. The major difference between programmatic evaluation and programmatic assessment, however, is that the former is process oriented while the latter examines a program's affect on student learning outcomes. Additionally, newer faculty members may be confused by the term "program (or programmatic) review" and its relationship to the above terminology. Gaff, Ratcliff, and Associates (1996) define program review as "the periodic monitoring of an academic program to determine what knowledge should form the substance of education, how it should be organized in a curriculum, and how it should be communicated to students" (p. 591). Defining assessment language, then, is an important consideration for ensuring clarity within higher education (Bennion, 2002) and PA education (J. Cawley, personal communication, May 6, 2002) in particular.

Perhaps the most critical of these assessment-related challenges is that of faculty development. As noted by Palomba and Banta (1999), "Of all the important factors in creating a successful assessment program, none matters more than widespread involvement of those who are most affected by it" (p. 53). Faculty members charged with the planning and implementation of assessment need formal instruction in the assessment process. Research conducted by Licklinder, Schnelker, and Fulton (1997) and Huba and Freed (2000) finds that institutional support for assessment-related faculty development must be a sustained, long-term endeavor to achieve positive gains in faculty attitudes and their knowledge base. The challenge, then, is to gain institutional resources to facilitate assessment-related faculty development and to use that development to subsequently energize the assessment effort. 
One of the first issues that faculty often face when planning assessment activities is the analysis of the mission statement and its seamless linkage to institutional, or program, goals and objectives. It is in the mission statement that the educational values of the institution, and by extension the faculty, are captured and crystallized. However, Banta, Lund, Black, and Oblander (1996) observe that, "Too often, these statements fail to say much about students or student learning" (p. 4). Hence, whether at the institutional or programmatic level, the linkages between mission statements and goals should, ultimately, be reflected in the final student learning outcomes. At its most specific, the values of the institution and faculty will be manifested in the classroom as carefully crafted student learning outcomes become reality.

Having established consistent institutional values and created avenues to establish what students should know and be able to do with their knowledge; faculties are next challenged with how to measure student outcomes. As Boland and Laidig (2001) note, "The need to identify and or construct valid measurement tools is critical to the success of data collection and interpretation" (p. 86). Given that there is a heavy reliance upon testing in the assessment of student learning, it is interesting to note that "not all college teachers know how to write good tests" (Jacobs \& Chase, 1992, p. 15). Thus, the challenge of identifying and constructing measurement tools often appears daunting in terms of time, labor, and care to those faculty members who have never developed new methods for ascertaining student learning.

The next challenge is how faculty members use assessment results to affect growth on the part of the institution, themselves, and the students they teach. In 1996, Banta et al. found that "assessment and improvements are often separated by a single 
important point: assessment focuses on the what, improvement on the what-you-do-with$i t^{\prime \prime}$ (p. 50). It appears, then, that establishing linkages between assessment results and real improvements is a crucial step in the process.

Another challenge facing institutions and programs is that of using of assessment results. Palomba and Banta (1999) note that a "key issue is how assessment results will be linked to other important processes" (p. 43). Research has found that to affect real change through the use of assessment results, these results need to be an integral part of such institutional mechanisms as curriculum review, strategic planning, and faculty development (El-Khawas, 1995; Hutchings \& Marchese, 1990; Palomba \& Banta, 1999). The challenge to assessment practitioners is the integration of the assessment process with the mechanisms listed above.

The final challenge is the communication of assessment results to a multitude of different audiences. Given the cyclic nature of the assessment process, the dissemination of assessment results is an important step in affecting change at an institution. Banta (2002) observes that in order to effectively communicate assessment results practitioners should: communicate frequently, know their audiences, and know their information. Faculty need to make important decisions about how frequently results are disseminated, to whom they are disseminated, and what specific results are provided to the respective audiences. A dissemination plan is an essential component of the assessment process.

Given the numerous and varied assessment challenges discussed above, it is hypothesized that the 133 accredited Physician Assistant training programs in the United States (Accreditation Review Commission on Education for the Physician Assistant, 2003) are meeting these challenges in a myriad of different ways. Logically, one may 
assume, then, that some programs are more successful than others in meeting these challenges. How are institutions planning and implementing assessment programs? What issues do educators encounter during the assessment process? How are these issues being addressed? What has been learned as a result of addressing these issues? Currently, there is no collective, synthesized picture of the existing programmatic assessment practices in Physician Assistant education (L. J. Stuetzer, personal communication, August 28, 2003). This research seeks to investigate this problem.

\section{Purpose and Significance of the Study}

Given the above problem, the purpose of this research is threefold. First, the study's general purpose is to add additional assessment-related knowledge to the field of education and most specifically to PA education. In an effort to add to the existing body of assessment knowledge, this study will examine the internal programmatic assessments currently being implemented by PA educators. To paraphrase Zusman (1994), do colleges and universities use assessment as a mechanism to improve teaching and learning? The addition of incremental knowledge to assist in the answering of this question has intrinsic value to institutions of higher learning and the scholars in these institutions. In brief, organizations and people can potentially be affected by the results of this study through increases in programmatic improvement and student learning.

Second, the primary motivation for undertaking this investigation is to provide synthesized feedback to PA educators nationwide on the current assessment practices of their peers. Given the growing sense of isolation experienced by the professoriate today (Altbach, 1994, p. 231), the results of this research can serve to increase a sense of professional inclusion regarding assessment practices, accreditation concerns, and 
programmatic improvement strategies. It would seem, therefore, that the nature of this research and its subsequent findings will be of value to educational administrators and assessment practitioners through the increased communication of assessment activities within the discipline.

Third, the study is further intended to establish a baseline for the profession by identifying where PA education is currently located along the programmatic assessment continuum in higher education. The research results will provide rich data for future investigators who wish to explore programmatic assessment or its sub-categories for the specific benefit of the profession and higher education in general.

\section{Research Questions}

The examination of currently implemented internal programmatic assessments by PA educators will focus on the following seven research questions:

1. What types of institutional resources are available to conduct assessment?

2. How is assessment planning integrated into PA faculty development?

a. How is the faculty development initiative structured?

b. What incentives and rewards are used to motivate faculty participation?

3. What programmatic student learning outcomes (e.g., cognitive, affective, and psychomotor domains) are used by PA educators?

4. How are student learning outcomes integrated into PA program courses?

5. What measurement instruments (e.g., commercially-developed vs. locallydeveloped, direct vs. indirect) do PA educators use in the assessment of their programs?

6. How do faculties use assessment results to make program improvements? 
7. How do faculties communicate assessment results and to what audiences?

\section{Structure of Study}

The remainder of this research study includes the literature review and the research design and methods. Chapter Two focuses on a review of the literature. This chapter examines the scholarly literature to investigate previous assessment-related research results in the seven major areas illuminated by the research questions. Previous studies are reviewed and synthesized for the identification of the strengths and limitations contained in these studies. Chapter Three focuses on the research design and methods. The research design section of the study provides the rationale for the particular model. Further, the strengths and limitation of the model are discussed. The research method presents the site selection, sampling procedures, contact plan, and data collection and analysis. The issues of validity and reliability are addressed in this section. Lastly, the researcher's background and timeframe is discussed. The study ends with a brief conclusion. Immediately following the conclusion, a bibliography and appendix is provided. The appendix includes a Carnegie classification of accredited PA programs, pilot study participants, cover letters, and survey instrument. 


\section{CHAPTER TWO. REVIEW OF THE LITERATURE}

Having defined assessment in higher education, one is compelled to wonder at the origins of the movement. Aper and Hinkle (1991) provide a concise narrative addressing this issue:

Since the late 1960s concerns have been articulated in various forums over the quality and public accountability of institutions of higher education... [in the] 1970 s accountability tended to be strongly influenced by efforts to systematize and measure the resources committed to institutions of higher education and subsequently to analyze quantitative indicators of productivity... In the 1980s such interests did not abate but shifted toward obtaining evidence of the quality and effectiveness of colleges and universities in educating students. As a result, by early 1990 over forty of the states have adopted or plan to adopt policies of various kinds under the broad umbrella of assessment that are intended to enhance institutional accountability, provide impetus for the reform and improvement of educational practice, or both. (p. 539)

With this history in mind, the purpose of this literature review is to discover what assessment scholars and practitioners have learned in relation to the research questions outlined above (see page 6). The conceptual framework provided on the following page illustrates these research questions and their sub-categories. For example, the review examines the acquisition of institutional resources (Research Question \# 1), the role of institutional leadership, initial costs for assessment, and sustaining the assessment effort through budgeting cycles. 
Figure 1. Conceptual Framework

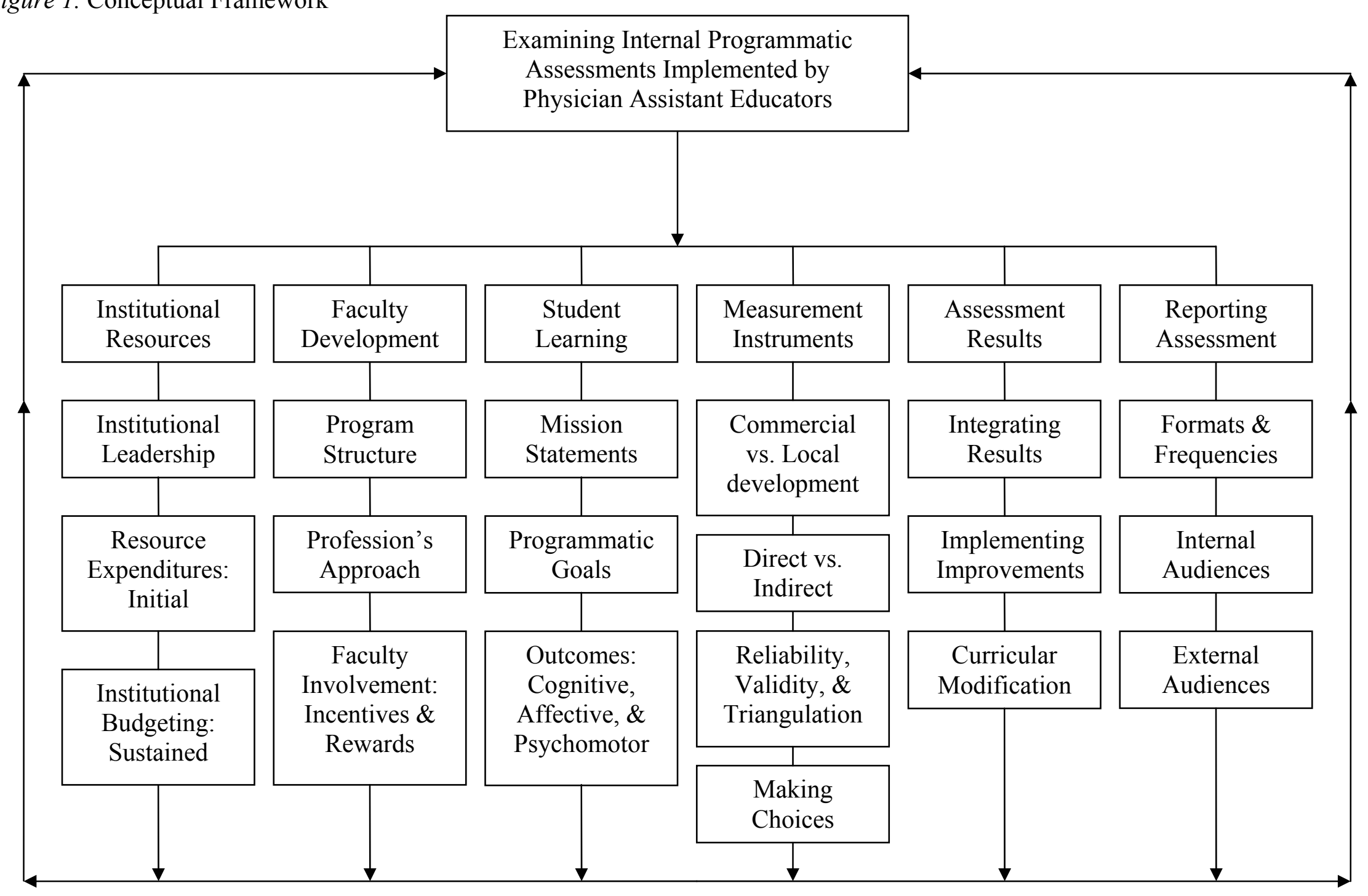




\section{Gaining Institutional Resources for Assessment}

The process of assessing student learning, like other programmatic or institutional endeavors, competes for scarce and valued resources. Based upon this competition, it is extremely important to gain executive-level support for assessment planning and implementation (Jones, 2002; Kuh, Gonyea, \& Rodriguez, 2002; Upcraft \& Schuh, 1996). Institutional executives and senior academic leaders become the "public advocate, leader, and facilitator for creating an institutional culture that is open to change, willing to take risks, and fosters innovations by providing real incentives for participants" (Jones, Voorhees, \& Paulson, 2002, p. 20). In sum, these individuals can provide multifaceted leadership through external, strategic, process, and technical vision (Peterson \& Vaughan, 2002). Without this strong political foundation, the assessment structure will fail (Terenzini, 1989).

\section{Institutional Leadership}

Given the direct linkage between institutional leaders and the successful acquisition of resources to support the assessment effort, it is worth examining those leadership traits that exist in flourishing assessment programs. In the National Postsecondary Education Cooperative study conducted by Jones, Voorhees, and Paulson (2002), a number of important leadership traits were identified as hallmarks of success. They noted that these leaders:

- $\quad$ are directly involved in the assessment process;

- meet regularly with assessment personnel;

- maximize honest, open, two-way communication;

- establish an environment based on trust; 
- treat faculty, staff, and administrators as collaborators in a team effort;

- demonstrate a commitment to assessment by providing real incentives for participation and support (e.g., time, teaching loads, grants, stipends, students);

- encourage assessment personnel to use a deliberate planning process;

- to make slow, incremental changes thereby increasing chances for success; and

- approve the integration of assessment and budget.

Obviously, to gain the above caliber of institutional sponsorship, assessment practitioners need to articulate and justify the diversion of resources to plan, implement, and sustain the assessment effort. It is essential that faculties transmit that "adequate resources are a necessary component of successful assessment strategies" (Banta, Lund, Black, \& Oblander, 1996, p. 66). Further, faculties must ensure that decision makers understand the importance of earmarking resources solely for the purpose of conducting assessment activities (E. Goeres, personal communication, November 18, 2003).

\section{Resource Expenditures}

The literature illuminates a number of different costs associated with the assessment endeavor. The Middle States Commission on Higher Education (MSCHE) specifies that resources to conduct assessment initiatives should encompass "human, financial, technical, physical facilities, and other resources necessary to achieve an institution's mission and goals" (2003, p. 59). The commission identifies six areas in particular where leaders and faculties may expect to incur assessment expenses. These are related to: (a) personnel costs; (b) constructing new or purchasing existing assessment instruments; (c) administering instruments, conducting interviews or focus groups; (d) data entry; (e) computer hardware and software; and (f) communication costs for 
organizing efforts and for report and disseminating results (p. 59). There are, of course, a number of other costs that will need to be considered as well. Most specifically, the faculty incentive and reward protocols will provide the impetus that drives the entire assessment process forward. This will be explored in greater detail under Faculty Development (see page 15).

\section{Institutional Budget}

The resource expenditures described above are an obvious part of the initial assessment planning process; however, leaders and faculty need to be especially cognizant that many of these costs will remain as part of the resources required to sustain the assessment effort. For example, on one hand, the purchase of computer hardware to support assessment efforts can be considered an initial cost given that it will probably not need to be replaced for years. On the other hand, there are a number of routinely occurring sustainment costs (such as instrument selections, travel, and grants) that need to be forecasted in the institutional and assessment budgets.

Given the resource expenditures to sustain the assessment endeavor, senior leaders, as facilitators of the assessment process, need to recognize the importance of linking assessment to other institutional mechanisms (Banta, Lund, Black \& Oblander, 1996; Peterson \& Vaughan, 2002). In an effort to make the assessment process as cost effective and operationally efficient as possible, many leaders facilitate the linkage of the assessment effort to existing institutional mechanisms such as planning, budgeting, and curriculum review (American Association for Higher Education [AAHE], 1992; Jones, Voorhees, \& Paulson, 2002; Lopez, 1999; MSCHE, 2003). Ultimately, student assessment needs to be part of a "clearly defined strategy, which incorporates it into the 
more formal organizational and administrative framework" thus becoming an "important determinant of whether the resulting information will be used in making academic decisions" (Peterson \& Vaughan, 2002, p. 41).

"The measures of institution-wide support that prevail at each institution are a good indicator of the quality of the assessment effort" (Peterson, Vaughan, \& Perorazi, 2001, p. 78). Thus, the need to appropriate sufficient funding to initiate and sustain an assessment initiative cannot be overstated. Lopez (1999) notes that "institutions that have demonstrated improvements in their assessment programs have administrators who recognize that assessment activities require an investment of institutional dollars" (p. 29).

Lopez also states that a strong indicator of a healthy institution-assessment relationship is one where budget lines for assessment are approved in successive annual budgets. This aspect of assessment-related budgeting indicates the need for assessment personnel to be especially cognizant of the institutional planning and budgeting cycles and how assessment programs can be integrated into these mechanisms (Lopez, 1999). Further, Lopez notes that:

in colleges and universities where the expression "linking assessment to planning and budgeting" is not understood, there is always the danger that no special funds will be set aside for the assessment program and that activities it generates will have to be delayed for two or even three years. $(1999$, p. 32)

Two cases

The successes and failures of assessment initiatives to flourish as a result of resources can be highlighted by cases at Virginia Commonwealth University (VCU) and 
the University of Missouri-Kansas City (UMKC). At Virginia Commonwealth University, a public Research I of 21,800 students, a variety of different funds were used in the assessment of the Bachelor of Social Work (B.S.W.) program. In this particular case, the initiative's focus was on the assessment of the B.S.W. program to professional writing competence of seniors. Fuhrmann (as cited in Banta, Lund, Black, \& Oblander, 1996, p. 68), at VCU, attributes the success of their endeavor to the following:

All B.S.W. faculty were involved. The director of the program assumes the leadership and provides appropriate clerical support. The office of assessment funds the training of the faculty in holistic scoring and provides small financial incentives for participation.

At UMKC (Doctoral I, 9,800 students), the university planned to assess seniors through a locally-developed exam to test communication skills. The initiative, however, eventually failed as a result of inadequate resource funding. Aitken (as cited in Banta, Lund, Black, \& Oblander, 1996) noted several negative factors that led to the abandonment of the effort: (a) no faculty reward structure; (b) no release time; and (c) no financial commitment accompanying the project (p. 68).

Clearly, the planning, implementation, and sustainment of an assessment program competes for institutional monies. Just as clearly, "a supportive environment, characterized by effective leadership, administrative commitment, adequate resources, developmental opportunities, and time is important for effective assessment" (Banta, Lund, Black, \& Oblander, 1996, p. 68). The challenge for faculties, then, is to ensure that leadership at all levels understand the cost-benefit realities associated with assessment resource requests and expenditures. As with any program that competes for these scarce 
and valued resources, faculties must present well-organized articulations and justifications for why the assessment initiative should receive funding over other deserving programs. Penultimately, faculties have the responsibility to make the case that assessment should be highly valued at their institutions. As Lopez (1999) observes, "It has long been recognized that how an institution uses its resources is a direct reflection of its values" (p. 30).

\section{Faculty Development in Assessment}

The preparation and development of faculty to plan, implement, and sustain an institution's assessment endeavor is essential (Jones, 2002). Given that faculties shoulder the burden of the assessment process, it is incumbent upon administrators and faculty alike to ensure that a dynamic, well-organized faculty development program exists at their institutions. It is just as important that these programs provide ample opportunities for faculty to gain assessment knowledge and expertise. Additionally, faculty should be afforded chances to explore and experiment with assessment concepts and ideas (Jones, 2002). Most importantly, faculties need to acquire the confidence to use what they have learned for the improvement of their students, themselves, and the institution. The central purpose of faculty development, then, is to prepare faculty to successfully meet the demands and challenges of student learning assessment.

\section{Program Structure}

The literature discusses a number of different aspects (e.g., who, what, when, how) related to the structure of faculty development programs. In regard to who should provide consultation or advisement to faculty in assessment-related areas, scholars divide this population between those internal and external to an institution (Borden, 2002; Jones, 
Voorhees, \& Paulson, 2002). Internally, for example, programs can utilize on-campus experts such as institutional researchers to teach faculty about good instruments for measuring student learning (Jones, 2002). Another example might include having a representative of the budget committee discuss the best methods for assessment practitioners to integrate their program into the budgeting cycle.

An institution or program may find, however, that it lacks the available expertise to address an assessment issue. In this case, faculties frequently invite off-campus experts to visit the program and provide assistance. In the event that an assessment program is in the earliest stages of consideration, an expert may provide an overview of the entire process and valuable insights regarding assessment challenges. Additionally, these experts may, for example, provide information on particular pitfalls and lesson's learned to faculties further into their programs.

There are a number of considerations regarding what faculty development programs should deliver to assessment participants. Initially, faculty development programs should address issues such as assessment philosophy, language, and intentions (Bennion, 2002; Huba \& Freed, 2000; Palomba \& Banta, 1999). Other important faculty development sessions that should be delivered early in the process include faculty involvement and gaining institutional resources. Ultimately, there is a wide range of possible assessment topics that will need to be presented to faculty members to address the entire spectrum of assessment from initial planning through evaluating the assessment effort itself. Faculty development planners should also note that these sessions will need to revisit most topics on a regular basis as new assessment participants cycle through the faculty development program. 
The sequencing of when assessment topics are presented to faculty should receive considerable attention from faculty development planners. Single sessions or episodic delivery of assessment-related faculty development information have proven to be inefficient methods of equipping faculty with the tools they need to successfully meet assessment goals and objectives (American Association for Higher Education, 1992; Huba \& Freed, 2000; Licklider, Schnelker, \& Fulton, 1997). Thus, as Jones (2002) notes, successful programs are those that have "thoughtfully planned and developed a series of ongoing faculty development activities” (p. 81). Ideally, assessment topics should be presented to faculty members far enough in advance for the newly acquired information and skills to be integrated into the initial and subsequent planning stages. Additionally, Jones (2002) recommends that one- or two-week periods in the summer are an excellent time to bring faculty together to begin collaborating on new assessment phases or initiatives.

Finally, faculty development planners will need to consider how they intend to deliver assessment-related information. Obviously, a well-organized, well-publicized program that meets regularly and provides meaningful information stands the greatest chance of assisting faculty in the assessment effort (Jones, 2002; Palomba \& Banta, 1999). For example, the Alderson-Broaddus College Physician Assistant (PA) program is currently experimenting with a long-range faculty development plan that will present assessment topics to faculty members on a monthly basis (Michael Holt, personal communication, May 1, 2003).

In addition to short monthly sessions, faculty development planners will inevitably discover that they need more time to present material and collaborate on 
assessment projects. In these cases, the literature suggests that planners consider scheduling a series of seminars, retreats, or workshops to allow more time for faculty dialogue and exploration of topics (Garrison, 2000; Jones, 2002; Professional and Organizational Development Network in Higher Education, 2002). Alderson-Broaddus used this recommendation in 2003 when they planned a series of four-hour workshops every three weeks over a six-month period. Surveys taken at pre- and post-series indicate a dramatic increase in PA faculty comprehension and confidence regarding numerous aspects of the assessment process (Michael Holt, personal communication, September 12, 2003).

\section{A Discipline's Approach}

Having examined the above, it is worth noting certain historical aspects of faculty development within the PA discipline itself. Since the establishment of the first PA program at Duke University in 1965, the profession, and by extension the number of training programs, has expanded at a rapid rate. To illustrate, there are 133 accredited PA programs at the time of this review. This equates to approximately 3.5 new programs created for every year of the profession's existence. "This brisk growth has forced the PA profession to focus on the issue of PA faculty development and recruitment, as there is currently a shortage of well trained PA educators" (Carrington, 1998, p. 103).

Recognizing this shortage of well trained PA educators, the Association of Physician Assistant Programs (APAP) and the Accreditation Review Commission on Education for the Physician Assistant (ARC-PA) have taken steps to address this issue. As early as 1977, the PA profession recognized the need to assist PA educators in preparation for successful integration into academia (Carrington, 1998, p. 104). In the 
years since, the APAP, ARC-PA, and its members have continued to study, monitor, and address this trend through: (a) research and publication; (b) conferences and forums; and (c) training programs and workshops (Blessing, 1999; Carrington, 1998; Glicken \& Blessing, 1998; McCarty, Stuetzer, \& Somer, 2001).

What evidence, then, is provided in the literature about how assessment planning is integrated into PA faculty development? From an accreditation standpoint, McCarty, Stuetzer, and Somer (2001) state a philosophy that "encourage[s] efforts toward maximum educational effectiveness" (p. 24). The 2002 Accreditation Standards for Physician Assistant Education (Sec. A2.15, Professional Development) further states that, "The program must assure continuing professional growth of the core faculty by supporting their clinical, teaching, scholarly, and management responsibilities" (p. 7). Like accreditation standards in other disciplines, these standards provide general guidelines within which individual PA programs may incorporate assessment planning. Assessment planning in PA education began appearing in 1997 with the emergence of the APAP-sponsored Basic Skills Faculty Development Workshop, the Advanced Faculty Skills Development Workshop, and the Program Director Skills Development Workshop (Glicken \& Blessing, 1998, p. 97). Under the basic workshop, seminars in improving course design, writing course objectives, and assessment and evaluation of students were offered. The advanced skills workshop provided seminars in problem-based learning, critical thinking, and active learning. Additionally, curricular evaluation, course outcomes, and overall program evaluation were offered. As could be expected, the program director workshop focused on "areas related to information and skills required for system management and evaluation" (Glicken \& Blessing, 1998, p. 
98). Seminars specifically related to assessment planning included: (a) mission and vision statements; (b) accreditation and self-study; (c) grant preparation; and (d) budget.

Since their appearance in 1997, the above workshops have evolved and continue to be offered at the annual APAP Education Forum. In 2003, the forum will offer a Basic Skills Faculty Workshop and a Leadership Training Program. Assessment-related seminars that will be available to faculty educators include those in course design, writing objectives, and student assessment. Additionally, seminars such as curriculum development, outcomes assessment, and faculty development are also being offered (APAP, 2003).

As a professional body, APAP obviously recognizes and addresses aspects of assessment-related faculty development. This professional-level attention signals individual PA programs that the association is attempting to meet the needs of new faculty members. Likewise, the ARC-PA provides general guidelines to faculties regarding standards that must be met in support of these areas. As to what assessmentspecific faculty development measures are currently being undertaken by individual PA programs, there is a paucity of published material in the scholarly literature.

\section{Faculty Involvement}

Having examined the literature concerning the integration of assessment and faculty development, it is noteworthy that Banta, Lund, Black, and Oblander (1996) observe that "faculty development is not enough...to get faculty fully involved in assessment. Visible incentives should be provided to encourage faculty to develop the necessary skills to undertake assessment efforts as a means of improving the teaching and learning on campuses" (p. 53). Jones (2002) affirms this observation by recommending 
that leadership "consider providing real incentives to gain faculty support and motivation for frequently time-consuming innovations" (p. 83). Given the centrality of faculty to any assessment endeavor, what incentives do scholars illuminate in the literature that can assist faculty development and assessment planners in motivating faculty toward a sense of responsibility and ownership in the process?

\section{Faculty Responsibility}

Clearly, motivation, incentives, and rewards are inextricably linked. Palomba and Banta (1999) provide a well organized discussion addressing these issues using the four "Rs" of faculty involvement (p. 53). These "Rs" include: (a) faculty responsibility; (b) faculty resources; (c) faculty rewards; and (d) faculty resistance. In their discussion, they note that faculty involvement will occur in numerous areas. For example, some faculty may serve as institutional or programmatic assessment coordinators or on different assessment-related committees. Other faculty members may be responsible for major components of the plan such as assessment instruments, data analysis, writing reports, or dissemination plans. Ultimately, the author's recommend establishing "an explicit list of expectations about the roles of various groups involved in the assessment process" (p. 55). The incentive for faculty to participate, then, comes from being part of a formal, well organized process that clearly defines roles and responsibilities for participants.

\section{Faculty Resources}

The second component of Palomba and Banta's discussion on increasing faculty participation in assessment efforts involves the use of institutional resources as incentives. Jones (2002) recommends that administrators and faculty consider that: 
The key is identifying what faculty value that might be used as incentives - summer salary to work on the initiatives, release time from teaching a course during the academic year to reallocate time to implement the innovation, new support from a graduate or teaching assistant, or resources to attend national conferences. (p. 83)

Jones also notes that an especially important signal that institutional leaders can send to faculty to encourage involvement in the assessment endeavor is that of including participation in the promotion and tenure process.

In addition to the measures indicated by Jones, Palomba and Banta (1999) note other, more subtle, forms of resource incentives that should mirror faculty responsibilities. Faculty, they recommend, will need access to "written materials developed on campus...[and] from other sources" (p. 55). For example, faculty will need funding to generate "pamphlets describing assessment, question and answer documents" (p. 55) and a multitude of administrative office supplies. Funding should also be allocated to address the costs incurred for subscriptions to peer-reviewed publications (e.g., Assessment Update, Journal of Faculty Development) and the purchase of assessment texts (e.g., Transforming the Curriculum [Jones, 2002], Building a Scholarship of Assessment [Banta \& Associates, 2002).

Faculty Rewards

A formal, well publicized reward system to compensate faculty for work on assessment projects is the third component of the discussion on increasing faculty involvement in assessment. In establishing an authentic reward system for 
faculty participation, administrators and assessment planners will need to appeal to intrinsic and extrinsic rewards (Borden, 2002; Palomba \& Banta, 1999).

Intrinsic.

Intrinsically, planners need to articulate the benefits of increased interdepartmental, college, and institutional interactions with faculty colleagues. Additionally, many faculty may benefit from new insights regarding the linkages between the mission statement, goals, and student learning outcomes. Planners can also begin establishing the merits of increased understandings regarding the direct linkages between, for example, the assessment process and curriculum review, institutional budget, and accreditation bodies (Palomba \& Banta, 1999). Providing time for faculty to work on projects and to publish and present results of assessment initiatives also sends an important signal to faculty that assessment is important and that their contributions are valued (Banta, 2002; Jones, 2002). Lastly, the most important intrinsic reward to faculties is the assurance that assessment results will not be used to penalize them (Bordern, 2002).

\section{Extrinsic.}

There are a myriad of extrinsic rewards available to motivate faculty members to participate in the assessment process (Banta, 2002; Jones, 2002). One of the most efficient and effective methods of rewarding faculty for their assessment contributions is a consistent, well publicized recognition process (Rodrigues, 2002). The Middle States Commission on Higher Education (2003) recommends that institutional leaders make a point of using assessment language, being conversant on assessment projects, and publicly noting the efforts of individual faculty members or departments. More 
specifically, Rodrigues (2002) recommends that institutional leaders send personal notes of thanks to individual faculty members as well as writing official letters for their performance files. Perhaps the most powerful signal that institutional leaders can send to faculty members regarding recognition is the inclusions of assessment in the promotion and tenure process (Palomba \& Banta, 1999).

As noted earlier by Jones (2002), grants and stipends are also an excellent way to reward faculty efforts in assessment. The author's research indicates that "internal grants help support or foster innovations that faculty design but could not be implemented without additional resources" (p. 83). An example of these internal grants can be found at Ohio University where “ $\$ 200,000$ annually is set aside for awards to six units that propose to improve undergraduate education using assessment data" (Palomba \& Banta, 1999). Radford University uses a small grants system of $\$ 2000$ each for faculty assessment proposals (Banta, Lund, Black, \& Oblander, 1996).

The research completed by Jones (2002) also examined external grants for institutions and faculty. These research results indicate that "important seed money to begin pilot projects" (p. 83) is available from sources such as the Fund for the Improvement of Postsecondary Education or professional associations such as the American Accounting Association. For Physician Assistant faculty members specifically, the Association of Physician Assistant Programs Research Institute has grants available for a variety of initiatives (APAP, 2003).

Lastly, it is important that leaders and planners facilitate off-campus growth for their faculty members by providing monies for travel to other institutions or assessment conferences (Palomba \& Banta, 1999). Again, funding faculty travel and per diem to 
conferences and other institutions sends important signals to faculty that the institutional emphasis on assessment is being supported with concrete actions. Additionally, planners may wish to consider sending assessment practitioners from several different departments simultaneously to further develop a greater sense of cohesion and community.

\section{Faculty Resistance}

The final R, faculty resistance, has been saved until the end of this review, "but it is important to be aware of its nature" (Palomba \& Banta, 1999, p. 71). This potential resistance may be found at all levels of an institution among faculty, administrators, and staff alike. In its report covering a 10-year period of assessment activities, Lopez (1999) at the North Central Association of Colleges and Schools found three major factors associated with resistance to assessment efforts:

- misunderstandings about the nature and purpose of assessing student academic achievement and about what constitutes an assessment program, academic program review, and evaluation of institutional effectiveness;

- strongly negative reactions to the idea of "measuring" learning and the thought that assessment results could be used to actually improve students' learning; and

- lack of information and technical skills needed to understand and implement assessment (p. 9).

There are, of course, other reasons for faculty resistance to assessment, but the literature demonstrates that these are usually linked in some fashion to the factors identified by Lopez.

The above factors, then, may constitute formidable challenges for assessment and faculty development planners. Given the potential for these issues to arise, planners need 
to be vigilant for their manifestation and anticipate addressing these very real concerns on the part of those who will drive the assessment process (Rodrgues, 2002). Using the research, insights, and recommendations developed by assessment scholars in this review will help prevent assessment from being perceived as an "intrusive imposition by outsiders or a bureaucratic chore, rather than as a useful tool for the purpose of effectively accomplishing educational goals and intended student learning outcomes (Lopez, 1999, p. 9).

Ultimately, faculty development has the potential to be an impetus of individual and cultural transformation for assessment participants. For example, the faculty development process provides an opportunity for individuals to acquire new knowledge, ideas, and skills as well as receive important feedback on their current practices. Culturally, assessment-based faculty development can provide the momentum for the transition from a teacher-centered to student-centered learning environment (Huba \& Freed, 2000). At its very essence, this process should be considered a force for positive, non-punitive improvements at the institutional, programmatic, faculty, and student levels. To do this, however, faculty development programs need to be dynamic, meaningful learning environments that empower faculty to achieve assessment goals. Using the information discussed above, those interested in faculty development and assessment can apply these transformational elements to create the conditions that allow assessment to take root and flourish. As Angelo (1999) observes, it all begins with building a shared trust, a shared language, shared motivations, and shared guidelines. 


\section{Programmatic Student Learning Outcomes}

What does the body of scholarly literature say about programmatic student learning outcomes? In its broadest sense, assessment, and by extension student learning outcomes, requires "reconsideration of the essential purposes and expected academic and nonacademic outcomes of a college education. It also requires clarity of institutional and programmatic purpose as well as a specificity of practice often absent on many campuses" (Terenzini, 1989, p. 645).

Given this need for reconsideration and clarity, researchers in higher education agree that the "assessment of student learning begins with educational values" that enact "a vision of the kinds of learning that we most value for students and strive to help them achieve" (American Association for Higher Education [AAHE], 1992, p.2). Researchers also agree that it is an inclusive, collaborative effort among stakeholders that forges this vision (AAHE, 1992; Banta, 2002; Banta, Lund, Black \& Oblander, 1996). Having established such a vision, educators and administrators next set about articulating that vision through mission statements, goals, and student learning outcomes.

\section{Mission Statements}

The importance of developing thoughtful, well-crafted mission statements cannot be overemphasized. The Middle States Commission on Higher Education (MSCHE) notes that, “An institution's mission, at both broad and specific levels, serves as the context within which to assess student learning, and it is important that mission serves as the backdrop for assessment efforts at the institutional, program, and course levels" (MSCHE, 2003, p. 8). For example, comprehensive university missions are driven by the needs of the states they serve, private colleges by their boards of trustees, and faith-based 
institutions by their ecclesiastical missions (p. 8). Ultimately, an institution's mission statement will shape its goals and student learning outcomes (Astin, 1991; Huba \& Freed, 2000; MSCHE, 2003; Palomba \& Banta, 1999).

\section{Goals}

Having crafted a mission statement that accurately reflects the institutional and programmatic values, educators next articulate their respective goals. In its Principles of Good Practice for Assessing Student Learning (1992), the AAHE concluded that "assessment is a goal-driven process" that requires "clear, shared, implementable goals" that form the cornerstones of the assessment effort (p.2). These goals communicate intended educational results in general terms. For example, Palomba and Banta (1999) describe goals as "broad learning concepts such as clear communication, problem solving, and ethical awareness" (p. 26). In discussing PA education, Glicken (2002) underscores similar goals such as problem-based learning, informatics, and increasing cultural awareness for future students of the discipline.

The distinction regarding the specific definition of goals and their role within institutional and programmatic assessment is such that numerous researchers have been compelled to address this component of the assessment process at length (AAHE, 1992; Banta, 2002; Huba \& Freed, 2000; Lopez, 2000; MSCHE, 2003). The North Central Association of Colleges and Schools Commission on Institutions of Higher Education, illustrates this point. In their 10-year longitudinal study of assessment efforts, they discovered: 
....that in virtually all NCA colleges and universities, the single most important lesson faculty and administrators have learned... is that goals and objectives need focus on students, on what students will be able to demonstrate that they know, believe, and can do, not on what the institution or its faculty provide, offer, or do for students (Lopez, 2000, p. 23).

\section{Student Learning Outcomes}

Once programmatic goals have been developed, educators are challenged with developing objectives or, more accurately, student learning outcomes (SLO). SLOs "are used to express intended results in precise terms" (Palomba and Banta, 1999, p. 26).

In an academic environment that increasingly advocates a student-centered approach (Huba \& Freed, 2000), writing precise SLOs, whether at the programmatic or course level, can be frustrating for faculty members (Lopez, 2000). In their study, the NCA found that the best way to prevent faculty frustrations before writing precise student-centered SLOs is to provide faculty development opportunities in the form of written material and especially seminars and workshops (p. 24).

Regardless of how faculty development occurs and the student learning outcomes are crafted, scholars agree that the composition of SLOs is a collaborative process by program faculty (Aper \& Hinkle, 1991; Banta, 2002; Terenzini, 1989). At this stage in the process, then, the programmatic SLOs will be those outcomes identified by faculty consensus that most readily manifest the vision identified in the mission statement. Programmatically, these SLOs are what graduates will know and can do as a result of their educational experience in that program (Palomba \& Banta, 1999). 


\section{Student Learning Outcomes and Course Integration}

Well written instructional outcomes are a key guide to student learning (Stuetzer, 1999, p. 223). What, however, constitutes a well-written learning outcome? Huba and Freed (2000) identify eight characteristics of effective student learning outcomes (SLO) on learner-centered college campuses. These characteristics will form the framework for the remainder of this discussion on SLOs. These characteristics are as follows:

\section{Characteristic 1}

Intended learning outcomes are student-focused rather than professor-focused (Huba \& Freed, 2000, p. 99). This characteristic addresses what students should know, understand, believe, and be able to do as a result of their course experience (Palomba \& Banta, 1999; Stuetzer, 1999). SLOs, then, should begin their statements of intended learning outcome thus, "Students will be able to..." For example, note the goal and subsequent learning outcome taken from the Kent State University Office of Academic Assessment (2003):

Goal: To develop responsible persons who will dedicate themselves to the ... enhancement of the physical environment. Learning Objective: Students will be able by their junior or senior years to critique various ethical and legal policies that impact the physical environment and defend, in both verbal and written work, their choices as to those that benefit this environment.

\section{Characteristic 2}

Intended learning outcomes focus on the learning resulting from an activity rather than on the activity itself (Huba \& Freed, 2000, p. 99). Worded differently, Stuetzer 
(1999) recommends that faculty "write each objective as a learning outcome rather than a learning process" (p. 224). Palomba and Banta (1999) note that "many faculty include learning objectives in their syllabi, although the language may describe what the instructor intends to cover rather than what students are expected to know" (p. 32). For example, "Students will write a 20 page paper" as opposed to "the instructor will show students the important components of a paper" (E. A. Jones, personal communication, September 9, 2003). The Alderson-Broaddus College PA Program (2003) provides an example of how faculty can incorporate the above characteristic in their outcomes: The student will demonstrate actions commensurate with humane, empathetic behavior in medicine.

\section{Characteristic 3}

Intended learning outcomes reflect the institution's mission and the values it represents (Huba \& Freed, 2000, p. 100). Numerous assessment scholars note that the manifestation of institutional and programmatic values is an essential component of well crafted learning outcomes at the course level (MSCHE, 2003; Palomba \& Banta, 1999; Pike, 2002). This characteristic prompts faculty to ask themselves if the values expressed in their mission statement are actually being reflected and learned as a result of course attendance.

\section{Characteristic 4}

Intended learning outcomes are in alignment at the course, academic program, and institutional levels (Huba \& Freed, 2000, p. 107). This characteristic is related to outcomes-based education research conducted by W. G. Spady in the 1990s. The premise 
here is that outcomes are designed backward and delivered forward. This is to say that outcomes are designed thus:

$$
\text { Institution } \rightarrow \text { Program } \rightarrow \text { Course } \rightarrow \text { Unit } \rightarrow \text { Lesson. }
$$

Outcomes are then delivered thus:

Lesson $\rightarrow$ Unit $\rightarrow$ Course $\rightarrow$ Program $\rightarrow$ Institution (Huba \& Freed, 2000, p. 108).

In sum, the cumulative effect that students experience as they move through lessons, units, and courses should reinforce those major SLOs developed at the programmatic and institutional levels.

\section{Characteristic 5}

Intended learning outcomes focus on important, non-trivial aspects of learning that are credible to the public (Huba \& Freed, 2000, p. 112). This characteristic prompts faculty to integrate, or reexamine, the foundations of learning in their SLOs. The research conducted by Bloom (1956) and Bloom, Mesia, and Krathwohl (1964) regarding cognitive, affective, and psychomotor learning are a vital component of SLOs, but do faculty understand and incorporate their use? For example, within the cognitive domain, do faculties build a foundation of lower-order thinking skills (e.g., knowledge, comprehension) with the intent of achieving proficiencies in higher-order thinking (e.g., application, analysis, synthesis, and evaluation)?

Increasingly, the affective domain is recognized as a vital component of the student learning experience. However, do faculties understand and, more importantly, use the full spectrum of affective learning experiences in their SLOs? Do they utilize affective descriptors (e.g., receiving, responding, valuing, 
organization, and internalization) as they formulate learning experiences for their students (The University of Mississippi, 2003a)?

The value of psychomotor skills training has long been appreciated by educators, but have educators maximized this domain's potential as they develop SLOs? For example, do psychomotor SLOs only achieve imitation, manipulation, and precision (The University of Mississippi, 2003b)? Or, do faculties maximize the learning experiences by establishing SLOs that seek adaptation and origination as their objectives (Bloom, Mesia, \& Krathwohl, 1964)?

Lastly, do faculties develop SLOs that view these different learning domains as inseparable components of the same process? The body of literature suggests that educators, and here PA educators in particular, value Bloom's Taxonomy and strive toward incorporating these components in their respective programs (Glicken, 2002; Steutzer, 1999).

\section{Characteristic 6}

Intended learning outcomes focus on skills and abilities central to the discipline and based on professional standards of excellence (Huba \& Freed, 2000, p. 116). Faculties are cognizant that what they teach, and what students learn, should bear scrutiny from their peers both individually and collectively.

Professional organizations and accrediting bodies provide general and specific guidance to faculties regarding appropriate levels of academic content, rigor, and coherence. The Middle States Commission on Higher Education (2003), for example, provides a framework for its colleges and universities to demonstrate that "oral-written communication, scientific and quantitative reasoning, critical analysis and reasoning, 
technological competence, and information literacy" (p. 1) are being attained by graduates. In short, the literature demonstrates that faculty should ask themselves if their outcomes are "compatible with the best thinking in the discipline in terms of what is important to know and how information in the discipline is taught" (Huba \& Freed, 2000, p. 116).

\section{Characteristic 7}

Intended learning outcomes are general enough to capture important learning but clear and specific enough to be measurable (Huba \& Freed, 2000, p. 116). Increasingly, the literature addresses the issue of measuring outcomes beyond simple core content (Erwin, 2002a; Jonson \& Calhoun, 2000). In addition to core content, faculties are being challenged to develop outcomes that measure "integrative reasoning" and "attitudes \& dispositions" (Jonson \& Calhoun, 2000, p. 6).

\section{Characteristic 8}

Intended learning outcomes focus on aspects of learning that will develop and endure but that can be assessed in some form now (Huba \& Freed, 2000, p. 117). Determining the full effect of the college experience on a student's life is difficult to analyze, however, learning outcomes can gauge the progress that students make as they proceed through lessons, units, courses, and indeed programs and institutions themselves (p. 117). Like the assessment process itself, SLOs measure where students “end up," but they also provide the rich data about the student's journey (Jonson \& Calhoun, 2000). This data tells educators at the course through institutional level "about curricula, teaching, and kind of student effort that lead to particular outcomes" (American Association for Higher Education [AAHE], 1992, p. 1). 
At the outset of this discussion on student learning outcomes, Terenzini (1989) observes that the process of developing SLOs requires educators to reconsider "the essential purposes and expected academic and nonacademic outcomes of a college education" (p. 645). The literature clearly demonstrates that numerous assessment scholars and practitioners are reexamining these purposes and as a result they are attaining greater clarity about their institutions, its programs, and the subsequent student learning. Mission statements, institutional and programmatic goals, and SLOs are being scrutinized, re-crafted, and implemented. As a result of this reflective process, educators across this nation are forging the visions that are ultimately manifested in their students as a result of the seamless linkages between mission statements, goals, and student learning outcomes.

\section{Measurement Instruments in Assessment}

The measurement of learning can be a contentious issue. Terenzini (1989) noted that "faculty reservations about the measurability of outcomes" must be addressed in the assessment process (p. 651). Thirteen years later, Maki (2002) makes a similar observation. However, in spite of these reservations by some faculty members about measuring learning, numerous scholars recognize the need for instruments that gauge what students learn during their collegiate experience (American Association for Higher Education, 1992; Aper \& Hinkle, 1991; Lopez, 1999; Maki, 2002; Stark \& Lattuca, 1997; Steutzer, 1999).

\section{Commercially-Developed Instruments}

During the process of selecting appropriate instruments for the measurement of student learning, there are a number of decisions that faculties will need to make about 
these instruments. For example, faculty members will need to choose between commercially-developed and locally-developed instruments. Commercially-developed instruments are available to assess general education outcomes, specific disciplines, and specific learning skills (Erwin, 2000a; Palomba \& Banta, 1999).

The primary strength of using the commercially-developed instruments produced by national testing companies is their documented reliability and validity (Jones, Voorhess, \& Paulson, 2002). Palomba and Banta (1999) note an additional strength of these instruments is that "national norms for comparison have been developed" (p. 99). However, they caution faculties to scrutinize these norms. Specifically, faculties should note and consider the types of institutions that established the norms and over what time period these norms evolved.

The major limitation of commercially-developed instruments is that they may not measure what faculties hope to assess. Jones, Voorhess, and Paulson (2002) observe that some faculty members "do not believe that commercial tests accurately or meaningfully measure whether students have achieved the educational goals specific to the academic program or institution” (p. 31). Finally, instruments may not provide sufficient information (e.g., direction, guidance) about the specifics (e.g., where, how) to improve student learning (Jones, Voorhess, \& Paulson, 2002).

\section{Locally-Developed Instruments}

The major strength of locally-developed instruments is that they can be tailored to meet the needs of individual curricula. Erwin (2000a) notes that, "In some cases, there is not a measure that adequately examines the forms of student achievement that have been the focus of curriculum objectives, producing a need to develop a test locally" (p. 1). 
Regarding formative assessments, Erwin states that "often only outcome data derived from locally developed tests provide enough congruence with the learning objectives and curriculum aims, in addition to yielding a sufficient quantity of information, to guide decisionmaking” (p. 2). An especially important value-added aspect of locally-developed instruments is that they promote a sense of faculty ownership and synergy in the assessment process (Jones, Voorhess, \& Paulson, 2002; Palomba and Banta, 1999).

If designed poorly, locally-developed instruments risk losing their credibility to measure learning. Thus, the major limitation of locally-developed instruments lies in the expertise and resources required to design valid and reliable instruments (Erwin, 2000b; Palomba \& Banta, 1999). In their research for the National Postsecondary Education Cooperative, however, Jones, Voorhess, and Paulson (2002) found that this limitation can be overcome if faculties maximize the use of social science faculty, institutional researchers, and assessment practitioners during the design of their instruments. Another limitation of local instruments is that of faculty skepticism regarding the fact that "most are designed, administered, and scored by the same individuals who use the results to assess their programs" (Palomba \& Banta, 1999, p. 100). Given this potential, Jones, Voorhess, \& Paulson (2002) recommend that assessors be thoroughly trained by on- and off-campus experts as a faculty development objective. Ultimately, "many schools seem to be heading toward using a combination of locally developed and nationally normed assessment methods" (Erwin, 2000b, p. 3).

\section{Direct Instruments}

Instruments for gauging student learning are generally divided between direct and indirect methods (Palomba \& Banta, 1999). Direct, or performance, measures include 
"performance assessments that require students to demonstrate their competence in one or more skills" (p. 95). These measures include, for example:

- Objective tests and essays

- Classroom assignments

- Oral examinations and presentations

- Products

- Poster presentations

- Problem sets

- Case studies and simulations

- Portfolios

- Capstones, practicums, and internships

- National licensure and professional exams

Although other forms of direct measurement exist, those listed above represent many of the most prominent in the literature (Banta, Lund, Black, \& Oblander, 1996; Glicken, 2002; Major \& Jones, 2001; Maki, 2002; Palomba \& Banta, 1999).

Direct instruments have a number of strength and limitations. The power of these instruments is that they answer several of the most important questions about student learning (Middle States Commission on Higher Education [MSCHE], 2003). They answer, for example:

- What did students learn as a result of an educational experience?

- To what degree did students learn?

- What did students not learn (p. 31)?

An additional strength of direct measurements is their long familiarity with audiences internal and external to academia. As a result, the data collected from their use is generally well understood by stakeholders (MSCHE, 2003). For instance, these audiences can readily comprehend that student or graduates at a particular institution scored higher than at another institution. From these scores, stakeholders frequently make assumptions about the students, faculties, and the institutions. 
Direct instruments have two primary limitations. First, these instruments "provide no evidence as to why the student has learned or why he or she has not learned" (p. 31). This limitation is of particular importance given the implications and assessment's goal of student, faculty, and institutional improvement. Another limitation of direct instruments is their inability to measure value-added experiences and the resulting growth. Ultimately, value-added information provides stakeholders with insights on the cognitive, affective, psychomotor, and social growth that occurs in the time between entry and graduation from the institution (MSCHE, 2003).

\section{Indirect Instruments}

Indirect, or reflective, methods of measuring student learning are defined as those methods that "ask students to reflect on what they have learned and experienced rather than to demonstrate their knowledge and skills, providing proxy information about student learning" (Palomba \& Banta, 1999, p. 96). These measures include:

- Classroom assessment techniques

- Reflective papers and journals

- Interviews

- Focus groups

- Surveys (e.g., student, exit, alumni, employer)

These instruments, then, are the most representative of the indirect methods found in the literature (Jones, 2002; Maki, 2002; MSCHE, 2003; Schulman, Fabringer, \& Skaff, 1999).

Like direct instruments, indirect instruments have a number of strengths and limitations. One of the strengths of indirect instruments is their ability to gather feedback from students about how programs are working and can be improved (Jones, 2002). Palomba and Banta (1999) make a similar observation about the ability of these 
instruments to "yield details about instructional or curricular strengths that direct measures alone cannot provide" (p. 12). However, Erwin (200b) notes that these instruments may prove of limited value if students fail to take assessment seriously.

The major limitation of indirect instruments is that they "do not evaluate student learning per se, and therefore should not be the only means of assessing outcomes" (MSCHE, 2003, p. 33). Additionally, like direct methods, these instruments are limited in their ability to provide value-added data. Given the movement away from value-added instruments (Ewell, 1991), the above limitation may be of minor consequence. Although indirect instruments may be less familiar and more time consuming for faculty, their effectiveness in gauging student learning is an important aspect of assessment (Erwin, 2000b; Jones, 2002; Maki, 2002).

\section{Reliability and Validity}

Issues of instrument reliability and validity are a consistent concern of faculties. As defined in Fraenkel and Wallen (2003), "Reliability refers to the consistency of the scores obtained — how consistent they are for each individual from one administration of an instrument to another and from one set of items to another" (p. 165). Said another way, does the instrument consistently deliver what it is designed to deliver? If not, Cherry and Meyer (1993) note that the most probable causes for discrepancies are: (a) the instrument; (b) administration/scoring procedures; or (c) the respondents. Thus, Palomba and Banta (1999) recommend faculties scrutinize their instruments and the conditions under which they are administered.

Validity is defined as "the appropriateness, meaningfulness, correctness, and usefulness of the inferences a researcher makes" and it is "the most important idea to 
consider when preparing or selecting an instrument for use" (Fraenkel \& Wallen, 2003, p. 158). Validity, then, is dependent upon the amount and of type evidence used to support the interpretations that faculties make regarding their data (p. 159). There are three major categories of evidence that faculty can collect: (a) construct-related validity; (b) criterionrelated validity; and (c) content-related validity (Palomba \& Banta, 1999, p. 91).

Definitions for these types of validity can be found under Definitions of Key Terms (see page 61).

Given the importance of reliability and validity in the development of assessment instruments, faculties are encouraged to consult Borg, Gall, and Gall (1993), Farenkel and Wallen (2003), and Patton (2002). Ultimately, "the questions of reliability and validity center around building confidence in assessment findings, determining the applicability of the findings to improving the educational experience, and assuring some level of precision or consistency with respect to replication" (Banta, Lund, Black, \& Oblander, 1996, p. 12).

\section{Triangulation}

Patton (2002) and Wiersma (1986) define triangulation as a form of crossvalidation whereby several kinds of methods and data converge to demonstrate validity. Denzin (1978) has identified four different types of triangulation: (a) Data triangulationthe use of a variety of data sources in a study; (b) Investigator triangulation-the use of several different researchers or evaluators; (c) Theory triangulation-the use of multiple perspectives to interpret a single set of data; and (d) Methodological triangulation-the use of multiple methods to study a single problem or program (Denzin, 1978; Patton, 2003). Triangulation, then, can assist faculties in "explaining how and why and which students 
learn and develop desired outcomes" (Maki, 2002, p. 2). Additionally, "information through multiple lenses contributes to developing a narrative that tells a story about student learning so that institutions can identify successful learning experiences, as well as improve upon learning experiences to enhance student learning" (p. 2).

The use of triangulation to measure student learning, then, underscores the rationale for several points continually emphasized by assessment scholars in this section of the literature review. First, the process of selecting appropriate methods of assessing student learning is an intensive undertaking. As a result, faculties are encouraged to utilize experts (e.g., institutional researchers and assessment scholars) to assist them during all stage of planning and implementation of measurement instruments. Second, the need for multiple measures across the entire spectrum of the learning (e.g., cognitive, affective, and psychomotor domains) is essential. The use of numerous commercially and locally developed, direct and indirect instruments used in combination before, during, and after attendance at an institution will provide a multidimensional picture of student learning.

\section{Making Choices}

Given what has been covered in the literature regarding instruments to this juncture, faculties will next begin to make choices about who, what, when, and how to measure student learning. For example, faculties will need to decide who should be measured. In this case, Palomba and Banta (1999) note that, "Practitioners must develop clear criteria to identify individuals who will be required or invited to participate in assessment projects" (p. 110). For example, entry into a particular institution may require mandatory assessment of general education before admittance. Likewise, those students 
desiring entry into, for example, Physician Assistant programs may be the only ones required for a particular assessment. Once eligibility is ascertained, faculty should determine sampling procedures and sizes through consultation among themselves and the experts that have assisted them to this point.

The next major choice that faculty will need to consider is what needs to be measured. For example, faculties may want to focus specifically on a particular domain of learning (e.g., cognitive, affective, or psychomotor). Or, faculties may be interested in measuring particular subject areas such as critical thinking, problem solving or reflective judgment (Erwin, 2000a). Still another possible measurement may be one that assesses differences and similarities in content knowledge and skill integration (Jones, 2002). Obviously, there are a multitude of measurements that faculty can undertake and while the thought of this may be overwhelming to some faculty, it certainly reinforces the need for well-crafted mission statements, goals, and student learning outcomes (Banta, Lund, Black, \& Oblander, 1996; Jones, 2002).

Another choice faculty will need to make regards when particular measurements will occur. For example, faculties may develop instruments to take measurements during the freshman year, senior year, and beyond (Upcraft \& Schuh, 1996). Programmatically, faculties may want to monitor progression as students move from entry through midpoint to exit and in the years that follow (Accreditation Review Commission on Education for the Physician Assistant, 2002). Obviously, meaningful longitudinal studies will provide faculties with the greatest degree of reliable information about what their students know and can do as a result of their collegiate experience (Jones, Voorhees, \& Paulson, 2002). 
A final choice that faculties will need to consider is how to use assessment instruments. The most obvious choices to be made will entail faculty discussions regarding commercial, local, direct, and indirect instruments. However, faculty will also need to consider ways to use these instruments once they are selected. For example, will some of the instruments be used in a pre- and post-information mode? This decision has a direct linkage to the paragraph above as longitudinal designs usually collect this data (Palomba \& Banta, 1999).

An additional consideration for faculty will be determining what instruments will be embedded (or unobtrusive) and what instruments will be administered out of class (Erwin, 2000a; Jones, Voorhees, \& Paulson, 2002; Suskie, 1996). Course-embedded assessment is the collection of "assessment information within the classroom, not simply for convenience but because of the opportunity this provides to use already-in-place assignments and course work for assessment purposes" (Palomba \& Banta, 1999, p. 13). These assessments are more cost-effective and less likely to be affected by student motivation (Huba \& Freed, 2000). A less favored approach is that of out-of-classroom assessments. In this approach, students are often involved in a day of testing to determine student learning. The use of this approach, however, has declined in recent years due concern about poor student motivation (Huba \& Freed, 2000).

Lastly, establishing good criteria, designing or selecting good instruments, and refining or implementing a faculty's data collection process is vital to course or programmatic improvement. The use of the methods found in this review can "enable an institution to identify effective pedagogy and educational practices, as well as identify where pedagogy and practice can be improved or innovations developed to more greatly 
assure student's learn and develop desired outcomes" (Maki, 2002, p. 3). As Terenzini (1989) notes, "The issue is not really whether "assessments" should be made, but rather what is to be the nature, sources, and quality of the evidence on which those judgments are based" (p. 651).

\section{Using Assessment Results to Make Program Improvements}

"Because the specifics of assessment vary from campus to campus, assessment practitioners need to think about the kinds of actions that will foster the use of assessment information on their own campuses" (Palomba \& Banta, 1999, p. 303). In regard to the actions that can foster the use of assessment results, this section of the literature review will concentrate on five major areas: (a) continuous improvement; (b) program review and planning; (c) budgeting; (d) teaching and learning; and (e) improving assessment.

\section{Integrating Results and Implementing Improvements}

Numerous scholars and assessment practitioners note the importance of using assessment results for the purposes of continuous programmatic and institutional improvement (Huba \& Freed, 2000; Middle States Commission on Higher Education [MSCHE], 2003; Peterson \& Vaughan, 2002). The literature further demonstrates that these improvements focus on two central points: accountability and quality assurance (National Center for Postsecondary Improvement [NCPI], 1998). This fact, however, places these points in a state of tension. As Huba and Freed (2000) note, assessment may be "dominated by the need to convince constituencies that funds are well spent and this leads us to gather the type of assessment data that supports the contention that no change is needed" (p. 68). Quality improvement is at odds with this notion, however, as it denotes an impetus toward change and growth (p. 68). 


\section{Planning and Review}

"If assessment is to be successful, it must be linked to other processes" (Palomba \& Banta, 1999, p. 305). Programmatic planning and review are two of the areas where assessment results are used. Aper and Hinkle (1991) note that assessment results should be "linked to comprehensive strategies for planning or program review that encourage change and improvement" (p. 545). Over a decade later, Peterson and Vaughan (2002) found that, "Many institutions had policies designed to assure the use of student performance indicators in academic planning and review and to encourage student involvement in assessment activities" (p. 35). Additionally, Peterson, Vaughan, and Perorazio (2001) concluded that those institutions with a high emphasis on assessment possessed much higher levels of institutional integration. This integration resulted in more formal and regular linkages for planning and reviews (p. 83).

\section{Budgeting}

Assessment results may also influence programmatic and institutional budgets. Palomba and Banta (1999) found that some institutions "explicitly link the assessment process to their internal budgeting process, setting aside a block of funds for initiatives to improve student learning based on recommendations from assessment activities" (p. 43). They also note that some institutions (e.g., Ohio University, Truman State University, and the University of Tennessee) "have been successful in using assessment results to make their case for additional funding from state government" (p. 43). Peterson, Vaughan, and Perorazio (2001) note that those institutions with a high degree of formalized integration were "loosely coupled" to the budgetary process (p. 84). Ultimately, "linking the assessment process of an institution with its operational planning 
and budgeting processes is essential to the ongoing success and cost effectiveness of every assessment program" (Lopez, 1999, p. 31).

\section{Teaching and Learning}

The use of assessment results to improve teaching and learning is one the principal tenets of the assessment process (Angelo, 1999; Ewell, 2002; Palomba \& Banta, 1999; Stroup, 2002). Given that today's assessment movement in higher education has been evolving since the mid-1980s (Evenbeck \& Kahn, 2001; Ewell, 2002), it is perplexing that all 50 states received an "incomplete" grade for student learning in the 2000 and 2002 state-by-state assessments conducted by the National Center for Public Policy and Higher Education (NCPPHE) known as "Measuring Up" (Ewell, 2003; NCPPHE, 2000, 2002). This finding, however, did not surprise many educators as the assessment of learning has consistently proved challenging (Angelo, 1999; Suskie, 2000). In regard to Measuring Up specifically, Miller (2001b, p. 2) provides a number of valuable insights on the use of "grade cards" in higher education today:

...because we have no comparable state-by-state information on learning, the report card was unable to assign a grade for the most important result, learning. This does not mean that states are paying no attention to this question. Many have campus-based assessment programs in place, and some have instituted statewide testing, at least for their public institutions. But giving grades on learning in subsequent editions...will require comparable information across states about what colleges students know and can do. 
Callan and Finney (2002) echo Miller's commentary during their discussion on assessing educational capital.

Although the above may suggest to those outside of academia that the academy is not assessing for learning, this simply is not true. The literature is replete with the published efforts of scholars to collect, analyze, and affect change based upon assessment results (Banta, 2002; Miller, 2001b; MSCHE, 2003; Palomba \& Banta, 1999). The issue, then, is the tension that exists between the American society and higher learning as to: (a) Whose learning should be measured; (b) What learning should be measured; and (c) How the results should be used to shape public policy (Miller, 2001b, p. 2). The answers to the questions continue to evolve (Ewell, 2003; Miller, 2001a, 2001b).

In the interim, assessment practitioners continue to assess teaching and learning within their respective intuitions (Banta, 2002). Evenbeck and Kahn (2001) note that "campus assessment efforts have been most meaningful and effective when they have been conducted within the disciplines, using processes and procedures that articulate desired outcomes and measure them in light of the department's mission" (p. 25). The results of these efforts provide valuable "insights into the type of learning occurring in the program, and we are better able to make informed decisions about needed program changes" (Huba \& Freed, 2000, p. 15).

Individual institutions and faculties use assessment results to achieve a number of successes. Palomba and Banta (1999) note that "some of the most dramatic improvements in teaching and learning as a result of assessment have occurred in twoyear institutions" (p. 310). For example, they find results prompting faculty toward increases in "active-learning modes, improving advising, and initiating remediation" (p. 
310). The literature also demonstrates that assessment programs result in program and course modifications or introductions (Banta, Lunda, Black, \& Oblander, 1996; Cottrell \& Jones, 2002; MSCHE, 2003).

The final area to be examined under this section of the literature review is how assessment results are used to improve the assessment process itself. The entire practice of programmatic and institutional assessment is based upon a premise of ongoing, cyclical feedback with a goal of continuous improvement (American Association of Higher Education [AAHE], 1992; Banta, Lund, Black, \& Oblander, 1996). “One way to ensure that the [assessment] plans are effective is to build an evaluation process and schedule it into the plan" (MSCHE, 2003, p. 63).

Assessment

Assessment practitioners can evaluate the effectiveness of their assessment plans by asking themselves questions like those framed by Huba and Freed (2000, p. 85):

- Is the institution or academic program reaching its goals for assessment?

- Have we formulated intended learning outcomes in a timely fashion?

- How do courses and program assessment complement each other?

- Have we completed the assessment cycle for at least some of our learning outcomes?

- If not, what changes are needed in assessment itself?

Asking these types of questions about assessment-related progress prompts participants to continually reflect on and discuss the entire process (Banta, 2002).

In an effort to use assessment results to improve upon the process itself, faculties often link results to other mechanisms for improvement. Banta (2002) notes that "peer 
review is a particularly appropriate method for assessing assessment” (p. 279). Peterson (1996) at Dixie College and Cunningham (2002) at Rivier College use the methods (e.g., five-column model) developed by Nichols and Nichols (1995) to improve their assessment process. Regardless of where and how assessment results are introduced into the cycle of process improvement, it is important for faculty to remember that "when we initiate new approaches to assessment at the course, program, or institutional levels, we should plan at the outset to evaluate them" (Huba \& Freed, 2000, p. 85).

\section{Curricular Modification}

A clear indication of institutional priorities can be found in the curriculum (Palomba \& Banta, 1999). Thus, if there is a student-centered, assessment-based culture at a given institution this will be manifested in the respective programmatic curricula. Stark and Lattuca (1997) define the curriculum as an academic plan that includes "decisions about what, why, and how a specific group of students are expected to learn, as well as a way of knowing what they have or have not learned, and of using this information to improve the plan" (p. 2). Clearly, this definition makes direct linkages between the assessment process and curriculum development (Ewell, 2002). "Ideally, when we participate in assessment, we begin to view...curriculum as an interrelated system of experiences through which students achieve the intended learning outcomes of the program" (Huba \& Freed, 2000, p. 70).

Having established the linkage between the assessment process and curriculum development, the scholarly literature also examines how assessment results are integrated into the curriculum. In a general sense, "assessment data about student learning can help us keep a learner-centered perspective during curriculum development and revision" (p. 
70). More specifically, faculty use a wide array of quantitative and qualitative data collection instruments to determine if the curriculum is successfully facilitating student learning (Banta, 2002). Palomba (2002) notes that multiple measures of student learning can be achieved through the use of pre- and post-objective tests, essays, capstone experiences, surveys, and focus groups. Maki (2002) adds to these measures with an additional explanation of instruments and their value in triangulation. Ultimately, using assessment data assists faculty members in learning "whether or not the curriculum has been effective" (Huba \& Freed, 2000, p. 70).

Proposals to modify curriculum need to incorporate the above data to achieve credibility and be considered (Palomba, 2002; Palomba \& Banta, 1999; Peterson, Vaughan, \& Terorazio, 2001). In making result-driven curricular modifications, however, the literature cautions faculty about the mechanisms that facilitate change. The Middle States Commission on Higher Education (2003) notes that "changes in programmatic curricula as a result of assessment data do not happen automatically....however, if the department plan outlines specific procedures for examining assessment results and implementing curricular revision, those changes are more likely to occur” (p. 67). The Accreditation Review Commission on Education for the Physician Assistant (ARC-PA) underscores the importance of this observation by making these procedures part of their accrediting criteria (Blessing, Stuetzer, \& Somers, 2001). Lastly, the AAHE (1992) and Jones, Voorhees, and Paulson (2002) recommend that faculties view the assessment process and curricular revision as ongoing commitments thus they require continual monitoring. 


\section{Communicating Assessment Results to Specific Audiences}

Teaching, learning, and assessment are collaborative efforts that rely on a high degree of open communication between stakeholders internal and external to academia (Angelo, 1999; Douglas \& La Voy, 2002; Suskie, 2000; Tiberious, R. G., Sackin, H. D., Slingerland, J.M., Jubas, K., Bell, M., Matlow, A., 1989). Creating or broadening channels of communication between these audiences has numerous favorable impacts on the assessment process. Banta and Kuh (1998) note, for example, that creating opportunities for dialogue "encourages educators to develop a broader, more inclusive understanding of the complex nature of their institutions and better understanding of their respective contributions" (p. 47) to learning. Perhaps most importantly, increased dialogue helps these different audiences develop a common language and understanding of the assessment process and its goals (Angelo, 1999; Palomba \& Banta, 1999).

Consistent, timely, and accurate reporting on the progress and results of the assessment effort creates and maintains feedback loops (Lopez, 1999). Preparing reports to diverse audiences, however, requires thorough planning. Terenzini (1989) cautions that given the "involvement of a wide variety of people and offices, crossing not only academic departmental lines, but vice-presidential areas as well....the reporting line(s) for each office or group should be given careful attention" (p. 652). Palomba and Banta (1999) observe that, "Anyone who has the responsibility for report writing must anticipate the kinds of audiences that will receive reports, as well as specific needs and interests of these audiences" (p. 318). Lastly, it is worth remembering that "those who are most likely to be affected by the results should have the opportunity to examine them first" (p. 327). 


\section{Reporting Formats}

Given these and other considerations, assessment practitioners need to select the appropriate reporting formats for the corresponding audiences (Erwin, 1996). The literature discusses annual reports, executive summaries, special reports, newsletters, abstracts, and presentations (Banta, Lund, Black, \& Oblander, 1996; Lopez, 1999). Other sources mention similar types of reports such as comprehensive reports, theme reports, institutional report cards, specific audience reports, college-departmental extracts, and web reports (Palomba \& Banta, 1999). Ultimately, assessment practitioners need to recognize that a "significant challenge for those who collect campuswide information is to make it meaningful to various audiences" (p. 318). Using the appropriate format for the respective audiences can achieve this end (Jones, Voorhees, \& Paulson, 2002).

Regardless of the format being used, there are a number of components that these reports share in common. Most reports, for example, begin with an introduction and explanation of the project's objectives (Palomba \& Banta, 1999; Lopez, 1999). Next, the methodology, results, conclusion, and recommendations are presented. Then, these reports discuss the use of the results, observations about the process, and an executive summary. Obviously, smaller reports, such as newsletters, student newspaper articles, and abstracts, will possess only limited amounts of information within the above areas (Lopez, 1999). Lastly, Upcraft and Schuh (1996) note that, "The most common mistake investigators make is to send a complete and comprehensive report (most often modeled after a typical doctoral dissertation) to all intended audiences" (p. 280). Clearly, the appropriate reporting formats should be sent to the appropriate target audiences. 
Another aspect of reporting assessment results that receives attention by scholars is that of confidentiality and comparisons. Palomba and Banta (1999) advise faculties to "consider who will likely see results and what type of information should be shared. In general, it pays to operate on the assumption that reports will circulate widely, even if that was not the intention" (p. 327). Friedman and Hoffman (2001) and Upcraft and Schuh (1996) make a similar observations. Palomba and Banta further caution against reports that appear to make comparisons between individual students, faculty members, courses, or departments.

\section{Frequency of Reports}

The preparation of specific assessment reports is part of the larger process that is the dissemination of assessment results. As part of the dissemination process, assessment practitioners need to consider the frequency of report distribution. As Upcraft and Schuh (1996) note, "In disseminating assessment reports, timing can be everything" (p. 286). Given that the assessment effort is predicated on the expectation that assessment results will lead to decisions that affect institutions, faculties, and students, "reports should be released as decisions are being made, so that the findings and recommendations can become part of the decision-making process" (p. 286). They also note that those who commissioned the study are often in the best position to determine the distribution of assessment results. Ultimately, a "useful distribution plan considers the needs of various audiences and the appropriate sequence of report sharing” (Palomba \& Banta, 1999, p. 328). 


\section{Internal Audiences}

The entire assessment process is based on open collegiality with the aim of improving institutions, programs, faculties, and students (Ewell, 2002). Given this inclusive atmosphere at all stages of the assessment process, the internal audience at an institution varies widely. Obviously, executive level personnel, senior administrative leaders, faculty, and even students are part of the internal audience (Erwin, 1996; Banta, Lund, Black, \& Oblander, 1996). There are, however, other groups that need to be considered in the internal distribution plan of assessment results. For example, planning, review, budget, and curriculum committees are high priority recipients for assessment updates and reports (Maki, 2002).

\section{External Audiences}

Including external audiences in the assessment cycle (Maki, 2002) complements the inclusion-oriented nature of the assessment endeavor. Based upon this nature, it is logical that numerous diverse stakeholders outside of academia be included in assessment's distribution plan for progress and results (Allen \& Bresciani, 2003; Ewell, 2003). These stakeholders include federal and state officials, accrediting and professional bodies, and philanthropic individuals and organizations (Erwin, 1996; Jones, 2002; Tam, 2001). Other external recipients of assessment reports include alumni, parents, trustees, employers, and the community at large (AAHE, 1992; Jones, Voorhess, \& Paulson, 2002; Wiggins, 1990).

Finally, scholars note that regardless of the format or audience, assessment information must be shared in frequent, meaningful ways (Jones, Voorhess, \& Paulson, 2002; Pike, 2002). At their essence, these reports are meant to inform stakeholders about 
the status of student learning in some form; hence these communications should be clear and concise with a solution-oriented approach (Brinko, 1993; Lopez, 1999). Like multiple measurements of student learning, efficient multidimensional dissemination of assessment information provides audiences with the most accurate portrayal of programmatic and institutional improvement and accountability (AAHE, 1992; Jonson \& Calhoun, 2000; Pike, 2002).

\section{Definitions of Key Terms}

Assessment:

Assessment is the process of gathering and discussing information from multiple and diverse sources in order to develop a deep understanding of what students know, understand, and can do with their knowledge as a result of their educational experiences; the process culminates when assessment results are used to improve subsequent learning (Huba \& Freed, 2000, p. 80).

Course-embedded assessment:

The collection of assessment information within the classroom, not simply for convenience but because of the opportunity this provides to use already-in-place assignments and course work for assessment purposes (Palomba \& Banta, 1999, p. 13). This method of assessment has also been called unobtrusive assessment by Suskie (1996).

Assessment methods (also called techniques or instruments):

These include:

- Direct instruments require students to demonstrate their knowledge and skills as they respond to the instrument itself. These instruments include objective tests, 
essays, oral presentations, and classroom assignments. Objective tests includes examinations of many kinds; the most common being multiple-choice, fill in the blank, true-false, essay, and problems (Palomba \& Banta, 1999, p. 11).

- Indirect instruments require students to reflect on what they have learned and experienced rather than to demonstrate their knowledge and skills, providing proxy information about student learning. These include: questionnaires, interviews, and focus groups (Palomba \& Banta, 1999).

- Commercially-developed instruments are those instruments designed by organizations specializing in testing. These instruments "provide information (including test scores and interpretative tools) to test takers, educational institutions, and others who require this information" (Educational Testing Service [ETS], 2003, p. 1). ETS, for example, designed the Major Fields Tests, Graduate Record Examinations, the Graduate Management Admission Test, and the Test of English as a Foreign Language.

- Locally-developed instruments are those instruments designed by the faculty. These instruments are designed to more closely assess local curricula than is possible for nationally- or internationally-oriented standardized tests. For example, these instruments may include: exams, papers, presentations, projects, and simulations.

Audiences:

- External audiences are those audiences found off-campus. External audiences include alumni, employers, regional and professional accreditors, and state governments. 
- Internal audiences are those audiences found on-campus. Internal audiences include the faculty, administration, and students (Palomba \& Banta, 1999). Capstone experiences:

Capstones experiences are summative curricular approaches such as courses synthesizing all of the content to date within a particular major (and often attempting to connect that concept back to the institution's basic theme of general education and the liberal arts). They include final projects, theses, recitals, and internships (Gardner, 1998). Classroom Assessment Techniques (CATs):

Cross and Steadman (1996) describe CATs as "small-scale assessments conducted continually in college classrooms by discipline-based teachers to determine what students are learning in class" (p. 8). Several examples of CATs include: (a) The Minute Paper, (b) E-mail Minute, (c) Muddiest Point, and (d) Application Cards (Huba \& Freed, 2000).

Curricular modifications:

These are modifications made to the curriculum based upon: (a) assessment results and (b) how these changes assist the student in attaining previously identified student learning outcomes (Huba \& Freed, 2000).

Faculty development:

Faculty development is a phrase that has both a broad and a narrow definition. Broadly, it covers a wide range of activities that have as their overall goal the improvement of student learning. More narrowly, the phrase is aimed at helping faculty members improve their competence as teachers and scholars [Eble \& McKeachie, 1985] (Alstete, 2000, p. 1). 
Goals:

Goals communicate intended educational results in general terms. For example, Palomba and Banta (1999) describe goals as "broad learning concepts such as clear communication, problem solving, and ethical awareness" (p. 26).

Products:

Huba and Freed (2000) define products as those projects whose focus is on the development of a tangible product. The product itself, as well as the process and quality of reasoning that led to it, is evaluated.

Program Evaluation:

Program evaluation focuses on a program's stakeholders, scope, data, and reporting much like programmatic assessment. The major difference between programmatic evaluation and programmatic assessment, however, is that the former is process oriented while the latter examines a program's effect on student learning outcomes. For an example of program evaluation methods, see Robert Stake's (1973) responsive evaluation model.

Program Review:

The periodic monitoring of an academic program to determine what knowledge should form the substance of education, how it should be organized in a curriculum, and how it should be communicated to students (Gaff, Ratcliff, \& Assoc., 1996, p. 591). Portfolios:

Portfolios are produced in response to a goal developed by the professor. The students gather examples of their work such as past products and written reflections of 
their learning experiences thus portfolios include both direct and indirect evidence of student learning as assessed by faculty (Huba \& Freed, 2000). Reliability:

The consistency of the scores obtained - how consistent they are for each individual from one administration of an instrument to another and from one set of items to another (Fraenkel \& Wallen, 2003), p. 165).

Student Learning Outcomes:

Huba and Freed (2000) define student learning outcomes as the kinds of things that students know or can do after instruction that they did not know or could not do before the instruction. There are three major foci in regard to these outcomes:

- Cognitive outcomes: This area of student learning and assessment is focused on thinking skills. Bloom’s (1956a) taxonomy encompassing knowledge, comprehension, application, analysis, synthesis and evaluation is the standard model for designing these outcomes.

- Affective outcomes: Bloom (1956b) defines these as those areas that emphasize interests, attitudes, appreciations, values, and emotions.

- Psychomotor outcomes: These outcomes focus on the student's motor skill (Bloom) and performance (Palomba and Banta, 1998).

Triangulation:

Triangulation is a form of cross-validation whereby several kinds of methods and data converge to demonstrate validity (Patton, 2002; Wiersma, 1986).

- Data triangulation-the use of a variety of data sources in a study.

- Investigator triangulation-the use of several different researchers or evaluators. 
- Theory triangulation-the use of multiple perspectives to interpret a single set of data.

- Methodological triangulation-the use of multiple methods to study a single problem or program (Dezin, 1976; Patton, 2003).

Validity:

The appropriateness, meaningfulness, correctness, and usefulness of the inferences a researcher makes (Fraenkel \& Wallen, 2003, p. 158).

- Content-related evidence of validity-refers to the content and format of the instrument.

- Criterion-related evidence of validity-refers to the relationship between scores obtained using the instrument and scores obtained using one or more other instruments or measures (often called criterion).

- Construct-related evidence of validity-refers to the nature of the psychological construct or characteristic being measured by the instrument. 


\section{CHAPTER THREE. METHODS \\ Research Design}

This study was conducted utilizing mixed methods. These methods are defined as a "collection or analysis of both quantitative and qualitative data in a single study in which the data are collected concurrently or sequentially, are given a priority, and involve integration of the data at one or more stages in the process of research" (Creswell, Plano Clark, Gutmann, \& Hanson, 2003, p. 212). This study was approached from a “quantitative primary, quantitative first" orientation (Morgan, 1997). This orientation, then, began with a "quantitative approach as the primary method, using qualitative follow-up to evaluate and interpret the quantitative results" (Glathhorn, 1998, p. 34).

Type

\section{Concurrent Mixed Model Design}

To achieve the above, a concurrent mixed model design was utilized. A concurrent mixed model design is defined as:

a multistrand design in which there are two relatively independent

strands/phases: one with QUAL questions and data collection and analysis techniques and the other with QUAN questions and data collection and analysis techniques. The inferences made on the basis of the results of each strand are pulled together to form meta-inferences at the end of the study (Tashakkori \& Teddlie, 2003, p. 705).

The terms QUAN and quan are used in reference to the quantitative aspects of this study. The uppercase reference applies when the quantitative methodology is dominant. The 
lowercase reference applies when this methodology is less dominant. This same reference style also applies to QUAL and qual (Morse, 2003; Tashakkori \& Teddlie, 2003).

Visually, the concurrent mixed model design is diagrammed as follows (adoption of Tashakkori \& Teddlie, 2003, p. 688):

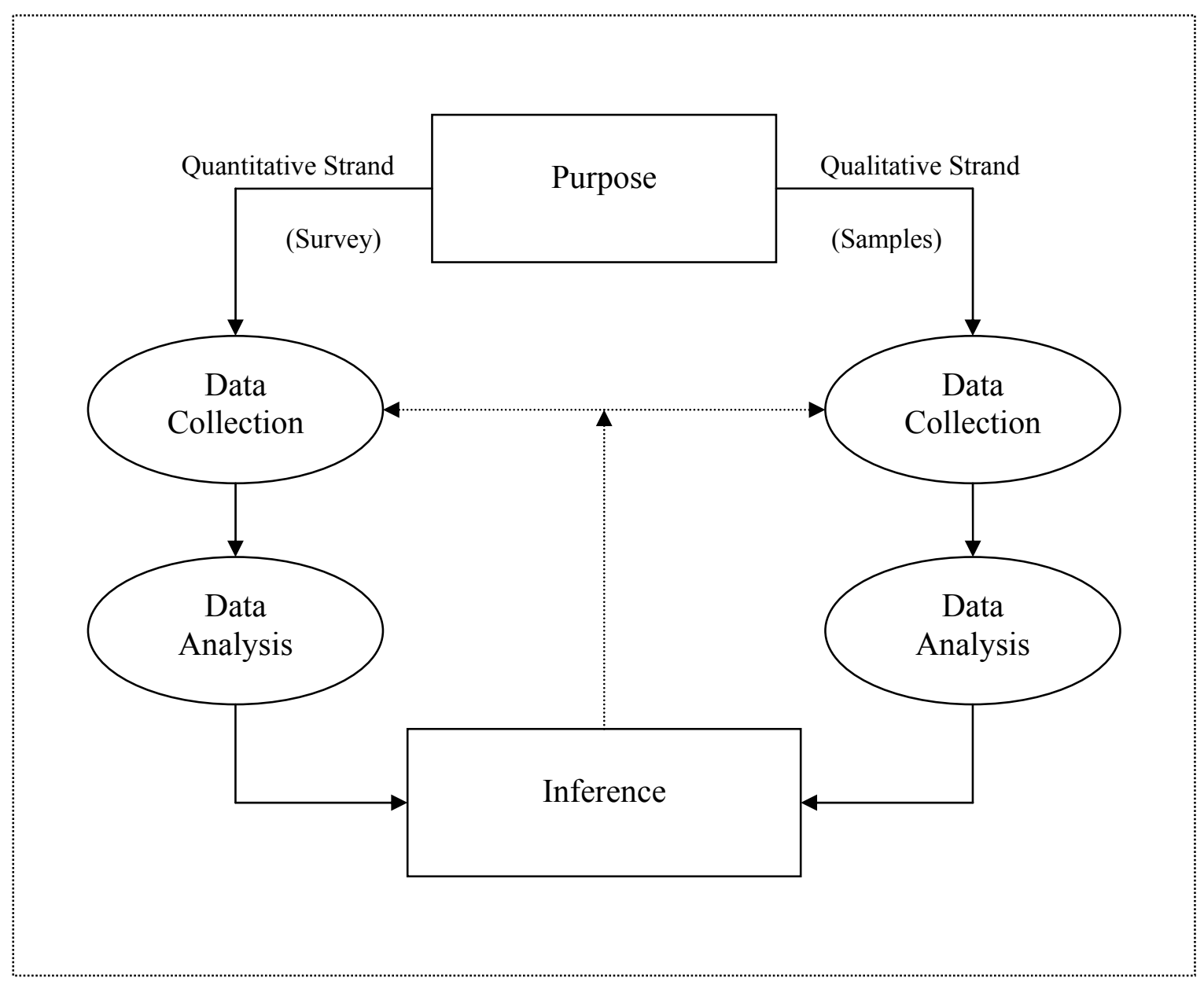

Figure 2. Concurrent Mixed Model Design.

\section{Concurrent nested design.}

The specific design selected within the above model is the concurrent nested design. In this particular design, a strand/phase is embedded within a predominate study (e.g., quan + QUAL or QUAN + qual) (Tashakkori \& Teddlie, 2003). For the purposes of this research, the quantitative strand was dominant 
(e.g., QUAN) and the qualitative strand was less dominant (e.g., qual).

Additionally, Creswell, Plano Clark, Gutmann, and Hason (2003) note that this approach is used to "confirm, cross-validate, or corroborate findings within a single study" (p. 229). The researchers diagram this design as follows (p. 226):

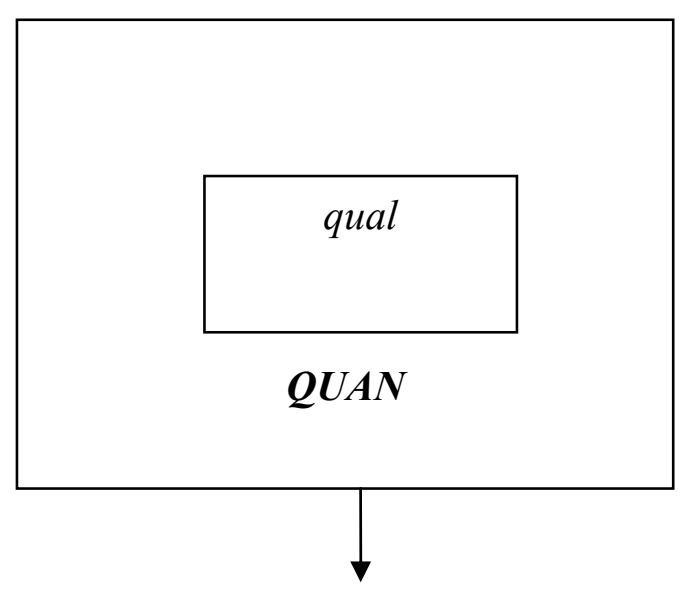

Analysis of Findings

Figure 3. Concurrent Nested Design.

\section{Quantitative strand.}

The quantitative strand of this design is descriptive in nature. Thus, this strand's purpose is to "describe the state of affairs as fully and carefully as possible" (Fraenkel \& Wallen, 2003, p. 15) as it pertains to internal programmatic assessment and Physician Assistant (PA) education. Given this strand, no causal relationships were sought during the course of the study. As noted in Chapter One, the objective was to determine programmatic assessment practices of PA educators. To achieve this end, the perceptions of PA program directors were studied utilizing a survey instrument. 


\section{Instrument.}

The quantitative strand was conducted by utilizing a survey that consists of closed- and open-ended items. PA program directors were surveyed and asked to complete a mailed questionnaire. A Survey of Internal Programmatic Assessments Implemented by Physician Assistant Educators (see Appendix A, p. 210) is a local instrument developed using the principles outlined by Suskie (1996) and Johnson and Turner (2003). The first page was designed to provide a definition of assessment, questionnaire instructions, and elicit demographic information. The instrument was designed to be attractive and easy to understand and answer.

The remainder of the questionnaire was comprised of 61 open-end and closed questions. The questions were arranged from broad to narrow in focus with the easiest questions in the first third of the survey. The questionnaire used a combination of Likert rating scales and checklists. Likert response variations ranged from strongly agree, agree, disagree, and strongly disagree. Questions requesting frequencies provided respondents with choices such as: frequently, sometimes, seldom, and never. The checklists provided the opportunity to select multiple responses to a single question. These questions were formatted to be unambiguous, focused, and concise. Further, the questions attempted to avoid bias or leading the respondents. A pilot study was conducted to determine if the questionnaire met these criteria.

The specific items in this instrument were designed to answer the research questions outlined in Chapter One. Table 1 illustrates those quantitative and qualitative items that were used to collect data for the corresponding research questions. 
Table 1

Data Collection and Sources

\begin{tabular}{|c|c|c|}
\hline$\underline{\text { Research Questions }}$ & QUAN: Survey & QUAL: Documents \\
\hline Gaining institutional resources & Questions: 1-6 & Guiding principles \\
\hline Faculty development & Questions: 7-18 & $\begin{array}{l}\text { Materials describing } \\
\text { incentives }\end{array}$ \\
\hline $\begin{array}{l}\text { Programmatic student learning } \\
\text { outcomes (SLO) }\end{array}$ & Questions: 19-26 & $\begin{array}{l}\text { Programmatic goals } \\
\& \text { SLOs }\end{array}$ \\
\hline $\begin{array}{l}\text { Student learning outcome } \\
\text { integration }\end{array}$ & Questions: 27-37 & Course SLOs \\
\hline Measurement instruments & Questions: $38-45$ & $\begin{array}{l}\text { Commercial and local } \\
\text { instruments }\end{array}$ \\
\hline Using assessment results & Questions: 46-53 & Assessment report \\
\hline $\begin{array}{l}\text { Communicating assessment } \\
\text { results }\end{array}$ & Questions: 54-61 & Assessment report \\
\hline
\end{tabular}

Note. $\mathrm{SLO}=$ Student Learning Outcomes

Questions 1 through 61 were derived from the research and publications of assessment scholars and practitioners. In the case of research question number one, for example, the literature revealed that the salient issue in gaining institutional resources for assessment activities relies heavily upon executive-level support. Based upon this issue, questions one through six sought to quantitatively determine the dynamics between PA programs and their institutional executives particularly as it pertained to funding the assessment endeavor. 
To further enhance the study, assessment plans and other supporting documentation were requested to more fully explore the qualitative dimensions of this dynamic. This strategy would also provide triangulation of the scholarly literature and survey instrument. Continuing with the case of research question number one, a sample of an institution's guiding principles in regard to assessment would either corroborate or refute the scholarly literature and survey responses. Graphically, this relationship was demonstrated as follows:

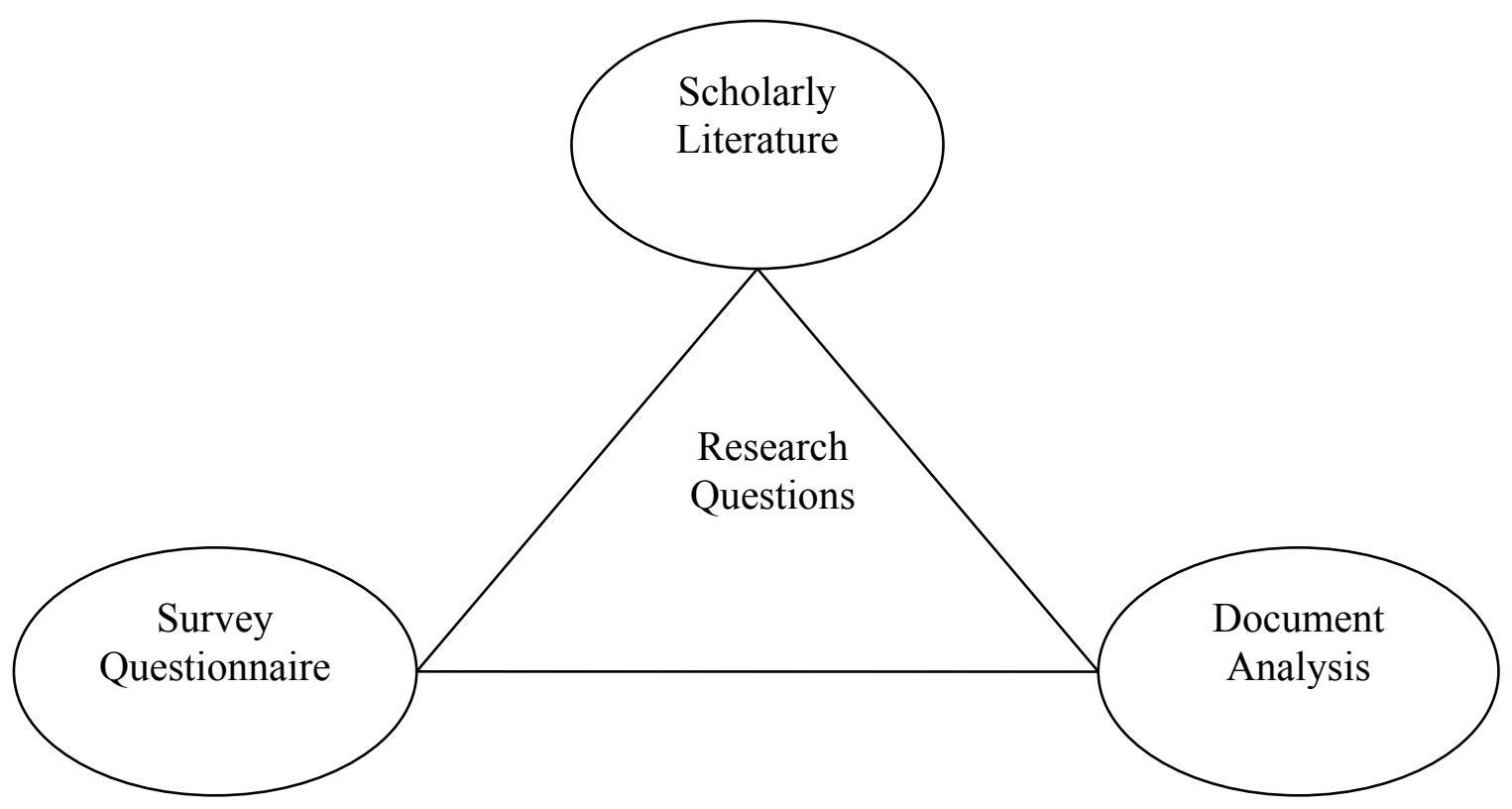

Figure 4. Triangulation of Research Questions.

\section{Qualitative strand.}

As indicated above, the qualitative strand of the design would augment the descriptive strand of the quantitative data gathered from the survey. The "nested" qualitative feature, then, would be utilized most specifically to "confirm, cross-validate, or corroborate findings" (Creswell, Plano Clark, Gutmann, \& Hanson, 2003, p. 229) in the quantitative strand. 
To achieve triangulation, the qualitative strand would utilize secondary data (Johnson \& Turner, 2003). Specifically, official documents, such as assessment plans and reports, were requested for analysis. As Tuckman (1999) notes, the principal intent of these kinds of documents is description, thus the information analyzed from these sources would address the research questions.

\section{Rationale}

A descriptive research approach would provide future readers with an indication of how PA faculties were conducting programmatic assessment. Thus, the design type was selected based on the researcher's desire to explore and describe the current state of programmatic assessment activities in PA education. Given this objective, the use of descriptive survey research would enable the researcher to determine "how members of a population distribute themselves on one or more variables" (Fraenkel \& Wallen, 2003, p. 396). Lastly, Glatthorn (1998) noted that descriptive studies can be especially valuable during the early stages of research in a particular area (e.g., assessment and PA education).

Given that the scholarly literature provides little information about current assessment activities at individual PA programs, a survey would provide data at "one point in time" (Fraenkel \& Wallen, 2003, p. 397) thus establishing a baseline for the profession and future longitudinal studies. In an effort to strengthen the study, mixed methods were selected to add increased depth to the descriptions gleaned through the survey. As Patton (2002) noted, "multiple sources of information are sought and used because no single source of information can be trusted to provide a comprehensive perspective (p. 306). 


\section{Strengths and Limitations of the Design}

\section{Strengths}

The concurrent nested design possessed three major strengths (Creswell, Plano Clark, Gutmann, \& Hanson, 2003). First, this design provided researchers the advantage of capitalizing on the strengths of both the quantitative and qualitative approaches. Next, the authors note that this design allows researchers to collect quantitative and qualitative data simultaneously during a single data collection phase. Lastly, they note that "researcher[s] can gain perspectives from the different types of data or from different levels within the study" (p. 230).

\section{Quantitative strand.}

The descriptive strand had a number of strengths. First, survey research is one of the most prevalent methodologies in educational research (Wiersma, 1995). Hence, this method has a long history of reliable data collection. Secondly, this method's familiarity to PA educators would provide ease of completion and increase the likelihood of return.

Thirdly, this design allowed the researcher to ask the same set of questions to the 133 PA program directors scattered throughout the United States. As Fraenkel and Wallen (2003) note, "The big advantage to survey research is that it has the potential to provide us with a lot of information obtained from quite a large sample of individuals" (p. 13). Ultimately, this design allowed the researcher to "describe the characteristics of the population by directly examining samples of that population" (Glatthorn, 1998, p. 75).

\section{Qualitative strand.}

The strength of performing a content analysis of numerous documents from different PA programs was the depth that could be achieved by gleaning data that would 
address the research questions and provide triangulation from data gathered through the survey. For example, Patton (2002) notes that documents provide a "behind-the scenes look at the program" (p. 307) that may not be revealed otherwise. As noted earlier, these documents will either corroborate or contradict survey results.

\section{Limitations}

The concurrent nested design also had a number of limitations. First, Creswell, Plano Clark, Gutmann, and Hanson (2003) note that the data collected within the individual strands must be "transformed in some way so that they can be integrated within the analysis phase of the research" (p. 230). Next, they note that there is little guidance by scholars thus far on how to accomplish this integration. Lastly, they observe that the use of the dominant quantitative strand and less-dominate qualitative strand features of this design leads to unequal levels of evidence that may prove a disadvantage during interpretation.

\section{Quantitative strand.}

There were a number of limitations with conducting descriptive survey research. Fraenkel and Wallen (2003) identified three potential problems with using this research design: (a) ensuring that the questions to be answered were clear and not misleading; (b) getting respondents to answer questions thoughtfully and honestly; and (c) getting a sufficient number of the questionnaires completed and returned so that meaningful analyses could be made (p. 13).

\section{Qualitative strand.}

Patton (2002) identified several limitations of document analysis. First, he noted that researchers need access to the documents before they can be analyzed. Once access 
is achieved, researchers may find that these documents were "incomplete or inaccurate" (p. 306). Additionally, it is noted that researchers might have difficulty "understanding how and why the documents were produced" (p. 499).

Research Methods

\section{Site Selection}

To answer the research questions outlined in Chapter One, the program directors from the respective PA programs were surveyed. Thus, the target population for this study consists of the 133 accredited PA training programs listed by the Accreditation Review Commission on Education for the Physician Assistant. Demographically, these programs are found in 39 states within the United States. The target population is distributed in the four major geographical regions of the country (e.g., North, South, East, and West). The programs are found in 17 different Carnegie classifications (see Appendix B, p. 219).

\section{Sampling Procedures}

Given that the research intent was to conduct a census of the program directors at all accredited PA programs, sampling procedures were not considered in this design. The census population, however, is distributed within the Carnegie classification as indicated on the following page (see Table 2). Within these classifications, PA programs were located in three major areas. The Carnegie classification containing the largest concentration of PA programs was found at the Doctoral/Research University level. A total of 40 programs $(30.08 \%)$ were found in this classification. The Master's Colleges and Universities classification comprised the next major concentration of PA programs. Thirty-six programs, or $27.07 \%$, were found in this classification. The Medical School, 
Centers, and Separate Health Profession Schools classification comprised the third largest concentration of PA programs. This area encompassed 33 programs (24.81\%). The remaining 19 programs (14.29\%) were found in the other Carnegie classifications. Five of the programs $(3.76 \%)$ were not found in the current Carnegie listing.

Table 2

Physician Assistant Programs by Carnegie Classification (Census)

\begin{tabular}{llcc}
\hline Carnegie Type: & $\mathrm{N}=133$ & $\%$ \\
\hline Doctoral/Research Universities_Extensive & (Public) & 14 & 10.53 \\
Doctoral/Research Universities_Extensive & (Private) & 10 & 7.52 \\
Doctoral/Research Universities_-Intensive & (Public) & 7 & 5.26 \\
Doctoral/Research Universities_-Intensive & (Private) & 9 & 6.77 \\
Master's Colleges and Universities I & (Public) & 7 & 5.26 \\
Master's Colleges and Universities I & (Private) & 24 & 18.05 \\
Master's Colleges and Universities II & (Public) & 1 & .75 \\
Master's Colleges and Universities II & (Private) & 4 & 3.01 \\
Baccalaureate Colleges_-Liberal Arts & (Private) & 3 & 2.26 \\
Baccalaureate Colleges_-General & (Private) & 5 & 3.76 \\
Baccalaureate/Associate's Colleges & (Public) & 1 & .75 \\
Baccalaureate/Associate's Colleges & (Private) & 1 & .75
\end{tabular}


Table 2 (continued)

Census Demographics (Population Distribution)

\begin{tabular}{lccc}
\hline \multicolumn{1}{l}{ Carnegie Type: Physician Assistant Programs } & $\mathrm{N}=133$ & \multicolumn{1}{c}{$\%$} \\
\hline Associate's Colleges & (Public) & 7 & 5.26 \\
Associate's Colleges & (Private) & 2 & 1.50 \\
Medical schools and medical centers & (Public) & 18 & 13.53 \\
Medical schools and medical centers & (Private) & 8 & 6.02 \\
Other separate health profession schools & (Private) & 7 & 5.26 \\
Not classed & & 5 & 3.76 \\
Totals & & 133 & 100.00 \\
\hline
\end{tabular}

\section{Contact and Approval.}

An initial, unofficial contact was made with five senior members of the Association of Physician Assistant Programs (APAP) to determine if there existed a need for this research project. These contacts were established, and have been maintained, through telephonic and electronic-mail conversations. Of the members contacted, all gave unanimous encouragement and support for this research. Formal endorsement to conduct this study was granted by Association of Physician Assistant Programs Research Institute / Research and Review Information Exchange on November 25, 2003. The West Virginia University (WVU) Institutional Review Board for the Protection of Human Subjects granted approval to conduct the study on December 1, 2003. 
Pilot

In an effort to further strengthen the study and the survey in particular, a pilot study was conducted (Fraenkel \& Wallen, 2003; Tuckman, 1999). The survey was sent to 10 program directors ( $8 \%$ of all program directors) in APAP. These directors were arbitrarily selected based upon geographical location, Carnegie classification, gender, education level, and focus of degree.

Upon receiving APAP and WVU approval to conduct the study, an advanced mailing (Suskie, 1996) was conducted via email notification. This mailing informed the pilot group that they: (a) had been selected for the pilot; (b) were encouraged to participate; and (c) would be receiving their surveys in a matter of days (see Appendix C, p. 226).

Following the advanced mailing, the pilot survey and cover letter were mailed to pilot participants. In the accompanying cover letter (see Appendix D, p. 228), directors were asked to provide feedback through their survey question responses as well as feedback regarding the survey's structure, formatting, and presentation. Directors are also asked to record how long it took them to complete the survey and to provide feedback on the cover letter itself. The researcher requested that the surveys be returned after a follow-up phone call, but within two weeks.

To ensure that important feedback was captured, a final component of the pilot study was a follow-up telephonic discussion with pilot participants. During this time, program directors were asked to participate in a follow-up telephone call to further discuss the instrument, thus adding further validity to the instrument. While looking at their respective surveys, the researcher and individual participants discussed: 
- cover letter content for clarity and understanding;

- time of survey completion;

- survey format and content for clarity and understanding; and

- sample requests for clarity and availability.

Based upon respondent feedback, changes to the survey instrument were based on the frequency and scale of specific oral and written comments. Like the primary survey, follow-up communications (e.g., email, telephone) were made with non-respondents.

\section{Pilot Feedback}

The pilot study was conducted in December 2003. The response rate for the study was $50 \%(\mathrm{~N}=5)$. During the follow-up discussions with the program directors, several trends emerged.

First, like the senior APAP members noted above, all of these respondents expressed encouragement for the study. Second, $60 \%$ of the program directors requested that examples be added to questions 42 through 45 to clarify what was meant by who, when, what, and how students are assessed. In the case of how (survey question 45), for example, the pilot-survey item read: Our program has developed clear criteria to identify how assessment will take place. In an effort to increase the clarity of this item the following was added: (e.g., exam, journals, etc.). Third, the directors reported completing the survey in 20 to 30 minutes. The mean time to completion was 24 minutes.

Other than the three trends above, no other major patterns emerged during the pilot study. After adding the examples to survey question 42 through 45 , the survey was fielded in January 2004. 


\section{Cover Letters}

Contact with the respective PA program directors was initiated through an advanced mailing and cover letter. Similar to the pilot cover letter, directors received a cover letter (see Appendix E, p. 231) inviting them to participate in the study. The cover letter was developed based on recommendations from numerous research scholars (Fraenkel \& Wallen, 2003; Suskie, 1996; Tuckman, 1999).

Cover letters accompanied all questionnaires. Program directors were assured that their participation was voluntary and that anonymity and confidentiality would be protected. Participants were also informed that they would receive the results of the survey upon completion. Additionally, the participants were asked to complete the questionnaire within two weeks of the post date. A postage-paid, self-addressed envelope was included in the questionnaire packet.

\section{Response Rate}

Achieving an adequate response rate was important. As Upcraft and Schuh (1996) note, however, "even in the best of circumstances, mailed questionnaires rarely yield more than a 50 percent return response, with 25 percent to 30 percent being more typical" (p. 40). Hence, a 50\% return rate (or 67 respondents) was considered appropriate for this study. In the event the response rate was too low, the researcher planned two follow-up cycles with non-respondents. 


\section{Data Analysis}

\section{Quantitative Strand}

The data was analyzed by compiling all of the returned questionnaires, coding the responses to individual questions, and summarizing the information to formulate research conclusions. The data was analyzed and reported as percentages, means, and ranges.

\section{Qualitative Strand}

An additional feature of analysis was the use of qualitative data to assist in triangulation of survey responses. Collected documents were analyzed for pertinence to the research questions. Analysis focused on the major themes identified in the review of scholarly literature, research questions, and survey topics (e.g., gaining institutional resources, student learning outcomes, etc.). Content analysis was guided through the use of a program document protocol (see Appendix F, p. 234).

The program document protocol was designed to examine the following requested documents:

\section{- Assessment plans}

- Assessment reports

- Guiding principles for assessment (institutional or programmatic)

- Materials that describe incentives for faculty participation in assessment

- Examples of programmatic goals and student learning outcomes

- Examples of student learning outcomes at the course-level

- Commercially- and locally-developed instruments (e.g., direct, indirect) 
Those thematic patterns identified within the body of the documents that substantiate or refute survey responses were recorded and added to the results that become part of the conclusions and recommendations regarding assessment practices and PA education.

\section{Trustworthiness}

Trustworthy data is most closely associated with a design that collects valid and reliable information (Johnson \& Turner, 2003). Although scholars have identified a myriad of issues related to validity and reliability (Maxwell, 1996; Johnson \& Turner, 2003), this study will focus on those noted by Suskie (1996) as they pertain to survey questionnaires.

\section{Reliability (Consistency)}

Suskie identifies two types of consistency in survey research: (a) consistency within the questionnaire [i.e., internal consistency] and (b) consistency over time [i.e., test-retest reliability] (p. 54). Instruments that possess internal consistency are those that collect similar responses to similar questions. Test-retest reliability applies to an instrument that collects consistent responses over a given period of time.

To establish internal consistency for this study's instrument, two strategies were incorporated: (a) similar questions were asked in different sections on the survey [e.g., questions 19 and 30] and (b) correlation of item scores using statistical analysis. Establishing consistency over time was not a major research concern, thus a rest-retest process was not planned. As Suskie observes, "Consistency over time is only a rare concern since most questionnaires deal with opinions or other information that is expected to change over time. Indeed, the purpose of a questionnaire study is often to collect information to help us facilitate change" (p. 55). 


\section{Validity (Truthfulness)}

Suskie (1996) defines a valid questionnaire as one that "measures accurately what you want it to measure and the inferences you make from this questionnaire will be accurate" (p. 56). To achieve this validity, then, researchers are compelled to collect and triangulate corroborating information about a subject. In essence, "the more corroborating measures you collect, and the more disparate they are in nature, the better your evidence that your questionnaire is valid" (p. 57).

To establish validity for this study's instrument, several strategies were incorporated. First, the survey results were compared (i.e., triangulated) against the scholarly literature and document analysis as discussed and illustrated in Table 1 (see page 66). Secondly, the instrument was processed through the West Virginia University

Institutional Review Board for the Protection of Human Subjects and the Association of Physician Assistant Programs Research Institute / Research and Review Information Exchange process to ensure non-trivial/redundant research was conducted within the discipline. Thirdly, upon completion of the above process, the instrument was piloted to further establish validity.

\section{Researcher's Background}

\section{Professional}

The researcher is a commissioned officer in the United States Army. During the past 27 years, the researcher has been assigned to numerous reconnaissance, Special Forces, and Special Operations units. Cumulatively, the researcher has spent years operating in Europe, Africa, the Middle East, and Asia. The researcher led a Special Forces A-Detachment in combat during the first Gulf War. 
The researcher has presented, taught, and assessed education for numerous Department of Defense, academic, national, and international audiences. Those of particular note include:

- Combat Trauma Management:

- Kenya, 1987; Oman, 1992; Thailand, 1996

- Infectious Diseases:

○ Kenya, 1987-89; Honduras, 1988; Somalia, 1988; Oman, 1992; Thailand, 1996; Tanzania, 1999; Kosovo, 2000

- Counter-Terrorism:

- International Committee of the Red Cross-University of Geneva-Hunter College-Fordham University, 2000-2001

- Land Mine Awareness:

- Pakistan, 1989; International Committee of the Red Cross-University of Geneva-Hunter College-Fordham University; 2000-2001; University of Hawaii, 2001

\section{Academic}

The researcher graduated with distinction from the University of Oklahoma (B.S., Physician Associate) in 1995 and earned a Master of Physician Assistant Studies degree (Family Medicine) from the University of Nebraska in 1997. The researcher is currently a doctoral candidate at the University of West Virginia's Department of Advanced Leadership Studies. The researcher recently planned and taught a year-long (2002-2003) faculty development course in programmatic assessment to the Alderson-Broaddus Physician Assistant faculty. The author is currently co-teaching Assessment in Higher 
Education at West Virginia University and is teaching Public Health and Human Ecology at Alderson-Broaddus College. Lastly, the researcher has recently had an article entitled, "Anatomy of a MEDRETE," published in the Journal of Special Operations Medicine. An additional paper entitled, "Addressing Key Challenges in Higher Education Assessment," is currently in press at Penn State University Press (i.e., Journal of General Education).

\section{Timeframe}

The timeframe for this research is as follows:

November $2003 \quad$ Proposal defense

Proposal to Association of Physician Assistant Programs

Proposal to West Virginia University Institutional Review Board Advanced mailing for pilot study

December 2003 Pilot survey and results. Changes implemented to survey January $2004 \quad$ Advanced mailing for census

Survey sent to all PA program directors

Reminders sent to PA program directors who do not respond February $2004 \quad$ Analyze data March $2004 \quad$ Write results and draw conclusion with recommendations April $2004 \quad$ Dissertation defense: April 19, 2004

Conclusion

The planning and implementation of institutional and programmatic assessment to ascertain what students have learned and how well they have learned it entails a series of challenges. As demonstrated in the review of the scholarly literature, some of the most 
prominent challenges in assessment involve the acquisition of institutional resources, faculty development, and the integration of student learning outcomes. Other challenges include the measurement of student learning outcomes, using assessment results to affect change, and the reporting assessment activities to specific audiences.

Given the assessment challenges discussed thus far, it is assumed that the 133 accredited Physician Assistant (PA) training programs in the United States are meeting these challenges in a variety of ways. Currently, however, there is no collective, synthesized picture of the existing programmatic assessment practices in PA education. This research seeks to provide a glimpse of these practices.

PA educators from across the nation will provide the quantitative and qualitative data that determines the shape, depth, and form of this picture. Hence, this data and its subsequent analysis will: (a) add additional assessment-related knowledge to the field of education and most specifically to PA education; (b) provide synthesized feedback to PA educators nationwide on the current assessment practices of their peers; and (c) establish a baseline for the profession by identifying where PA education is currently located along the assessment continuum in higher education. It is the researcher's sincere wish that ultimately this work can in some small way contribute to the learning of those who serve the healthcare needs of our society. 


\section{CHAPTER FOUR. RESULTS}

Introduction

This study examined the internal programmatic assessments implemented by Physician Assistant (PA) educators. This chapter is organized by the research questions identified in the first chapter of this study. The results of this research are presented topically based upon the survey instrument (e.g., survey questions 1-6 present results on gaining institutional resources). As noted in Chapter Three (Figure 3, p. 64), the research was conducted using mixed-methods (e.g., Concurrent Nested Design). Thus, the results presented here are of both a quantitative and qualitative nature. Triangulation was achieved through the integration of scholarly literature/research questions, quantitative (i.e., survey results), and qualitative (i.e., document analysis) components.

During the data collection phase of this research, a census was conducted examining the assessments implemented by Physician Assistant (PA) educators. A survey questionnaire was sent to each of the 133 PA program directors in the nation. A 33\% response rate was obtained for this census. Of the 44 directors responding to the survey, $39 \%$ (17 respondents) provided assessment samples with their completed questionnaire.

\section{Demographic Characteristics of Physician Assistant Program Directors}

\section{Gender and Education}

The PA program directors that completed the survey were reviewed to determine the following demographic information: gender, education level, institutional Carnegie classification, and geographical distribution (see Tables 3-5). The respondents were equally divided by gender. The majority (66\%) of directors had completed a Masterslevel degree. The next highest percentage (32\%) had earned a doctoral degree. 
Table 3

Program Directors' Demographics by Gender and Education

Item

$\mathrm{N}=44$

$\%$

Gender

Female

$22 \quad 50$

Male

22

50

Education Level

$\begin{array}{lrr}\text { Baccalaureate Degree } & 1 & 2 \\ \text { Master's Degree } & 29 & 66 \\ \text { Doctoral Degree } & 14 & 32\end{array}$

Geographical Distribution

Geographically, the respondents were clustered in several regions: the Northeast with $27 \%$ and $18 \%$ each in the Southeast, Midwest, and Southwest (see Table 4).

Program directors at institutions of higher learning in the Western region account for $11 \%$ of the sample population.

Table 4

Program Directors' Demographics by Geographical Distribution

$\underline{\text { Item }}$

$\mathrm{N}=44$

$\%$

Geographical Region:

Northeast

Southeast

Midwest

West
12

8

8

5
27

18

18

11 
Table 4 (continued)

Program Directors' Demographics by Geographical Distribution

\begin{tabular}{llr}
\hline Item & $\mathrm{N}=44$ & $\%$ \\
\hline & & \\
Southwest & 8 & 18 \\
Pacific & 2 & 5 \\
Northwest & 1 & 2 \\
\hline
\end{tabular}

Note. Rounding error.

\section{Demographic Characteristics of Physician Assistant Programs}

The Physician Assistant (PA) programs involved in this study were examined to determine the numbers and percentages in the following areas: (a) Carnegie classification; (b) faculty status; (c) current student enrollment; (d) annual number of graduates; (e) number of years accredited; and (f) year of last accreditation. Results from Survey

Program demographics by Carnegie classification.

Survey data indicates that PA programs are from a wide range of institutions distributed across seven major geographical regions of the United States of America. Approximately one-third (34\%) of respondents were located at Doctoral/Research Universities (Carnegie Foundation for the Advancement of Teaching, 2000) and onequarter $(25 \%)$ were located at programs in Medical Schools and Medical Centers (see Table 5). The program directors from Master's Colleges and Universities accounted for $18 \%$ of the total number of respondents. Additionally, Baccalaureate and Associates College respondents accounted for $11 \%$ and 5\%; respectively. Finally, those PA program 
directors at Other Separate Health Profession Schools comprised 7\% of the total respondents.

In addition to returning the survey questionnaire, program directors were also asked to provide various samples of documents related to the survey topics. Seventeen directors provided the requested documents for analysis (see Table 5). Of those directors supplying documents, over three-fourths (83\%) are from: Doctoral/Research Universities (41\%); Baccalaureate Colleges (24\%); and Master's Universities/Colleges (18\%).

Table 5

Program Demographics by Carnegie Classification

$$
\text { Survey }(\mathrm{N}=44) \quad \text { Documents }(\mathrm{N}=17)
$$

Item $\mathrm{N} \quad \%$ $\mathrm{N} \quad \%$ Carnegie Classification:

Doctoral/Research University Master's University/College Baccalaureate Colleges Associates College Medical Schools/Medical Centers Other Health Professions Schools

$\begin{array}{rrrr}15 & 34 & 7 & 41 \\ 8 & 18 & 3 & 18 \\ 5 & 11 & 4 & 24 \\ 2 & 5 & 1 & 6 \\ 11 & 25 & 1 & 6 \\ 3 & 7 & 1 & 6\end{array}$

Note. Rounding error.

Faculty status at Physician Assistant programs.

Faculty status is divided between those faculty members who hold full-time or part-time positions. Slightly over half (55\%) of PA program directors had one to five full- 
time faculty members (see Table 6). Eighteen directors (41\%) reported six to ten full-time faculty members.

Fifty percent of directors reported that they had between one and five part-time faculty members in their PA programs (see Table 6). An additional $27 \%$ indicated that they do not have any part-time faculty members at their programs. In sharp contrast to the majority of programs, the directors responding with six to ten (11\%), 11 to $20(5 \%)$, and greater than $20(7 \%)$ part-time faculty members were relatively few in number.

Table 6

Faculty Status at Physician Assistant Programs

$\mathrm{N}=44$

$\%$

Full-time status

$\begin{array}{lrr}1-5 & 24 & 55 \\ 6-10 & 18 & 41 \\ 11-20 & 1 & 2 \\ 21-30 & 1 & 2\end{array}$

Part-time status

0

1-5

6-10

11-20

$>20$
12

22

5

2

3
27

50

11

5

7

Current student enrollment in Physician Assistant programs.

The number of students enrolled in PA programs ranged from 30 to 230 (see Table 7). Twenty-five (57\%) directors reported enrollments of between 51 and 100 
students in their programs. Twenty percent of program directors indicated that their current enrollments are between 30 and 50. Four directors (9\%) reported enrollments of 101 to 150 students. An additional five respondents (11\%) noted current enrollments of 151 to 200 students. Only one director had student enrollments between 201 and 250. The total number of students enrolled at these 44 programs was 3748 with an average enrollment of 85 students per program.

Table 7

Current Student Enrollment in Physician Assistant Programs

Item $\quad \mathrm{N}=44 \quad \%$

Number of students enrolled:

$\begin{array}{lrr}30-50 & 9 & 20 \\ 51-100 & 25 & 57 \\ 101-150 & 4 & 9 \\ 151-200 & 5 & 11 \\ 201-250 & 1 & 2\end{array}$

Note. Rounding error.

Annual number of graduates from Physician Assistant programs.

The number of students who graduated from these PA programs on an annual basis ranges from 12 to 100 . Nearly one-half $(48 \%)$ of the respondents indicated that between 26 to 50 students graduate (see Table 8 ). One-third of the directors (34\%) reported student graduation rates between 12 and 25 . The total number of annual graduates reported by these 44 program directors was 1648 . The average size graduating class among these programs was comprised of 37 students. 
Table 8

Annual Number of Graduates from Physician Assistant Programs

\begin{tabular}{lcc} 
Item & $\mathrm{N}=44$ & $\%$ \\
\hline & & \\
Annual graduates & & \\
& & \\
$12-25$ & 15 & 34 \\
$26-50$ & 21 & 48 \\
$51-75$ & 4 & 9 \\
$76-100$ & 3 & 7 \\
$101-125$ & 1 & 2 \\
\end{tabular}

\section{Number of years Physician Assistant programs accredited.}

These PA programs had been accredited by a professional accreditation body (currently the Accreditation Review Commission on Education for the Physician Assistant) from 1 to 34 years. Thirty-nine percent of directors responding to the survey indicated that their programs have been accredited for six to ten years (see Table 9). Nearly one-quarter (23\%) indicated that their programs have been accredited for 31 to 35 years. Eight (18\%) directors responded that their programs have been accredited for one to five years. The programs accredited for 21 to 30 years comprise $14 \%$ of all responses to this item. One director $(7 \%)$ indicated a program accreditation in the category of 11 to 20 years. On average, these programs had been accredited for 15 years. 
Table 9

Number of Years Physician Assistant Programs Accredited

Item

Accreditation length (yrs.):
6-10

11-20

21-30

$31-35$
$\mathrm{N}=44$

$\%$

$\begin{array}{rr}8 & 18 \\ 17 & 39 \\ 3 & 7 \\ 6 & 14 \\ 10 & 23\end{array}$

Note. Rounding error.

\section{Current accreditation of Physician Assistant programs.}

The most recent accreditation of these programs ranged from one to seven years. Forty-one percent of PA program directors reported their most recent accreditation between 2001 and 2002 (see Table 10). An additional 30\% of directors indicated being granted accreditation (i.e., new or renewal) within the past year. Nine (20\%) directors responded that their most current accreditation was issued in the period between 1999 and 2000. The final four (9\%) directors in this category reported that their programs received their latest accreditation in 1997 to 1998 timeframe. 
Table 10

Current Accreditation of Physician Assistant Programs

\begin{tabular}{|c|c|c|}
\hline Item & $\mathrm{N}=44$ & $\%$ \\
\hline \multicolumn{3}{|l|}{ Year: } \\
\hline 1997-1998 & 4 & 9 \\
\hline $1999-2000$ & 9 & 20 \\
\hline $2001-2002$ & 18 & 41 \\
\hline 2003-2004 & 13 & 30 \\
\hline
\end{tabular}

Development and implementation of assessment plans at Physician Assistant programs.

Physician Assistant (PA) program directors were asked for information regarding the development and implementation of their respective assessment plans. Results of the Survey and Document Analysis

Of the 44 Physician Assistant (PA) program directors who responded to the survey, 52\% indicated that their assessment plans were not fully developed (see Table 11). Fifty-three percent indicated that their assessment plans were not fully implemented. None of the 17 samples that arrived for analysis included a complete assessment plan; thus it was impossible to ascertain the level of development or implementation at these programs by examining only their documents. 
Table 11

Development and Implementation of Assessment Plans at Physician Assistant Programs

\begin{tabular}{|c|c|c|c|c|c|c|c|c|}
\hline \multirow[b]{2}{*}{$\mathrm{N}=44$} & \multicolumn{2}{|c|}{ SA } & \multicolumn{2}{|c|}{ A } & \multicolumn{2}{|c|}{$\mathrm{D}$} & \multicolumn{2}{|c|}{ SD } \\
\hline & $\mathrm{N}$ & $\%$ & $\mathrm{~N}$ & $\%$ & $\mathrm{~N}$ & $\%$ & $\mathrm{~N}$ & $\%$ \\
\hline Plan fully developed.............. & 1 & 2 & 20 & 45 & 20 & 45 & 3 & 7 \\
\hline Plan fully implemented.......... & 1 & 2 & 20 & 45 & 21 & 48 & 2 & 5 \\
\hline
\end{tabular}

Note. Rounding error. $\mathrm{SA}=$ Strongly Agree. $\mathrm{A}=$ Agree. $\mathrm{D}=$ Disagree. $\mathrm{SD}=$ Strongly Disagree.

\section{Research Findings by Research Question}

As stated above, the following data is presented topically based upon the research questions. Each research question and sub-questions are discussed in the order that they occur in the questionnaire. Under each research question heading, the quantitative (i.e., questionnaire) data is discussed in a narrative format and then followed with a table to display the data in a graphic format. Next, the qualitative (i.e., document sample) data is presented in narrative format as it applies to certain areas and will either corroborate or refute the data from the questionnaire. The qualitative data is also presented in tables. Three or four qualitative examples are then provided to facilitate the triangulation process. Lastly, a data summary completes each major section of the chapter.

\section{Gaining Institutional Resources for Assessment Activities}

This section of Chapter Four addresses research question number one: What types of institutional resources are available to conduct assessment? To answer this question, 
PA program directors were asked six different questions designed to elicit information regarding: (a) executive-level support; (b) characteristics of assessment culture at their institutions; (c) articulation of projected resource expenditures for assessment costs; (d) allocation of resources for initial assessment costs; (e) sustained assessment cost forecasting by line-item in successive budgeting cycles; and (f) the program's guiding principles for assessment (see Appendix A, p. 210).

Results from Survey

\section{Executive-level support for assessment.}

One-half $(50 \%)$ of the program directors strongly agreed that they receive executive-level support for their assessment efforts. An additional 43\% of directors indicated agreement with the support statement. Seven percent of directors disagreed that executive-level support is available to their program's assessment efforts.

Assessment culture at institutions with Physician Assistant programs.

The survey instrument next focused on the assessment culture facilitated by institutional leaders (i.e., presidents, vice presidents, deans, or institutional committee chairs). PA program directors were asked to indicate those items that characterize their institutional assessment culture (see Table 12). A majority (79\%) of directors believed that campus leaders view them as collaborators in the assessment process. Approximately one-half of program directors reported effective communication, a trusting environment, and deliberate planning. Additional aspects of the assessment culture (i.e., being directly involved in assessment, integrating assessment costs in the budget, instituting authentic incentives for participation in assessment, and meeting regularly with faculty on 
assessment issues) were cited by 38 to $41 \%$ of program directors. Five of the program directors provided no responses to the questions contained in the checklist.

Table 12

Leadership Factors in a Culture of Assessment

\begin{tabular}{|c|c|c|}
\hline$\underline{\text { Leaders }}$ & $\mathrm{N}$ & $\%$ \\
\hline Are directly involved in the process & 16 & 41 \\
\hline Meet regularly with assessment personnel & 12 & 31 \\
\hline Maximize effective communications & 21 & 54 \\
\hline Establish an environment of trust & 21 & 54 \\
\hline Treat faculty as collaborators & 31 & 79 \\
\hline Institute authentic incentives & 13 & 33 \\
\hline Encourage deliberate planning & 20 & 51 \\
\hline Facilitate incremental change & 7 & 18 \\
\hline Approve integration in budget & 15 & 38 \\
\hline
\end{tabular}

Note. Multi-response item.

Acquisition of institutional resources for assessment activities.

Under this topic, data was sought on the projection, allocation, and budgeting for assessment expenditures. Slightly over half of program directors (55\%) indicated that they have articulated their projected expenditures for assessment activities at the senior leadership level (see Table 13). Forty-one percent of respondents, however, reported that this articulation had not occurred as yet. When asked if institutional leaders had allocated resources for initial (or start-up) assessment costs, $60 \%$ of directors reported in the affirmative. Closely approximating the percentage in the preceding (and related) question, $41 \%$ of directors indicated that leaders had not allocated initial assessment resources. 
When queried regarding whether sustained assessment costs had been forecasted by line-item in successive budgets, however, the margin between those responding affirmatively and negatively widened sharply. Sixty-six percent of respondents indicated that sustained costs are not currently being forecasted. Lastly, directors were asked if their programs had guiding principles that addressed their assessment process. Threequarters of PA program directors responded in the affirmative. Despite the researcher's request, no documents regarding guiding principles were returned with the surveys.

Table 13

Acquisition of Institutional Resources for Assessment Activities

\begin{tabular}{|c|c|c|c|c|c|c|c|c|c|}
\hline \multirow[b]{2}{*}{ Item } & \multirow{2}{*}{$\begin{array}{c}\text { Total } \\
\mathrm{N} \\
\end{array}$} & \multicolumn{2}{|c|}{ SA } & \multicolumn{2}{|c|}{ A } & \multicolumn{2}{|c|}{$\mathrm{D}$} & \multicolumn{2}{|c|}{ SD } \\
\hline & & $\mathrm{N}$ & $\%$ & $\mathrm{~N}$ & $\%$ & $\mathrm{~N}$ & $\%$ & $\mathrm{~N}$ & $\%$ \\
\hline Articulation of expenditures & 44 & 3 & 7 & 21 & 48 & 16 & 36 & 4 & 9 \\
\hline Allocation of resources & 44 & 2 & 5 & 24 & 55 & 16 & 36 & 2 & 5 \\
\hline Dedicated line item & 44 & 1 & 2 & 14 & 32 & 23 & 52 & 6 & 14 \\
\hline Guiding principles & 43 & 8 & 19 & 25 & 58 & 10 & 23 & 0 & 0 \\
\hline
\end{tabular}

Note. Rounding error. $\mathrm{SA}=$ Strongly Agree. $\mathrm{A}=$ Agree. $\mathrm{D}=$ Disagree.

$\mathrm{SD}=$ Strongly Disagree

Faculty Development in the Assessment Process

This section of Chapter Four addresses research question number two: How is assessment planning integrated into Physician Assistant (PA) faculty development? Directors of PA programs were asked questions about faculty development issues such as: (a) faculty as an essential human resource; (b) use of assessment experts; (c) type and 
frequency of assessment presentations and workshops; (d) faculty participation levels; (e) definition of faculty roles and expectations; (f) types of incentives for faculty participation in assessment; and (g) faculty resistance to assessment efforts (Appendix A, p. 210).

Results from the Survey

Human resources and the use of assessment experts.

Nearly all (96\%) of program directors considered faculty an essential element of their assessment efforts. Fifty-five percent of respondents reported that on-campus experts teach faculty development sessions on assessment issues each year (see Table 14). In contrast, $30 \%$ of directors revealed that on-campus experts had never taught assessment-related faculty development sessions to their faculty. The remaining directors indicated that experts were teaching on a monthly (2\%), quarterly $(7 \%)$, and biannual (7\%) basis. Conversely, slightly over half (61\%) of program directors responded that offcampus experts had never taught assessment-related faculty development. Other directors $(23 \%)$ indicated that off-campus experts taught assessment on an annual basis.

Table 14

Human Resources and the Use of Assessment Experts

\begin{tabular}{|c|c|c|c|c|c|c|c|c|c|}
\hline \multirow[b]{2}{*}{$\underline{\text { Item }}$} & \multicolumn{2}{|c|}{ Monthly } & \multicolumn{2}{|c|}{ Quarterly } & \multicolumn{2}{|c|}{ Bi-Annually } & \multicolumn{2}{|c|}{ Annually } & Never \\
\hline & $\mathrm{N}$ & $\%$ & $\mathrm{~N}$ & $\%$ & $\mathrm{~N}$ & $\%$ & $\mathrm{~N}$ & $\%$ & $\mathrm{~N} \quad \%$ \\
\hline Use of on-campus experts & 1 & 2 & 3 & 7 & 3 & 7 & 24 & 55 & 1330 \\
\hline Use of off-campus experts & 1 & 2 & 4 & 9 & 2 & 5 & 10 & 23 & 2761 \\
\hline
\end{tabular}

Note. Rounding error. 


\section{Type and frequency of assessment sessions.}

The types of assessment-related faculty development sessions include: (a) formal presentations; (b) hands-on, interactive, single-topic workshops; (c) hands-on, interactive, multi-topic workshops; and (d) an open-ended option. The questionnaire sought to determine if PA program faculty were being exposed to different forms of development. The frequency of assessment-related faculty development was calculated based upon the number of sessions (i.e., 1, 2-3, 4-5, 5+, never) that program members participated in during the past academic year.

In regard to the number of formal assessment presentations offered to faculty in the past academic year, $25 \%$ indicated once, $36 \%$ indicated two to three times, and $32 \%$ indicated that formal presentations had never been offered (see Table 15). Additionally, fifty percent of program directors responded that hands-on, interactive, single-topic workshops had never been offered to their faculty, while $30 \%$ responded that these opportunities were offered two to three times per year at their institutions. The disparity between those offered hands-on, interactive, multi-topic workshops and those not offered them is even more striking than the aforementioned figures. Sixty-four percent of directors responded that this type of assessment session had never been offered at their institution, while other directors indicated once (14\%) or two to three times (16\%) in the past academic year.

In regard to other forms of assessment-related faculty development, open-ended responses included, "Assessment workshop being planned for Chairs" and "One-hour faculty forums" two to three times in the past academic year. Another director replied 
that assessment sessions are a "part of annual [faculty] retreats and quarterly faculty meetings."

Table 15

Type and Frequency of Assessment Sessions

\begin{tabular}{lrrrrrrrrrr}
\hline Type: & 1 & $\%$ & $2-3$ & $\%$ & $4-5$ & $\%$ & $5+$ & $\%$ & Never & $\%$ \\
\hline FP & 11 & 25 & 16 & 36 & 2 & 5 & 1 & 2 & 14 & 32 \\
STWS & 5 & 11 & 13 & 30 & 2 & 5 & 2 & 5 & 22 & 50 \\
MTWS & 6 & 14 & 7 & 16 & 2 & 5 & 1 & 2 & 28 & 64 \\
Other & 0 & 0 & 3 & 7 & 0 & 0 & 0 & 0 & 0 & 0 \\
& & & & & & & & & &
\end{tabular}

Note. Multi-response item. FP= Formal Presentation. STWS = Single-topic Workshops. MTWS = Multi-topic Workshops. Other = Open-ended option.

Physician Assistant educator attendance at assessment-related development.

Directors were also asked how many of their faculty members had attended faculty development sessions specifically on assessment topics in the past academic year. Responses ranged from zero to twenty-one with the mean being 3.66.

Assessment topics at faculty development sessions.

To analyze the topical nature of assessment-related faculty development sessions, respondents were provided a multi-response checklist and instructed to mark as many applicable responses as needed for their institutions and programs. The most prevalent topic $(80 \%)$ at assessment-related faculty development sessions was student learning outcomes (see Table 16). Next, the topics in faculty development and assessment, instruments for measuring learning, and using assessment results to affect change clustered in frequency with respondents reporting $68 \%, 66 \%$, and $61 \%$; respectively. 
An additional cluster of assessment-related faculty development topics (i.e., reporting assessment results, assessment philosophy, and assessment language) was evident in the $43 \%$ to $55 \%$ range. Under the open-ended option for this checklist, two program directors $(5 \%)$ indicated that their sessions had not focused on any of the options available on the checklist. They did, however, reply that their sessions addressed "writing good test questions" and "the use of technology" in assessment.

Table 16

Assessment Topics at Faculty Development Sessions

\begin{tabular}{lcc} 
Sessions & $\mathrm{N}=44$ & $\%$ \\
\hline & & \\
Assessment philosophy & 22 & 50 \\
Assessment language & 19 & 43 \\
Gaining institutional resources & 7 & 16 \\
Faculty development and assessment & 30 & 68 \\
Student learning outcomes & 35 & 80 \\
Instruments for measuring learning & 29 & 66 \\
Using assessment results to affect change & 27 & 61 \\
Reporting assessment results & 24 & 55 \\
Other & 2 & 5 \\
Missing data & 1 & 2 \\
\end{tabular}

Note. Multi-response item.

Physician Assistant faculty roles and expectations in the assessment process.

Program directors were asked if faculty roles in assessment are well-defined at their institutions and programs. Of the 44 respondents in this study, the majority of respondents (68\%) replied in the affirmative (agree and strongly agree) when asked if 
faculty roles in assessment are well-defined. Thirteen directors (30\%) did not believe that their faculty roles are clearly defined.

When asked whether institutional and programmatic faculty expectations in assessment were well-defined, 28 (64\%) respondents replied in the affirmative. Fifteen (34\%) respondents, however, did not believe that faculty expectations in the assessment process are well-defined. One director (2\%) did not supply data for either question. Lastly, one respondent noted in the margin of the questionnaire that "recent turnovers in faculty and a restructuring of the department have influenced clearly defined roles in assessment."

Physician Assistant faculty incentives to participate in the assessment process.

Physician Assistant (PA) program directors were given a multi-response checklist to indicate those incentives in use at their institutions to increase faculty participation in assessment activities. Respondents indicated by a wide margin (57\%) that their institutions provide no incentives to increase faculty participation (see Table 17). At those institutions that did provide incentives, program directors reported that time to work on assessment initiatives (45\%) and travel to assessment conferences (75\%) were most common. Two directors (10\%) replied to the open-ended option. One director indicated that "providing lunch" to faculty is used to gain participation at assessment presentations. The other director noted that "faculty development funds" are used as an incentive.

In a related question, respondents were asked how many of their faculty members had received the above incentives during the past year. Twenty-nine (66\%) out of 44 directors reported that none of their faculty members had received assessment incentives 
during this timeframe. The remaining fifteen respondents (34\%) noted that their members had received incentives in the past year. The number of faculty receiving these incentives at each of the 15 programs ranged from 1 to 8 with 3 members being the most common.

\section{Table 17}

Faculty Incentives to Participate in the Assessment Process

\begin{tabular}{lcrr} 
Incentives & Total N & N & $\%$ \\
\hline None & 44 & 25 & 57 \\
& & & \\
Small grants (less than \$2000) & 20 & 6 & 30 \\
Large grants (more than \$2000) & 20 & 1 & 5 \\
Stipends & 20 & 2 & 10 \\
Time & 20 & 9 & 45 \\
Travel to assessment conferences & 20 & 15 & 75 \\
Travel to other institutions & 20 & 3 & 15 \\
Use of graduate student & 20 & 3 & 15 \\
Other & 20 & 2 & 10 \\
& & & \\
\hline
\end{tabular}

Note. Multi-response item.

Physician Assistant faculty rewards for participation in the assessment process.

In this section of the survey, PA program directors were asked about intrinsic and extrinsic rewards that are used at the various institutions to recognize Physician Assistant faculty members for their participation in assessment activities.

Intrinsic rewards.

Program directors were presented with a multi-response checklist and instructed to mark as many items as were applicable to their institutions (see Table 18). Twentyfour of the directors $(55 \%)$ choose not to mark any of the available responses. 
Additionally, they choose not to use the open-ended option available for indicating other potential intrinsic rewards.

Eighty-five percent of respondents indicated that an increased interaction with other faculty members is the most frequent intrinsic reward for assessment participation. Forty-five percent of the directors reported that assessment results are not used against the faculty.

Table 18

Faculty Reward System (Intrinsic)

\begin{tabular}{lrr} 
Rewards $\quad \mathrm{N}=20$ & $\mathrm{~N}$ & $\%$ \\
\hline & & \\
Increased interaction with other faculty & 17 & 85 \\
Increased interaction at other institutions & 7 & 35 \\
Increased understanding of institutional linkages & 3 & 15 \\
Knowing that assessment results are non-punitive & 9 & 45 \\
& & \\
\hline
\end{tabular}

Note. Multi-response item.

\section{Extrinsic rewards.}

Extrinsically, Physician Assistant (PA) program directors were queried about six possible faculty rewards and provided an open-ended option for additional possibilities. As with intrinsic rewards above, the most frequent response to this checklist is no response by 20 of the respondents (see Table 19).

Of the 15 directors who do provide responses to the checklist, $75 \%$ reported "inclusion in the promotion and tenure process" as the most common extrinsic reward for participation in the assessment endeavor. The next most frequent responses were 
expressions of gratitude from leaders $(50 \%)$, presentations at national conferences $(35 \%)$, publications (30\%), and letters of commendations (30\%). As above, the PA program directors did not utilize the open-ended item.

Table 19

Faculty Reward System (Extrinsic)

\begin{tabular}{lrr} 
Rewards & $\mathrm{N}$ & $\%$ \\
\hline & & \\
Personal expressions of gratitude from leaders & 10 & 50 \\
Public expressions of gratitude from leaders & 4 & 20 \\
Letters of commendation & 6 & 30 \\
Inclusion in promotion and tenure process & 15 & 75 \\
Publication in journals and books & 6 & 30 \\
Presentations at national conferences & 7 & 35 \\
& & \\
\hline
\end{tabular}

Note. Multi-response item.

Resistance to the assessment process by Physician Assistant educators.

PA program directors were asked about faculty resistance to the assessment process. Approximately three-fourths of program directors (73\%) reported that faculty resistance is not an issue in their programs. Eleven directors (25\%), however, indicated that faculty resistance to assessment is an issue at their programs. One program director commented that faculty members have developed resistance to participating in assessment activities secondary to "being overworked" and having "no time, resources or expertise from leaders." 
The researcher requested documents pertaining to faculty rewards for participation in assessment activities. However, no relevant materials that addressed this topic were returned with the questionnaires.

\section{Programmatic Student Learning Outcomes at Physician Assistant Programs}

This section addresses research question number three: What programmatic student learning outcomes (SLOs) (e.g., cognitive, affective, and psychomotor domains) are used by Physician Assistant (PA) educators? To answer this question, PA program directors were asked numerous question on the survey instrument (see Appendix A, p. 210).

Results of the Survey

Alignment of programmatic mission statement and goals.

When asked if their programmatic mission statements were in alignment with their respective institutional mission statements, the great majority $(91 \%)$ of PA program directors responded in the affirmative (see Table 20). Next, nearly all (98\%) of the directors indicated that their programmatic goals were developed in accordance with their mission statements. Similarly, respondents reported that their programmatic goals were clear $(98 \%)$ and shared by their faculty members $(95 \%)$. When asked if their programmatic goals were fully implemented, $80 \%$ of directors agreed or strongly agreed.

Development of programmatic student learning outcomes.

Physician Assistant program directors were next asked about their specific programmatic SLOs to determine if they follow good principles of practice (Huba \& Freed, 2000). Respondents reported that their SLOs are expressed precisely (91\%), were 
developed through a collaborative process with other faculty members $(84 \%)$, and manifested the vision identified in their mission statements (96\%) (see Table 20).

Table 20

Programmatic Student Learning Outcomes at Physician Assistant Programs (Survey)

\begin{tabular}{|c|c|c|c|c|c|c|}
\hline \multirow[b]{2}{*}{ Item } & $\mathrm{SA}$ & A & \multicolumn{2}{|c|}{$\mathrm{D}$} & \multicolumn{2}{|c|}{ S D } \\
\hline & $\mathrm{N} \%$ & $\mathrm{~N} \%$ & $\mathrm{~N}$ & $\%$ & $\mathrm{~N}$ & $\%$ \\
\hline Alignment of mission statement & 2251 & 1842 & 3 & 7 & 0 & 0 \\
\hline Goals based on mission statement & 2149 & 2251 & 0 & 0 & 0 & 0 \\
\hline Clear programmatic goals & 1842 & 2456 & 1 & 2 & 0 & 0 \\
\hline Shared programmatic goals & 1842 & 2353 & 2 & 5 & 0 & 0 \\
\hline Fully implemented goals & 1433 & 2047 & 8 & 19 & 1 & 2 \\
\hline SLOs are expressed precisely & 1535 & 2456 & 4 & 9 & 0 & 0 \\
\hline SLOs are a collaborative process & 1740 & 1944 & 7 & 16 & 0 & 0 \\
\hline SLOs manifest the mission vision & 1740 & 2456 & 2 & 5 & 0 & 0 \\
\hline
\end{tabular}

Note. Rounding error. SLO $=$ Student Learning Outcomes. SA = Strongly Agree. $\mathrm{A}=$ Agree. $\mathrm{D}=$ Disagree. $\mathrm{SD}=$ Strongly Disagree.

\section{Results of Document Analysis}

\section{Alignment of programmatic mission statement and goals.}

Directors were asked to provide examples of their programmatic goals and student learning outcomes. Of the 17 samples submitted, $41 \%$ contained the requested items. Eighty-six percent of the samples indicated PA program goals are clear, developed in accordance with the institutional and programmatic mission statements, and are fully implemented (see Table 21). Of the documents analyzed, however, none indicated that programmatic goals are shared by the faculty members at the respective programs. 


\section{Development of programmatic student learning outcomes.}

Eighty-six percent of the samples demonstrated that the programmatic student learning outcomes (SLOs) manifest the vision identified in the mission statement (see Table 21). When analyzed using Bloom's (1956) criteria, all of the samples revealed that the cognitive and psychomotor domains of learning are being integrated in programmatic SLOs. Seventy-one percent of the samples demonstrated that the affective domain is being integrated.

Table 21

Programmatic Student Learning Outcomes at Physician Assistant Programs (Documents)

$\underline{\text { Item }}$ $\mathrm{N}=7$ $\%$

Alignment of mission statement 6 Goals based on mission statement Clear programmatic goals Shared programmatic goals Fully implemented goals SLOs are expressed precisely SLOs are a collaborative process SLOs manifest the mission vision SLOs focus on cognitive domain SLOs focus on affective domain SLOs focus on psychomotor domain 86

$6 \quad 86$

$6 \quad 86$

$0 \quad 0$

$6 \quad 86$

$6 \quad 86$

$\begin{array}{ll}6 & 0\end{array}$

$6 \quad 86$

$7 \quad 100$

$5 \quad 71$

$7 \quad 100$

Note. $\mathrm{SLO}=$ Student Learning Outcomes.

\section{Examples from Document Analysis}

Tables 22 and 23 provide selected programmatic mission statements, goals, and

SLOs at Physician Assistant programs identified in the documents. The tables are 
designed to demonstrate the process of alignment and how the respective institutional mission statements are manifested in the classroom.

The first example is from a public Doctoral/Research University-Extensive (Carnegie Foundation for the Advancement of Teaching, 2000) (see Table 22). This program is over 30 -years old, has seven full-time and eight part-time faculty members, enrolls 66 students, and averages 32 graduates annually.

The second example is also from a public Doctoral/Research UniversityExtensive (Carnegie Foundation for the Advancement of Teaching, 2000) that has been operating over 30 -years old (see Table 22). Similar to the first example, this program has six full-time and five part-time faculty members, enrolls 72 students, and average 36 graduates annually.

Table 22

Selected Programmatic Mission Statements, Goals, and SLOs at Physician Assistant Programs

\begin{tabular}{lll} 
Item & Example 1 & Example 2 \\
Institutional Mission Statement: & $\begin{array}{l}\text { High academic } \\
\text { standards }\end{array}$ & $\begin{array}{l}\text { Building intellectual } \\
\text { inquiry }\end{array}$ \\
Programmatic Mission Statement: & $\begin{array}{l}\text { High quality primary } \\
\text { care services }\end{array}$ & $\begin{array}{l}\text { Educating competent } \\
\text { Physician Assistants }\end{array}$ \\
Programmatic Goal: & $\begin{array}{l}\text { Gather pertinent historical } \\
\text { and physical data }\end{array}$ & $\begin{array}{l}\text { High quality, effective } \\
\text { Physician Assistants }\end{array}$ \\
Programmatic SLO: & $\begin{array}{l}\text { Complete and focused } \\
\text { medical history }\end{array}$ & $\begin{array}{l}\text { Think critically and } \\
\text { objectively }\end{array}$ \\
\hline
\end{tabular}

Note. SLOs $=$ Student Learning Outcomes. 
The Carnegie Foundation for the Advancement of Teaching (2000) classifies the third example's institution as a Master's College or University I (Private) (see Table 23). This program has been operating for three years, has four full-time and five part-time faculty members, enrolls 32 students, and averages graduating 14 Physician Assistants annually.

Example four is classified as an Other Separate Health Professions School (Carnegie, 2000) and has been operating for 30 years (see Table 23). This program has six full-time and twelve part-time faculty members, enrolls 104 students and graduates an average of 40 Physician Assistants annually.

Table 23

Selected Programmatic Mission Statements, Goals, and SLOs at Physician Assistant Programs

\begin{tabular}{lll} 
Item & Example 3 & Example 4 \\
\hline Institutional Mission Statement: & Service to the community & $\begin{array}{l}\text { Encourages Christian values } \\
\text { \& service to others }\end{array}$ \\
Programmatic Mission Statement: & $\begin{array}{l}\text { Healthcare to underserved } \\
\text { patients }\end{array}$ & $\begin{array}{l}\text { Empathetic, humanitarian } \\
\text { primary care providers }\end{array}$ \\
Programmatic Goal: & $\begin{array}{l}\text { Inspire a desire to work } \\
\text { with recent immigrants \& } \\
\text { low-income neighborhoods }\end{array}$ & Humanitarianism \\
& $\begin{array}{l}\text { Facilitate referral to } \\
\text { community resources \& } \\
\text { social service agencies }\end{array}$ & $\begin{array}{l}\text { Develop an increased } \\
\text { awareness in caring for } \\
\text { and helping other people }\end{array}$
\end{tabular}

Note. SLOs $=$ Student Learning Outcomes. 
Data Summary of Programmatic Mission Statements, Goals, and SLOs at Physician Assistant Programs

Data from the submitted documents and completed surveys revealed consistent patterns. For example, the survey data indicated that $91 \%$ of Physician Assistant programs are formulating precise student learning outcomes (SLOs). Document analysis of submitted samples corroborated this data by demonstrating $86 \%$ of sample SLOs are written precisely. Corroboration continued when comparing the alignment of institutional and programmatic mission statements (survey: $91 \%$, documents: $86 \%$ ), alignment of programmatic mission statement and goals (survey: $98 \%$, documents: $86 \%$ ), and alignment of programmatic mission statement and SLOs (survey: 96\%, documents: 86\%).

Several disparities were also noted during analysis. Although $84 \%$ of program directors indicated that their programmatic goals were developed in collaboration with fellow faculty members, no evidence was found to corroborate this item during document analysis (e.g., roles, guidelines, practices). Further, 95\% of directors indicated that their goals are shared by the faculty. As above, no evidence to support this response was found in the documents submitted for analysis.

\section{Student Learning Outcome Integration}

This section of Chapter Four addresses research question number four: How are student learning outcomes (SLOs) integrated into Physician Assistant (PA) program courses? To answer this question, PA program directors were asked questions 27 to 37 on the survey instrument (Appendix A, p. 210). These questions are based upon the characteristics of effective learning outcomes developed by Huba and Freed (2000). 


\section{Results of the Survey}

Characteristics of effective student learning outcomes.

Physician Assistant program directors reported that their SLOs at the course-level are student-centered (95\%) and focus on the learning resulting from the activity rather than the activity itself (93\%) (see Table 24). Additionally, they indicated that their course-level SLOs reflect the institutional mission and values (91\%) and that these outcomes are in alignment at the course, program, and institutional levels (95\%). Further, respondents indicated that their course-level SLOs focus on aspects of learning that are: credible to the public (93\%); central to the discipline (100\%); and general enough to capture learning but clear and specific enough to be measured (99\%).

Effective integration of Bloom's taxonomy in course-level SLOS.

When queried regarding the specific domains of learning (Bloom, 1956;

Gronland, 1999) and their course-level student learning outcomes, all of the Physician Assistant (PA) program directors believed that their course outcomes focus on cognitive aspects of learning (e.g., knowledge, analysis, synthesis) (see Table 24). Only 83\% of respondents, however, reported that affective-SLOs (e.g., attitudes, values, emotions) are a part of course outcomes. In the psychomotor domain (e.g., coordination, performance, abilities), $93 \%$ of directors indicated that SLOs focus on these dimensions. 
Table 24

Characteristics of Effective SLOs in Physician Assistant Courses (Survey)

\begin{tabular}{|c|c|c|c|c|c|c|c|c|c|}
\hline \multirow[b]{2}{*}{ SLOs: } & \multirow{2}{*}{$\begin{array}{c}\text { Total } \\
\mathrm{N}\end{array}$} & \multicolumn{2}{|c|}{ SA } & \multicolumn{2}{|c|}{$\mathrm{A}$} & \multicolumn{2}{|c|}{$\mathrm{D}$} & \multicolumn{2}{|c|}{ SD } \\
\hline & & $\mathrm{N}$ & $\%$ & $\mathrm{~N}$ & $\%$ & $\mathrm{~N}$ & $\%$ & $\mathrm{~N}$ & $\%$ \\
\hline Are student-focused & 44 & 16 & 36 & 26 & 59 & 2 & 5 & 0 & 0 \\
\hline Focus on learning & 44 & 18 & 41 & 23 & 52 & 3 & 7 & 0 & 0 \\
\hline Reflect mission & 44 & 15 & 34 & 25 & 57 & 4 & 9 & 0 & 0 \\
\hline Are in alignment & 44 & 15 & 34 & 27 & 61 & 2 & 5 & 0 & 0 \\
\hline Are credible to stakeholders & 42 & 15 & 36 & 24 & 57 & 3 & 7 & 0 & 0 \\
\hline Are central to the discipline & 43 & 21 & 49 & 22 & 51 & 0 & 0 & 0 & 0 \\
\hline Are measurable & 43 & 12 & 28 & 29 & 67 & 2 & 5 & 0 & 0 \\
\hline Are being assessed now & 43 & 13 & 30 & 28 & 65 & 2 & 5 & 0 & 0 \\
\hline Focus on cognitive domain & 44 & 20 & 45 & 24 & 55 & 0 & 0 & 0 & 0 \\
\hline Focus on affective domain & 42 & 10 & 24 & 25 & 59 & 7 & 17 & 0 & 0 \\
\hline Focus on psychomotor domain & n 44 & 16 & 36 & 25 & 57 & 3 & 7 & 0 & 0 \\
\hline
\end{tabular}

Note. $\mathrm{SLO}=$ Student Learning Outcomes. $\mathrm{SA}=$ Strongly Agree. $\mathrm{A}=$ Agree. $\mathrm{D}=$

Disagree. SD $=$ Strongly Disagree.

\section{Results of Document Analysis}

Characteristics of effective student learning outcomes.

Of the 17 samples returned for document analysis, nine (47\%) of the samples included course-level student learning outcomes (SLOs). All of the SLOs examined in the samples reveal that Physician Assistant programs are formulating student-focused outcomes that center on the learning from the activity rather than on the activity itself (see Table 25). Additionally, 89\% of the SLOs reflect the institution's mission and are in alignment at the course, programmatic, and institutional levels. Lastly, all outcomes are 
credible to stakeholders, central to the discipline, measurable, and currently used in assessment.

Table 25

Characteristics of Effective SLOs in Physician Assistant Courses (Documents)

Item

$\mathrm{N}=9$

$\%$

SLOs are student-focused

9

100

SLOs focus on learning

SLOs reflect mission

9

SLOs are in alignment

8

100

SLOs are credible to stakeholders

8

SLOs are central to the discipline

SLOs are measurable

9

9

9

9

9

89

89

100

100

SLOs are being assessed now

100

100

Note. SLOs = Student Learning Outcomes.

Examples from document analysis.

Course-level student learning outcomes (SLOs) articulated in documents provided by Physician Assistant (PA) programs were analyzed to determine if these SLOs exhibited the eight characteristics of effective outcomes as defined by Huba and Freed (2000). Tables 26 and 27 compare selected examples of SLOs currently being used by Physician Assistant educators at the course level to the Huba and Freed criteria to demonstrate effectiveness.

Example one (see Table 26) is classified as an Other Separate Health Professions School (Carnegie Foundation for the Advancement of Teaching, 2000) and has been operating for 30 years. This program has six full-time and twelve part-time faculty 
members, enrolls 104 students and graduates an average of 40 Physician Assistants annually.

The second example is categorized as a private Baccalaureate College (General) by the Carnegie classification system (2000). This Physician Assistant program has been operating for two years and has three full-time and 2 part-time faculty members. This program has 34 students enrolled and projects that it will graduate eight Physician Assistants in 2004 (see Table 26).

Table 26

Characteristics of Effective SLOs in Physician Assistant Courses (Samples)

Characteristic

Student-focused:

Focus on learning from activity: Student will learn how to formulate a chief complaint

Reflects institutional mission: $\quad$ Relate major ethical theories to particular issues

Code of ethics, ethics in medicine, moral integrity

Patient confidentiality

Informed consent

Recite normal ranges for various lab values
Example 2

Student will be able to explain progress notes

Student will demonstrate a physical exam

Demonstrate communication skills necessary to provide healthcare

Communication skills, interpersonal skills, personal development

Value geriatric patient care skills

Geriatric medicine

Identify formal/inform support systems available to the geriatric patient 
Table 26 (continued)

Characteristics of Effective SLOs in Physician Assistant Courses (Samples)

Characteristic

Can be assessed now:
Example 1

Control peri-operative pain
Example 2

Demonstrate communication skills necessary to provide health care to patients

Note. SLOs $=$ Student Learning Outcomes.

Examples three and four, located in Table 27, are being used in separate courses at a public Associate's College (Carnegie Foundation for the Advancement of Teaching, 2000). This program is five years old, has 3 full-time faculty members, enrolls 52 students, and averages 25 graduates annually.

Table 27

Characteristics of Effective SLOs in Physician Assistant Courses (Samples)

Characteristic

Student-focused:
Example 3

Students will be able to identify and discuss major areas of ethical concern

Students will be able to discuss the methods by which PAs are certified, recertified, and licensed to practice
Example 4

Students will be able to construct a search strategy to for PAs retrieve relevant research articles

Students will be able to differentiate the various conditions, and describe the clinical manifestations of a particular disease 
Table 27 (continued)

Characteristics of Effective SLOs at Physician Assistant Programs (Samples)

Characteristic

Credible to stakeholders:

Central to the discipline:

Measurability:

Can be assessed now:
Example 3

Describe the role of state legislative and regulatory authorities in the regulation of health care delivery

Describe the general development of the PA profession

Discuss the many clinical and non-clinical roles of a $\mathrm{PA}$ in the modern health care systems

Identify the key topics of importance to PA practice
Example 4

Develop a team approach to health care that is able to draw upon the knowledge and skills of individual members

Problem-based learning

Describe the use, indications, and contraindications of pharmacotheraputics used in treatment of a particular disease

Develop an appropriate management plan when presented with a patient with a potential drug interaction

\section{Integration of Bloom 's taxonomy in course-level SLOS.}

The nine samples were analyzed to determine the existence, integration, and frequency of learning domains (Bloom, 1956; Gronland, 1999) in course-level student learning outcomes (SLOs). The data demonstrates that all of the Physician Assistant (PA) programs submitting samples for analysis are integrating cognitive, affective, and psychomotor learning in their respective SLOs (see Table 28). 
The analysis revealed that some of these programs are also integrating many of the sub-domains of learning in their SLOs. The entire spectrum of cognitive sub-domains (e.g., knowledge, comprehension, application) is used by the PA programs supplying these samples (see Table 28). The frequency of cognitive sub-domain integration within course-level SLOs ranges from one (11\%) to seven (78\%) per PA program. The subdomains integrated most frequently are application (78\%), synthesis (56\%), and knowledge (44\%).

The analysis further revealed that the affective sub-domains (e.g., receiving, responding, valuing) are the next most frequently integrated sub-domains at PA programs. The data demonstrated that all affective sub-domains are being integrated in SLOs. The frequency of integration ranged from $1(11 \%)$ to five $(56 \%)$ programs per sub-domain. Characterization by value is integrated most frequently (56\%). The next most frequently integrated sub-domains are responding (44\%) and valuing (44\%).

This document analysis disclosed that the psychomotor sub-domains (e.g., imitation, manipulation, articulation) received the least frequent level of integration in course-level SLOs. The data reveals that the frequency of integration ranged from one $(11 \%)$ to six $(67 \%)$ in four of the sub-domains (see Table 27$)$. The precision sub-domain is not integrated in any of these sample SLOs. Manipulation was the most frequently integrated psychomotor sub-domain (67\%) with the next most frequently integrated being naturalization (22\%). 
Table 28

Effective Integration of Bloom's Taxonomy in Course-Level SLOs (Documents)

Item

$\mathrm{N}=9$

$\%$

SLOs focus on cognitive domain:

9

100

Knowledge

Comprehension

Application

Analysis

Synthesis

Evaluation

$\begin{array}{ll}4 & 44 \\ 2 & 22 \\ 7 & 78 \\ 1 & 11 \\ 5 & 56 \\ 3 & 33\end{array}$

SLOs focus on affective domain:

5

56

Receiving

Responding

Valuing

$5 \quad 56$

Organization

$1 \quad 11$

Characterization by a Value

$4 \quad 44$

$4 \quad 44$

222

$5 \quad 56$

SLOs focus on psychomotor:

9

100

Imitation

Manipulation

Precision

11

Articulation

6

0

67

Naturalization

$1 \quad 11$

22

Note. SLOs $=$ Student Learning Outcomes.

\section{Examples from document analysis.}

The course-level student learning outcomes (SLOs) identified in the various documents provided by Physician Assistant (PA) programs (see Table 27) were analyzed to determine if these SLOs demonstrate an integration of Bloom's taxonomy (Bloom, 
1956; Gronland, 1999). Tables 29 and 30 provide examples of how PA educators are currently integrating this taxonomy at the course-level. These tables compare selected SLOs to the taxonomy to illustrate those domains that are currently being emphasized at these PA programs.

The first example (see Table 29) is classified as an Other Separate Health Professions School (Carnegie Foundation for the Advancement of Teaching, 2000) and has been operating for 30 years. This program has six full-time and twelve part-time faculty members, enrolls 104 students and graduates an average of 40 Physician Assistants annually.

The second example is taken from a private Baccalaureate College-General (Carnegie Foundation for the Advancement of Teaching, 2000). This program has been operating for two years and has three full-time and 2 part-time faculty members. This program has 34 students enrolled and projects that it will graduate eight Physician Assistants in 2004 (see Table 29).

Table 29

Integration of Bloom's Taxonomy in Course-Level SLOs (Samples)

Item $\quad$ Example 1 $\quad$ Example 2

Cognitive domain:

Knowledge Label the gradient of infection

Comprehension

Application

Analysis

Synthesis

Evaluation
Describe modes of the transmission Calculate the infant morality rate Analyze data/arrive at valid conclusion Develop an influenza surveillance plan Critique a public health campaign
Identify geriatric meds Explain a problem list 
Table 29 (continued)

Integration of Bloom's Taxonomy in Course-Level SLOs (Samples)

Item $\quad$ Example 1 $\quad$ Example 2

Affective domain:

Receiving Describe humanitarian assistance

Responding Volunteer for health-related agency

Valuing Explain altruism

Value geriatric patient care skills

Organization

Explain international aid agencies

Characterization

Defend global view

Psychomotor:

Imitation Volunteer for a health-related agency

Manipulation Conduct a PowerPoint presentation

Perform a physical exam

Precision

Articulation

Naturalization

Note. SLOs $=$ Student Learning Outcomes.

The third and fourth examples, located in Table 30, are from a public Associate's College (Carnegie Foundation for the Advancement of Teaching, 2000). This program is five years old, has 3 full-time faculty members, enrolls 52 students, and averages 25 graduates annually. 
Table 30

Effective Integration of Bloom's Taxonomy in Course-Level SLOs (Samples)

Item

Example 3

Example 4

Cognitive domain:

Knowledge

Identify key topics in PA practice

Describe indications for referral

Comprehension

Application

Describe regulation of PA practice

Construct a search strategy

Analysis

Synthesis

Evaluation

Discuss roles of a PA in health care

Describe development of PA profession

Develop a team approach

Analyze multi-source information

Synthesize multi-source information

Describe the treatment of a disease

Affective domain:

Receiving

Identify key topics in PA practice

Describe indications for consultation

Responding

Valuing

Discuss roles of a PA in health care

Organization

Characterization

Identify ethical concerns for PAs

Describe indications for referral

Synthesize multi-source information

Psychomotor:

Imitation

Construct a search strategy

Manipulation

Precision

Articulation

Construct a search strategy

Note. SLOs $=$ Student Learning Outcomes.

Data Summary of Course-Level Student Learning Outcomes at Physician Assistant Programs

The qualitative data closely paralleled that of the quantitative data. For example, the survey data indicated that Physician Assistant programs are formulating student- 
centered learning outcomes $(95 \%)$ that focus on the learning resulting from the activity rather than the activity itself (93\%). Document analysis corroborated the survey data by demonstrating that the nine samples submitted for study reflected these same characteristics.

This same trend emerged when examining the other characteristics of effective SLOs. The survey results revealed that $91 \%$ of PA program directors report their SLOs reflect institutional missions and that $95 \%$ of these SLOs are in alignment at the course, program, and institutional level. Document analysis supported this data by demonstrating that $89 \%$ of SLOs achieve the above characteristics. Although there were slight increases or decreases in the degree of variation when comparing the stakeholder credibility (survey: $89 \%$, documents: 100\%), centrality to the discipline (survey: $98 \%$, documents: 100\%), and measurability of the sample course-level SLOs (survey: 93\%, documents: $100 \%$ ), these finding were consistent between the survey results and the findings from document analysis.

The collected data corroborated that PA programs are using cognitive (survey: 100\%; documents: 100\%) and psychomotor (survey: 93\%; documents: 100\%) dimensions of learning when formulating their respective SLOs. The use of affectiveSLOs at PA programs (survey: 80\%), however, was refuted based upon those SLOs evidenced in the provided documents. Affective-SLOs were located in only $56 \%$ of the samples analyzed.

\section{Measuring Student Learning Outcomes}

This section of Chapter Four addresses research question number five: What measurement instruments (e.g., commercially-developed vs. locally-developed, directs 
vs. indirect) do Physician Assistant (PA) educators use in the assessment of their programs? To answer this question, PA program directors were asked questions 38 to 45 on the survey instrument (Appendix A, p. 210).

Results of the Survey

Use of commercially-and locally-developed instruments.

Forty-six percent of directors reported using commercially-developed instruments at least sometimes (see Table 31). However, nearly one-quarter (23\%) reported never using such instruments. PA program directors indicated using locally-developed instruments frequently (59\%) and a quarter (25\%) used them sometimes.

Table 31

Use of Commercially and Locally-Developed Instruments

\begin{tabular}{|c|c|c|c|c|c|c|c|}
\hline \multirow[b]{2}{*}{$\mathrm{N}=44$} & \multicolumn{2}{|c|}{ Frequent } & \multicolumn{2}{|l|}{ Some } & \multicolumn{2}{|c|}{ Seldom } & Never \\
\hline & $\mathrm{N}$ & $\%$ & $\mathrm{~N}$ & $\%$ & $\mathrm{~N}$ & $\%$ & $\mathrm{~N} \%$ \\
\hline Commercially-Developed Instruments & & 9 & 17 & & 13 & 30 & 1023 \\
\hline Locally-Developed Instruments & 26 & 59 & 112 & 25 & 2 & 5 & 511 \\
\hline
\end{tabular}

Note. Rounding error.

Use of direct, course-embedded instruments.

Respondents were asked to indicate how frequently Physician Assistant (PA) educators use various direct, course-embedded instruments to measure student learning in their programs. Direct measures are those measures that require students to demonstrate their knowledge and skills as they respond to the instrument itself. These instruments 
include objective tests, essays, oral presentations, and classroom assignments. Objective tests includes examinations of many kinds; the most common being multiple-choice, fill in the blank, true-false, essay, and problems (Palomba \& Banta, 1999, p. 11).

All program directors reported that they frequently use objective (i.e., written) tests (see Table 32). Respondents indicated the use of case studies or simulations frequently (59\%) and others reported using them some of the time (39\%). Capstone experiences, practicum, or internships are used frequently (59\%) by PA program directors. Twenty-three percent of directors reported using these instruments sometimes. Directors also indicated that they never (62\%) use portfolios in their programs and another $26 \%$ indicated seldom using them.

The remaining direct, course-embedded instruments (see Table 32) received a more even distribution of responses. Respondent indicated using essays and oral examinations frequently or some of the time; $61 \%$ and $57 \%$ respectively. Program directors also responded that they seldom or never use products (64\%), poster presentations (55\%), and problem sets (52\%).

Program directors also used the open-ended option for this item. Two percent of the respondents indicated that they frequently use "clinical skills examinations." Another $2 \%$ of respondents reported that their programs use "projects" some of the time. Lastly, $2 \%$ responded that they use seldom use "thesis projects." 
Table 32

Use of Direct, Course-Embedded Instruments by Physician Assistant Educators

\begin{tabular}{|c|c|c|c|c|c|c|c|c|c|}
\hline \multirow[b]{2}{*}{$\underline{\text { Item }}$} & \multirow{2}{*}{$\begin{array}{c}\text { Total } \\
\mathrm{N}\end{array}$} & \multicolumn{2}{|c|}{ Frequent } & \multicolumn{2}{|c|}{ Some } & \multicolumn{2}{|c|}{ Seldom } & \multicolumn{2}{|c|}{ Never } \\
\hline & & $\mathrm{N}$ & $\%$ & $\mathrm{~N}$ & $\%$ & $\mathrm{~N}$ & $\%$ & $\mathrm{~N}$ & $\%$ \\
\hline Objective examinations & 44 & 44 & 100 & 0 & 0 & 0 & 0 & 0 & 0 \\
\hline Presentations & 44 & 21 & 48 & 20 & 45 & 3 & 7 & 0 & 0 \\
\hline Essays & 44 & 11 & 25 & 16 & 36 & 12 & 27 & 5 & 11 \\
\hline Case studies \& simulations & 44 & 25 & 57 & 17 & 39 & 1 & 2 & 1 & 2 \\
\hline Products & 39 & 6 & 15 & 8 & 20 & 11 & 28 & 14 & 36 \\
\hline Poster presentations & 41 & 2 & 5 & 16 & 39 & 8 & 19 & 15 & 36 \\
\hline Problem sets & 42 & 10 & 24 & 10 & 24 & 10 & 24 & 12 & 28 \\
\hline Oral examinations & 44 & 14 & 32 & 11 & 25 & 10 & 23 & 9 & 20 \\
\hline Portfolios & 42 & 0 & 0 & 5 & 12 & 11 & 26 & 26 & 62 \\
\hline CPI & 44 & 26 & 59 & 10 & 23 & 1 & 2 & 7 & 16 \\
\hline
\end{tabular}

Note. Rounding error. CPI = Capstones, Practicum, and Internships.

Use of indirect instruments by Physician Assistant educators.

Respondents were asked to indicate how frequently Physician Assistant (PA)

educators use various indirect instruments to measure student learning in their programs.

Indirect instruments require students to reflect on what they have learned and experienced rather than to demonstrate their knowledge and skills, providing proxy information about student learning. These include: questionnaires, interviews, and focus groups (Palomba \& Banta, 1999, p. 12).

The most prevalent indirect measurement instruments in use at these 44 programs are classroom assessment techniques (CATs). Cross and Steadman (1996) describe CATs as "small-scale assessments conducted continually in college classrooms by discipline- 
based teachers to determine what students are learning in class" (p. 8). Examples of CATs include: (a) The Minute Paper, (b) E-mail Minute, (c) Muddiest Point, and (d) Application Cards (Huba \& Freed, 2000). Eighty-three percent of respondents indicated that CATs are used either frequently or some of the time (see Table 33). The next most common indirect instrument utilized by PA programs is the employer survey with $75 \%$ of directors reporting frequent or some use. Patient surveys, however, are never used by $84 \%$ of respondents.

The use of interviews throughout the course of a student's learning experience at PA programs is reported by directors. This method is used frequently or some of the time during entrance into the programs (70\%), at mid-point in the programs $(65 \%)$, and upon exit from the programs $(67 \%)$.

Program directors also clarified their practice in the open-ended option for this item. Eleven percent of the respondents indicated that they use graduate/alumni surveys frequently or some of the time. Another $2 \%$ of directors reported that they use "clinical preceptor surveys" on a frequent basis.

Table 33

Use of Indirect Instruments by Physician Assistant Educators

\begin{tabular}{|c|c|c|c|c|c|c|c|c|c|}
\hline \multirow[b]{2}{*}{ Item } & \multirow{2}{*}{$\begin{array}{c}\text { Total } \\
\mathrm{N}\end{array}$} & \multicolumn{2}{|c|}{ Frequent } & \multicolumn{2}{|c|}{ Some } & \multicolumn{2}{|c|}{ Seldom } & \multicolumn{2}{|c|}{ Never } \\
\hline & & $\mathrm{N}$ & $\%$ & $\mathrm{~N}$ & $\%$ & $\mathrm{~N}$ & $\%$ & $\mathrm{~N}$ & $\%$ \\
\hline CATs & 42 & 21 & 50 & 14 & 33 & 4 & 10 & 3 & 7 \\
\hline Reflective papers-journals & 44 & 10 & 23 & 15 & 34 & 10 & 23 & 9 & 20 \\
\hline Entrance interviews & 43 & 25 & 58 & 5 & 12 & 1 & 2 & 12 & 28 \\
\hline Mid-point interviews & 42 & 20 & 48 & 7 & 17 & 3 & 7 & 12 & 28 \\
\hline Exit interviews & 42 & 21 & 50 & 7 & 17 & 2 & 5 & 12 & 29 \\
\hline
\end{tabular}


Table 33 (continued)

Use of Indirect Instruments by Physician Assistant Educators

\begin{tabular}{|c|c|c|c|c|c|c|c|c|c|}
\hline \multirow[b]{2}{*}{ Item } & \multirow{2}{*}{$\begin{array}{c}\text { Total } \\
\mathrm{N} \\
\end{array}$} & \multicolumn{2}{|c|}{ Frequent } & \multicolumn{2}{|c|}{ Some } & \multicolumn{2}{|c|}{ Seldom } & \multicolumn{2}{|c|}{ Never } \\
\hline & & $\mathrm{N}$ & $\%$ & $\mathrm{~N}$ & $\%$ & $\mathrm{~N}$ & $\%$ & $\mathrm{~N}$ & $\%$ \\
\hline Focus groups & 44 & 7 & 16 & 16 & 36 & 6 & 14 & 15 & 34 \\
\hline Employer surveys & 43 & 18 & 42 & 14 & 33 & 8 & 19 & 3 & 7 \\
\hline Patient surveys & 43 & 2 & 5 & 5 & 12 & 0 & 0 & 36 & 84 \\
\hline
\end{tabular}

Note. Rounding error. CATs $=$ Classroom Assessment Techniques.

\section{Measurement demographics at Physician Assistant programs.}

To further examine assessment implemented by Physician Assistant (PA) educators, data was collected on whom, when, what, and how assessments will occur in the respective PA programs. When asked if their programs have developed clear criteria to identify students who will be required or invited to participate in assessments, $65 \%$ of program directors responded in the affirmative (i.e., strongly agree, agree) (see Table 34). Eighty percent of directors reported that they also have clear criteria in place at their programs to identify when students will be required or invited to participate in assessments. Lastly, $91 \%$ of survey respondents indicated that their programs have established clear criteria on what and how assessments will take place. Despite requests for documents, a sufficient sample was not provided. 
Table 34

Measurement Demographics

SA

A

D

SD

$\underline{\text { Item }}$

N $\%$

$\mathrm{N} \quad \%$

$\mathrm{N} \quad \%$

$\mathrm{N} \quad \%$

Program criteria identifies:

who will be assessed

when assessments will occur

$\begin{array}{rr}9 & 20 \\ 10 & 23\end{array}$

$20 \quad 45$

$25 \quad 57$

$\begin{array}{llll}10 & 23 & 30 & 68\end{array}$

what will be assessed

how it will be assessed

$14 \quad 32$

$26 \quad 59$

$\begin{array}{rrrr}11 & 25 & 4 & 9 \\ 5 & 11 & 4 & 9 \\ 4 & 9 & 0 & 0 \\ 4 & 9 & 0 & 0\end{array}$

Note. $\mathrm{SA}=$ Strongly Agree. $\mathrm{A}=$ Agree. $\mathrm{D}=$ Disagree. $\mathrm{SD}=$ Strongly Disagree.

Using Assessment Results to Make Improvements at Physician Assistant Programs

This section of Chapter Four addresses research question number six: How do faculties use assessment results to make program improvements? To answer this question, Physician Assistant (PA) program directors are asked questions 46 to 53 on the survey instrument (Appendix A, p. 210).

Results of the Survey

Accountability or improvement.

When asked if programmatic accountability is the focus of their assessment efforts, $73 \%$ of program directors responded in the affirmative (i.e., strongly agree, agree) (see Table 35). Additionally, when asked if their assessment focus is on programmatic improvement, 97\% of respondents agreed or strongly agreed. Nearly all (96\%) program directors reported the integration of assessment results in programmatic planning. 
Further, all of the survey respondents indicated that results are incorporated in program review and curricular modifications. Ninety-eight percent of respondents indicated that assessment results are used to improve teaching and all directors report using results to improve student learning. Sixty percent indicated they use assessment data for increased budgets.

Table 35

Using Assessment Results to Make Improvements at Physician Assistant Programs

\begin{tabular}{|c|c|c|c|c|c|c|c|c|}
\hline \multirow[b]{2}{*}{ Item } & \multicolumn{2}{|c|}{ SA } & \multicolumn{2}{|c|}{ A } & \multicolumn{2}{|c|}{$\mathrm{D}$} & \multicolumn{2}{|c|}{ SD } \\
\hline & $\mathrm{N}$ & $\%$ & $\mathrm{~N}$ & $\%$ & $\mathrm{~N}$ & $\%$ & $\mathrm{~N}$ & $\%$ \\
\hline Accountability is the focus & 10 & 23 & 22 & 50 & 12 & 27 & 0 & 0 \\
\hline Improvement is the focus & 20 & 45 & 23 & 52 & 1 & 2 & 0 & 0 \\
\hline Planning is based on results & 17 & 39 & 25 & 57 & 2 & 5 & 0 & 0 \\
\hline Program review uses results & 21 & 48 & 23 & 52 & 0 & 0 & 0 & 0 \\
\hline Budget increases based on results & 2 & 5 & 24 & 55 & 12 & 27 & 6 & 14 \\
\hline Curricular change based on results & 21 & 48 & 23 & 52 & 0 & 0 & 0 & 0 \\
\hline Results used to improve teaching & 19 & 43 & 24 & 55 & 1 & 2 & 0 & 0 \\
\hline Results used to improve learning & 21 & 48 & 23 & 52 & 0 & 0 & 0 & 0 \\
\hline
\end{tabular}

Note. Rounding error. $\mathrm{SA}=$ Strongly Agree. $\mathrm{A}=$ Agree. $\mathrm{D}=$ Disagree. $\mathrm{SD}=$ Strongly Disagree.

\section{Communicating Assessment Results to Specific Audiences}

This section of Chapter Four addresses research question number seven: How do faculties communicate assessment results and to what audiences? To answer this question, Physician Assistant (PA) program directors were asked questions 54 to 59 on the survey instrument (Appendix A, p. 210). Specifically, PA program directors were asked about varying formats for reporting their assessment data to different stakeholders. 
Next, directors were asked to indicate with whom (i.e., internal and external audiences) they share assessment results. Lastly, the respondents were asked about different aspects regarding the dissemination of their assessment results.

Results of the Survey

Assessment reporting formats at Physician Assistant programs.

Approximately three-quarters (77\%) of program directors indicated that the most common format for reporting assessment results is an annual report (see Table 36). The next most common format reported is the comprehensive report (59\%). Respondents also indicated that they use specific audience reports (39\%), presentations (32\%), executive summaries (30\%), and special reports (30\%). Two percent of the directors reported the use of "semester reports."

Table 36

Assessment Reporting Formats

\begin{tabular}{lcr} 
Formats & $\mathrm{N}=44$ & $\%$ \\
\hline & & \\
Comprehensive reports & 26 & 59 \\
Annual reports & 34 & 77 \\
Executive summaries & 13 & 30 \\
Special reports & 13 & 30 \\
Newsletters & 3 & 7 \\
Presentations & 14 & 32 \\
Report cards & 4 & 9 \\
Specific audience reports & 17 & 39 \\
Web-based reports & 2 & 5 \\
\end{tabular}

Note. Multi-response item. 
Internal audiences receiving assessment reports.

Internally, $89 \%$ of program directors reported faculty members as the most common recipients of assessment reports (see Table 37). Two-thirds (66\%) of respondents indicated that other internal audiences include institutional executives and senior administrators. Slightly less than half (45\%) of the program directors reported assessment results to their students and one-quarter (25\%) reported the same to institutional committees (e.g., budget). Two percent of respondents indicated that they reported assessment results to "outside lecturers."

Table 37

Internal Audiences Receiving Assessment Reports

\begin{tabular}{lcc} 
Audiences & $\mathrm{N}=44$ & $\%$ \\
\hline Institutional executives & & \\
Senior administrators & 29 & 66 \\
Institutional committees (e.g., budget) & 29 & 66 \\
Faculty & 11 & 25 \\
Students & 39 & 89 \\
& 20 & 45 \\
\hline
\end{tabular}

Note. Multi-response item.

External audiences receiving assessment reports from Physician Assistant programs.

Externally, $86 \%$ of program directors reported their accrediting body as the most common recipient of assessment reports (see Table 38). The next most common external audiences to receive assessment results from these directors are professional bodies (25\%) and employers (23\%). Respondents also indicated that they send results to alumni 
(18\%), state government (18\%), and federal government (16\%). Using the open-ended option, one (2\%) director indicated that assessment results are sent to "clinical preceptors."

Table 38

External Audiences Receiving Assessment Reports

\begin{tabular}{lrr} 
Audiences & $\mathrm{N}=44$ & $\%$ \\
\hline Parents & 1 & 2 \\
Alumni & 8 & 18 \\
Employers & 10 & 23 \\
Accrediting bodies & 38 & 86 \\
Professional bodies & 11 & 25 \\
State government & 8 & 18 \\
Federal government & 7 & 16 \\
\end{tabular}

Note. Multi-response item.

Dissemination plan for assessment results at Physician Assistant programs.

Three-quarters $(75 \%)$ of PA program directors indicated that their reporting process considers the needs of various audiences and the appropriate sequence of report sharing (see Table 39). Seventy-two percent of directors also indicated that their reports are released prior to decisions being made so that the findings and recommendations can become part of the decision-making process. Sixty-nine percent of respondents indicated that their reports are initially released to those most affected by the assessment results. Lastly, $61 \%$ of the directors responded that their programs have a dissemination plan for reporting assessment results to the varying stakeholders. 
Despite requesting samples of dissemination plans used in reporting the results of student learning outcomes assessment, only one sample addressed the dissemination of results beyond the programmatic level. In this single sample, the PA program addressed the dissemination of assessment results to internal audiences, but there is no evidence that results are being disseminated to external audiences. This paucity precludes any in-depth analysis or generalizablity to the discipline at large.

Table 39

Dissemination Plan for Assessment Results at Physician Assistant Programs

\begin{tabular}{|c|c|c|c|c|c|c|c|c|}
\hline \multirow[b]{2}{*}{ Item } & \multicolumn{2}{|c|}{ SA } & \multicolumn{2}{|c|}{ A } & \multicolumn{2}{|c|}{$\mathrm{D}$} & \multicolumn{2}{|c|}{ SD } \\
\hline & $\mathrm{N}$ & $\%$ & $\mathrm{~N}$ & $\%$ & $\mathrm{~N}$ & $\%$ & $\mathrm{~N}$ & $\%$ \\
\hline $\begin{array}{l}\text { Results initially released to } \\
\text { those most affected............... }\end{array}$ & 6 & 14 & 24 & 55 & 13 & 30 & 1 & 2 \\
\hline $\begin{array}{l}\text { Results are part of the decision- } \\
\text { making process................. }\end{array}$ & 5 & 11 & 27 & 61 & 12 & 27 & 0 & 0 \\
\hline $\begin{array}{l}\text { Plan considers audiences and } \\
\text { sequencing of reporting........... }\end{array}$ & 7 & 16 & 26 & 59 & 10 & 23 & 1 & 2 \\
\hline $\begin{array}{l}\text { Program has a dissemination } \\
\text { plan for reporting assessments.. }\end{array}$ & 7 & 16 & 20 & 45 & 14 & 32 & 3 & 7 \\
\hline
\end{tabular}

Note. Rounding errors. $\mathrm{SA}=$ Strongly Agree. $\mathrm{A}=$ Agree. $\mathrm{D}=$ Disagree. $\mathrm{SD}=$ Strongly Disagree.

This chapter reports the results of a descriptive mixed-method (i.e., Concurrent Nested Design) research project designed to examine the internal programmatic assessments implemented by Physician Assistant (PA) educators. In examining these 
assessments, a census of all 133 PA programs in the nation was conducted. A survey response rate of 33\% (44 PA program directors) was achieved during the data collection process. Of the 44 respondents, 17 (39\%) included sample assessment documents for further analysis. Several patterns emerged during data analysis. These patterns will be discussed further in the next chapter. 


\section{CHAPTER FIVE. DISCUSSION \\ Introduction}

In the final chapter of the study that examines the internal programmatic assessments implemented by Physician Assistant (PA) educators, the researcher summarizes and discusses the major themes discovered during the course of data collection and analysis. The major headings in this chapter are: (a) Interpretation of Findings and Relationship to Previous Research, (b) Recommendations for Practice, and (c) Suggestions for Additional Research. The major subheadings are comprised of the seven research questions.

Interpretation of Findings and Relationship to Previous Research

The seven research questions that focused this study are addressed through a detailed synthesis of the 61 survey questions, applicable document data, and scholarly literature.

\section{Research Question 1:}

What types of institutional resources are available to conduct assessment?

The process of assessing student learning, like other programmatic or institutional endeavors, competes for scarce and valued resources. How, then, are PA programs across the United States faring in their resource acquisition process? Is the assessment of student learning outcomes being funded at the various institutions? How do these findings link to earlier research by other assessment scholars?

Executive-Level Support and the Assessment Culture

Based upon the above competition for scare resources, gaining executive-level support for the assessment process is of paramount importance (Jones, 2002; Kuh, 
Gonyea, \& Rodriguez, 2002; Upcraft \& Schuh, 1996). The survey data analyzed in this study indicates that $93 \%$ of PA program directors report that their assessment efforts have acquired executive-level support in general. As noted in their research on numerous institutions of higher learning and private sector organizations, Jones, Voorhees, and Paulson (2002) found that "a senior academic administrator becomes the public advocate, leader, and facilitator for creating an institutional culture that is open to change, willing to take risks, and fosters innovations by providing real incentives for participation” (p. 20).

Despite directors' perceptions of support from executives, this trend does not continue when they report on the degree of support in specific areas. Utilizing the criteria developed by Jones, Voorhees, and Paulson (2002) that characterizes an assessment culture, this study finds that only a single criterion (i.e., faculty treated as collaborators in the assessment process; 79\%) exceeds 55\% in the survey results. Further, less than onethird of institutional leaders demonstrate a commitment to assessment by providing authentic incentives for participation and support (e.g., time, reduced teaching loads, grants, stipends, etc.). As noted in 10-year study conducted by the North Central Association of Colleges and Schools, "Evaluation Teams have observed that institutions that have demonstrated improvements in their assessment programs have administrators who recognize that assessment activities require an investment of institutional dollars" (Lopez, 1999, p. 29).

The remaining criteria that indicate a "culture of assessment" form two patterns. The first pattern indicates that only about half of executive-level leaders currently maximize honest, open, two-way communication, establish an assessment culture based on trust, and encourage assessment personnel to use a deliberate planning process. The 
second pattern indicates that only about one-third of executive-level leaders are directly involved in the assessment process and meets regularly with assessment personnel. Additionally, only one-third of these leaders have approved the integration of assessment costs in the institutional and programmatic budgets.

\section{Articulation of Projected Resource Expenditures for Assessment Costs}

To gain substantive institutional sponsorship for an authentic assessment program, assessment practitioners need to articulate and justify the allocation of resources for the planning, implementation, and continuance of the assessment process. Given that just over half of the survey respondents indicate that they have articulated their projected expenditures for assessment activities at the executive level, this may account for the absence of assessment incentives at $70 \%$ of PA programs. Additionally, this may be a reflection of the fact that only one-half of program directors report fully developed and implemented assessment plans. Ultimately, it is incumbent upon faculty members to persuade institutional leaders about the significance of allocating resources specifically for the conduct of assessment activities (E. Goeres, personal communication, November $18,2003)$. It is also noteworthy that some regional and professional accrediting bodies require the specific funding of assessment activities.

\section{Allocation of Resources for Initial Assessment Costs}

Sixty percent of Physician Assistant (PA) program directors indicate that their institutional leaders have allocated resources for their initial assessment costs. The above percentage seems a promising start toward funding assessment efforts, but what is not known in this study is the nature of these costs and the degree to which they were funded 
at the various PA programs. The Middle States Commission on Higher Education (2003), for example, identifies some of these assessment expenditures as:

(a) personnel costs; (b) constructing new or purchasing existing assessment instruments;

(c) administering instruments, conducting interviews or focus groups; (d) data entry; (e) computer hardware and software; and (f) communication costs for organizing efforts and for report and disseminating results (p. 59). In reporting funding allocations for initial assessment costs, it is not known if PA programs addressed the types of considerations identified by the Middle States Commission on Higher Education.

Sustained Assessment Cost Forecasting by Line-Item in Successive Budgeting Cycles Sixty-six percent of the responding PA programs report that forecasting assessment costs by line-item in successive budgets is not occurring at their institutions. This seems to indicate that although $60 \%$ of institutional leaders are providing "start-up" costs for assessments, they have not yet recognized they need to fund an on-going assessment effort (American Association for Higher Education [AAHE], 1992) or it may mean that PA faculties have not yet articulated the need for sustained assessment funding. Unfortunately, when leaders and faculty are not cognizant of the need or fail to directly link the institutional planning and budgeting cycles to the assessment process the costs of sustaining the assessment effort may be superceded by other institutional needs. As Lopez (1999, p. 32) notes:

in colleges and universities where the expression 'linking assessment to planning and budgeting' is not understood, there is always the danger that no special funds will be set aside for the assessment program and that activities it generates will have to be delayed for two or even three years. 


\section{Guiding Principles for Assessment}

Seventy-seven percent of the survey respondents in this study report having a set of guiding principles upon which they base their assessment efforts. Unfortunately, none of the 17 samples that were examined during document analysis contained these principles, thus it is difficult to determine if PA programs are currently following the guiding principles and best practices recommended by numerous assessment scholars (AAHE, 1992; Huba \& Freed, 2000; Jones, Voorhees, \& Paulson, 2002; Palomba \& Banta, 1999).

\section{Research Question 2:}

How is assessment planning integrated into PA faculty development?

Given that Physician Assistant educators are responsible for the programmatic assessment process, it is incumbent upon administrators and faculty alike to ensure that a dynamic, well-organized faculty development program exists to facilitate this endeavor.

\section{Program Structure}

The scholarly literature identifies various structural features related to faculty development programs (Bennion, 2002; Borden, 2002; Jones, 2002; Licklider, Schnelker, \& Fulton, 1997). One feature that researchers repeatedly find is that any serious assessment endeavor must consider faculty an essential resource (Huba \& Freed, 2002; Jones 2002; Palomba \& Banta, 1999) and the survey results indicate that $96 \%$ of PA program directors agree with these researchers.

Who teaches faculty development sessions?

Another feature of assessment-related faculty development is who provides instruction to the faculty during development sessions. For example, a faculty can use 
internal, or on-campus, experts (e.g., institutional researchers) to address various subjects linked to certain assessment activities (Jones, 2002). The results of this research indicate that slightly more than half $(55 \%)$ of the PA programs responding have used on-campus experts once in the last academic year and an additional 30\% have never used these experts to conduct assessment sessions.

Institutions and programs sometimes discover that they require additional expertise for specific faculty development session. When this occurs, faculties may opt to invite off-campus experts to teach these sessions. Sixty-one percent of survey respondents, however, indicate they have never used off-campus experts to teach assessment-related topics to their faculty. Conversely, $23 \%$ of directors report inviting these experts or consultants to their programs once in the last academic year.

What topics are presented at faculty development sessions?

Scholars note several factors relating to what faculty development sessions should provide assessment practitioners. Benion (2002), Huba and Freed (2000), and Palomba and Banta (1999) specifically identify the need to address topics such as assessment language, philosophy, and intention for those faculty new to student learning outcomes assessment. There are, of course, a wide range of topics that faculty should immerse themselves in at all experience levels. What, then, comprises the content of assessment sessions at PA program? Based on survey data, the most frequent (80\%) assessment topic presented to PA faculty at assessment-related faculty development sessions is student learning outcomes. The literature demonstrates that faculty development sessions on this topic should address the features that comprise well-crafted SLOs (e.g., student-centered, integration of learning domains). 
Physician Assistant faculties are also receiving development sessions that indicate a range of experience levels in the assessment process. Approximately half ( 43 to $55 \%$ range) of program directors report sessions on assessment language, assessment philosophy, and reporting assessment results. Additional topics reported by directors include: faculty development and assessment (68\%), instruments for measuring learning (66\%), and using assessment results to affect change (61\%).

\section{How are faculty development session delivered?}

A well-publicized, dynamic, and on-going faculty development program provides the best opportunity of assisting PA educators in their assessment endeavor (Licklider, Schnelker, \& Fulton, 1997; Palomba \& Banta, 1999). Development sessions should include short, presentations that introduce new concepts and longer, more complex sessions where concepts can be applied (Garrison, 2000; Professional and Organizational Development Network in Higher Education [POD], 2002, 2004). This study indicates that 93\% of PA program faculty members annually participate in the shorter assessment presentations recommended in the literature.

The types of workshops recommended by POD are being offered to some PA educators. For example, 50\% respondents indicate that hands-on, interactive, single-topic workshops have never been offered to their faculty, while $30 \%$ respond that these opportunities are offered two to three times per year at their institutions. The disparity is even more striking when examining the data regarding hands-on, interactive, multi-topic workshops. Sixty-four percent of directors respond that this type of assessment session has never been offered at their institution, while other directors indicate once (14\%) or two to three times $(16 \%)$ in the past academic year. 


\section{When are faculty development session delivered?}

Multiple studies demonstrate that single sessions or episodic delivery of assessment-related faculty development information are inefficient methods of preparing faculty to successfully meet institutional or programmatic goals and objectives (American Association of Higher Education, 1992; Huba \& Freed, 2000; Licklider, Schnelker, \& Fulton, 1997). In regard to when PA educators receive faculty development in assessment topics, this study finds that, in the last academic year, formal presentations were offered to faculty: one time (25\%), two to three times (36\%), and never (32\%).

Workshops are even less frequently offered than formal presentations. In the last academic year, single topic workshops were offered to $30 \%$ of PA educators two to three times. Half of all survey respondents report this type of workshop has never been offered at their institutions. An even greater percentage of PA educators do not have access to multi-topic workshops in assessment. Sixty-four percent of program directors indicate that this form of faculty development has never been offered at their institutions. Lastly, survey data demonstrates that an average of 3.66 PA faculty members per program have attended an assessment session in the last academic year.

Faculty Responsibility

A sizable portion of PA faculties currently struggle with their assessment roles and expectations. Nearly a third of program directors report ill-defined faculty roles (30\%) and expectations (34\%) in the assessment process. Perhaps this is a result of the rapid expansion of PA programs during the 1990s (Carrington, 1998). If so, this certainly emphasizes the need for formalized roles and expectations. Regardless of the causes, "an 
explicit list of expectations about the roles of various groups involved in the assessment process can help clarify and establish responsibilities" (Palomba \& Banta, 1999, p. 55).

\section{Faculty Involvement}

Research conducted on how best to motivate faculty participation in the assessment process finds that "faculty development is not enough...to get faculty fully involved in assessment. Visible incentives should be provided to encourage faculty to develop the necessary skills to undertake assessment efforts as a means of improving the teaching and learning on campuses" (Banta, Lund, Black, \& Oblander, 1996, p. 53). Given the above it is disconcerting that 57\% of Physician Assistant (PA) program directors report that that their institutions provide no incentives to increase faculty participation in assessment.

At the 20 programs in this survey where incentives are available, respondents indicate that time to work on assessment initiatives (45\%) and travel to assessment conferences (75\%) as the most prevalent. As noted by Palomba and Banta (1999) funding faculty travel to conferences demonstrates to faculty that institutional or programmatic emphasis on assessment is being supported with concrete actions.

Jones (2002) identifies grants and stipends as authentic incentives for faculty efforts in assessment. For example, "internal grants help support or foster innovations that faculty design but could not be implemented without additional resources" (p. 83). Jones' research also indicates that external grants can provide "important seed money to begin pilot projects" (p. 83). Data from this survey indicates that 6 PA educators $(30 \%)$ have received small grants (less than \$2000) and 1 has received a large grant (more than 
\$2000). Although the incentives discussed above are used as incentives for conducting assessment activities, two-thirds (66\%) of PA program directors report that none of their faculty members have received assessment incentives during the past academic year.

Faculty Rewards

An authentic system comprised of intrinsic and extrinsic rewards is an essential element of gaining faculty support and involvement in assessment (Borden, 2002; Palomba \& Banta, 1999).

Intrinsic.

Over one-half (55\%) of PA program directors chose not to indicate available intrinsic reward options on the survey. Of those who did respond, a mere $15 \%$ find increased understanding of institutional linkages a rewarding aspect of assessment participation. Considering how vitally important these linkages are to the success of a student learning outcomes assessment program, this, too, is a worrisome indicator. Altbach's commentary on faculty isolation (1994) seems validated in that $85 \%$ of directors report that increased interactions with other faculty members as the most frequent intrinsic reward. Lastly, the scholarly literature identifies assurances that assessment results will not be used to penalize faculty as the most important intrinsic reward (Bordern, 2002). In this regard, slightly less than half (45\%) of survey respondents indicate that their assessment results are not used against them.

Extrinsic.

There are a myriad of extrinsic rewards available (Banta, 2002; Jones, 2002) to motivate Physician Assistant (PA) faculty participation in assessment programs. 
Rodrigues (2002) notes that one of the most efficient and effective methods of rewarding faculty for their assessment contributions are consistent, well-publicized recognition processes. Unfortunately, as indicated above, 57\% of PA program directors indicate that these processes are not in place at their institutions.

The inclusion of assessment participation in the promotion and tenure process signals the authenticity of institutional sponsorship of assessment initiatives (Palomba \& Banta, 1999). Of the 15 respondents who addressed these questions, $75 \%$ report inclusion in the promotion and tenure process as the most common extrinsic reward for participation in the assessment endeavor. Other indications of an authentic rewards system for PA faculty participation in assessment are: expressions of gratitude from leaders (50\%), presentations at national conferences (35\%), publications (30\%), and letters of commendations ( $30 \%)$. This data does illustrate that some PA educators are being rewarded for their efforts in programmatic assessment.

\section{Faculty Resistance}

The conduct of student learning outcomes assessment, as defined by numerous scholars (American Association of Higher Education, 1992; Ewell, 2002; Huba \& Freed, 2000), may encounter resistance from a number of potential arenas internal and external to a program. Externally, practitioners may, for example, receive rudimentary, ambiguous, or conflicting guidance from accrediting bodies, professional organizations, and institutions. Internally, a program director or faculty member may meet resistance to undertaking or increasing involvement in assessment from among faculty, administrators, and staff alike. In this research, three-quarters of PA program directors report no faculty resistance to assessment at their programs. 


\section{Research Question 3:}

What programmatic student learning outcomes are used by PA educators?

Terenzini (1989) notes that student learning outcomes (SLOs) assessment requires "reconsideration of the essential purposes and expected academic and nonacademic outcomes of a college education. It also requires clarity of institutional and programmatic purpose as well as a specificity of practice often absent on many campuses" (p. 645). The establishment of programmatic vision, mission statement, and goals provide the clarity that enables a program to ultimately develop SLOs that manifest its vision (American Association for Higher Education [AAHE], 1992; Banta, 2002; Terenzini, 1989).

\section{Programmatic Mission Statements}

The Middle States Commission on Higher Education (MSCHE) notes that, "An institution's mission, at both broad and specific levels, serves as the context within which to assess student learning, and it is important that mission serves as the backdrop for assessment efforts at the institutional, program, and course levels" (2003, p. 8). On this point, there is a strong triangulation between the literature, quantitative, and qualitative data collected from Physician Assistant (PA) programs. Ninety-one percent of respondents report alignment of institutional and programmatic mission statements and $86 \%$ documents corroborate this finding.

\section{Programmatic Goals}

Using its institutional and programmatic mission statements as points of reference, programmatic goals are next formulated in alignment with these statements to communicate intended educational results in general terms (Palomba \& Banta, 1999). On this topic, the 44 PA programs responding to this 
census provide strong evidence that their programmatic mission statements and programmatic goals are in alignment (survey: 98\%, documents: 86\%).

In its Principles of Good Practice for Assessing Student Learning (1992), the AAHE concluded that "assessment is a goal-driven process" that requires "clear, shared, implementable goals" that form the cornerstones of the assessment effort (p. 2). In this regard, it is obvious that PA faculties understand and apply the importance of the AAHE's guidelines. Survey responses from this research indicate that programmatic goals are clear (98\%) and fully implemented (80\%). Document data triangulate the literature and survey responses by revealing that clarity and implementation of goals is found in $86 \%$ of submitted samples.

Although survey data indicates that goals are shared by faculty members (95\%), no evidence was found in the documents that speak to this issue.

\section{Development of Programmatic Student Learning Outcomes}

Student learning outcomes (SLO) "are used to express intended results in precise terms" (Palomba and Banta, 1999, p. 26) and in academic environment that increasing advocates a student-centered approach (Huba \& Freed, 2000), writing precise SLOs, whether at the programmatic or course level, can be frustrating for faculty members (Lopez, 2000). The data from this study, again, triangulates strongly with the literature by indicating that PA faculty members are writing precise programmatic SLOs (survey: 91\%; documents: $86 \%$ ).

Crafting SLOs is a collaborative process (Aper \& Hinkle, 1991; Banta, 2002; Terenzini, 1989) that enables faculty members to identify those outcomes that best illustrate the vision identified in the mission statement. Based upon the survey results, 
collaboration in formulating SLOs is occurring at $84 \%$ of the PA programs that responded. However, documents analysis did not produce any evidence to corroborate or refute the survey data, thus triangulation was not achieved.

Lastly, and programmatically the most important, PA educators should examine their SLOs to determine if they reflect what graduates will know and can do as a result of their educational experience in that program (Palomba \& Banta, 1999). Put another way, do the SLOs manifest the institutional mission statement in the classroom on a day-to-day basis? Based upon the analysis, PA program directors and their respective faculties are achieving this objective in a strong, consistent manner. The alignment of institutional and programmatic mission statements, goals, and SLOs demonstrated by survey responses greater than $93 \%$ and findings in document samples greater than $85 \%$ attain triangulation consistent with previous research recommendations for best practices.

\section{Research Question 4:}

How are student learning outcomes integrated into PA program courses?

Huba and Freed (2000) and Stuetzer (1999) note that well-written instructional outcomes provide key guidance in teaching and student learning (p. 223). To determine what constitutes well-written outcomes, the eight characteristics of effective student learning outcomes (SLO) developed by Huba and Freed (2000) are used to evaluate course-level integration in Physician Assistant (PA) programs.

\section{SLOs are Student-Focused}

Intended learning outcomes are student-focused rather than professor-focused (Huba \& Freed, 2000, p. 99). The literature reveals that this characteristic addresses what students should know, understand, believe, and be able to do as a result of their course 
experience (Palomba \& Banta, 1999; Stuetzer, 1999). Data analysis from this study indicates that $95 \%$ of program directors report student-centered learning outcomes and this is confirmed in that all of the course-level SLOs submitted for analysis.

\section{SLOs Focus on Learning}

Intended learning outcomes focus on the learning resulting from an activity rather than on the activity itself (Huba \& Freed, 2000, p. 99). On this characteristic, PA programs again demonstrate a strong correlation with previous research. Survey data reveals that $93 \%$ of directors indicate that their SLOs focus on the above aspect and this is confirmed in $100 \%$ of the documents examined.

\section{SLOs Reflect the Institutional Mission and Values}

Intended learning outcomes reflect the institution's mission and the values it represents (Huba \& Freed, 2000, p. 100). Once more, the data from this research indicates that the courselevel SLOs within these PA programs are consistent with the scholarly literature. Ninety-one percent of directors report that their SLOs reflect institutional mission/values and $89 \%$ of the documents analyzed corroborate the survey data. Physician Assistant faculty members, then, have reviewed if the values expressed in their mission statements are actually being reflected and learned as a result of course attendance.

SLOs are in Alignment at the Course, Academic Program, and Institutional Levels

Intended learning outcomes are in alignment at the course, academic program, and institutional levels (Huba \& Freed, 2000, p. 107). Are PA faculty designing their SLOs backward and delivering them forward? Put another way, are their SLOs designed thus: Institution $\rightarrow$ Program $\rightarrow$ Course $\rightarrow$ Unit $\rightarrow$ Lesson? Are they, then, delivered thus: Lesson $\rightarrow$ Unit $\rightarrow$ Course $\rightarrow$ Program $\rightarrow$ Institution (Huba \& Freed, 2000, p. 108)? The 
data confirms that this does, indeed, appear to be the case. Triangulation is achieved through a strong, consistent corroboration between the scholarly literature, survey results (95\%), and documents analysis (89\%).

\section{SLOs Focus on Non-Trivial Aspects of Learning}

Intended learning outcomes focus on important, non-trivial aspects of learning that are credible to the public (Huba \& Freed, 2000, p. 112). When asked about this characteristic, $97 \%$ of program directors indicated that their SLOs meet are credible to the public. Of the samples available for analysis, all demonstrate the above characteristic.

What, however, is meant by non-trivial? This aspect of SLOs should motivate PA educators to evaluate the foundations of learning (E. Jones, personal communication, August 2003). In other words, how do course-level SLOs integrate the foundations of learning as defined by Bloom (1956) and associates (1964)? Do PA educators understand and incorporate the cognitive, affective, and psychomotor domains of learning in their SLOs? Based upon data analysis, PA educators are integrating cognitive (survey: 100\%; documents: 100\%) and psychomotor (survey: 93\%; documents: 100\%) dimensions of learning when crafting SLOs. Affective-SLOs at PA programs (survey: 80\%), however, is refuted based upon those SLOs evidenced in the provided documents $(56 \%$ of the samples analyzed).

\section{SLOs are Central to the Discipline}

Intended learning outcomes focus on skills and abilities central to the discipline and based on professional standards of excellence (Huba \& Freed, 2000, p. 116). Continuing the strong, consistent tendency of triangulation with previous research, all survey data and document analysis demonstrate that PA course-level student learning 
outcomes (SLOs) are central to the discipline. These finding seem to suggest that PA educators are cognizant that what they teach, and what students learn, should bear scrutiny from their peers both individually and collectively. Additionally, these programs appear to crafting course-level SLOs that are "compatible with the best thinking in the discipline in terms of what is important to know" (Huba \& Freed, 2000, p. 116).

\section{SLOs Capture Measurable Learning}

Intended learning outcomes are general enough to capture important learning but clear and specific enough to be measurable (Huba \& Freed, 2000, p. 116). This feature of SLOs refers to the increasing generality of SLOs from the course through institutional levels as well as the need for framing precise outcomes that can measure these outcomes. Developing SLOs that achieve the balance between this generality and preciseness can prove a complex task for PA educators (p. 116). For example, an SLO that is framed as: "PA students will be critical thinkers," is not precise enough for students or faculty to realize what is expected of them. However, if the SLO is framed thus: "PA students will demonstrate critical thinking skills, while taking a complex medical history and physical examination, to develop a differential diagnosis," provide students and faculty with a greater level of detail about the expectation for learning and teaching. Ninety-five percent of survey responses and all seven documents submitted for analysis demonstrate that PA educators are achieving this aspect of effective SLOs.

\section{SLOs are Enduring and Assessable}

Intended learning outcomes focus on aspects of learning that will develop and endure but that can be assessed in some form now (Huba \& Freed, 2000, p. 117). It is challenging to ascertain the full affect of the Physician Assistant educational experience 
on a student's life. The use of well-crafted SLOs can, however, provide indications and insights about the growth of these students as they proceed through their lessons, units, courses, and indeed programs and institutions themselves. The data reveals that $95 \%$ of program directors and PA educators are crafting the types of SLOs that are consistent with this criterion. Further, all the available document substantiate the survey results. Ultimately, these SLOs ideally generate data that enlightens PA faculties "about curricula, teaching, and kind of student effort that lead to particular outcomes" (American Association for Higher Education [AAHE], 1992, p. 1).

\section{Research Question 5:}

What measurement instruments do PA educators use in the assessment of their

$$
\text { programs? }
$$

The philosophies surrounding the measurement of learning and the methods for conducting these measurements may prove controversial within various Physician Assistant (PA) programs. Given the above potential, assessment scholars find that incorporating this dialogue in the assessment process is crucial for educators (Maki, 2002; Terenzini, 1989). Physician Assistant educators make numerous decisions about selecting appropriate instruments for the measurement of student learning,

Use of Commercial and Local Instruments

Commercially-developed instruments.

Commercially-developed instruments (CDIs) are available to assess general education outcomes, specific disciplines, and specific learning skills (Erwin, 2000a; Palomba \& Banta, 1999). The strength of these type instruments is their documented reliability and validity (Jones, Voorhess, \& Paulson, 2002) and availability of "national 
norms for comparison have been developed" (Palomba and Banta, 1999, p. 99). The data from this research indicates that $46 \%$ of the programs in this study report using CDIs sometimes; nearly one-quarter report never using such instruments. Perhaps this is because some faculty members "do not believe that commercial tests accurately or meaningfully measure whether students have achieved the educational goals specific to the academic program or institution" (Jones, Voorhees, and Paulson, 2002, p. 31). Additionally, despite the survey data above, $71 \%$ of documents analyzed annotate the use of discipline-specific CDIs such as the: (a) Physician Assistant Clinical Knowledge Rate and Assessment Tool (PACKRAT); (b) Objective Structured Clinical Exam (OSCE); and (c) Physician Assistant National Certifying Examination (NCCPA).

Locally-developed instruments.

Locally-developed instruments are especially appealing to faculties because "in some cases, there is not a measure that adequately examines the forms of student achievement that have been the focus of curriculum objectives, producing a need to develop a test locally" (Erwin, 2000a, p. 1). Additionally, faculties often discover that “only outcome data derived from locally developed tests...[yields] a sufficient quantity of information, to guide decisionmaking” for formative assessments (p. 2). Physician Assistant educators apparently concur with this research as program directors indicate using locally-developed instruments frequently (59\%) and a quarter (25\%) use them sometimes (see Table 31). Jones, Voorhees, and Paulson (2002) also note the valueadded benefit of using these instruments to promote a sense of faculty ownership and synergy in the assessment process. 


\section{Use of Direct and Indirect Instruments}

Direct, course-embedded instruments.

Direct, or performance, measures include "performance assessments that require students to demonstrate their competence in one or more skills" (Palomba \& Banta, 1999, p. 95). There are numerous types of these instruments, but the list below contains many of those used in assessment research:

- Objective (i.e., written) tests

- Case studies and simulations

- Essays

- Oral examinations

- Portfolios

- Poster presentations

- Presentations

- Problem sets

- Products

- Capstones, practicums, and internships

(Banta, Lund, Black, \& Oblander, 1996; Glicken, 2002; Major \& Jones, 2001; Maki, 2002; Palomba \& Banta, 1999).

The quantitative data from this research indicates that Physician Assistant educators use many of the instruments above. All of the programs frequently use objective tests. Case studies or simulations and capstone experiences, practicum, or internships are used frequently (59\%) at PA programs. Educators at these programs use essays and oral examinations frequently or some of the time; $61 \%$ and $57 \%$ respectively. The use of these instruments should ideally help PA educators determine several of the most important questions about student learning:

- What did students learn as a result of an educational experience?

- To what degree did students learn? 
- What did students not learn (Middle States Commission on Higher Education [MSCHE], 2003). p. 31)?

Additionally, some of these instruments are more likely to be utilized than others due to their long familiarity with audiences internal and external to PA programs. As a result, the data collected from their use is generally well understood by the stakeholders in these audiences (MSCHE, 2003).

Program directors also provided quantitative data on those direct instruments used infrequently or not at all. Survey respondents, for example, indicate that they never $(62 \%)$ use portfolios and another $26 \%$ indicate seldom using them. Data also demonstrates that they seldom or never use products $(64 \%)$, poster presentations $(55 \%)$, and problem sets (52\%). Perhaps, as indicated by the MSCHE above, these instruments are less used by PA educators as a result of their unfamiliarity.

\section{Indirect instruments.}

Indirect, or reflective, methods of measuring student learning "ask students to reflect on what they have learned and experienced rather than to demonstrate their knowledge and skills, providing proxy information about student learning” (Palomba \& Banta, 1999, p. 96). The instruments listed below are the most representative methods identified in the scholarly literature (Jones, 2002; Maki, 2002; MSCHE, 2003; Schulman, Fabringer, \& Skaff, 1999):

- Classroom assessment techniques

- Reflective papers and journals

- Interviews

- Focus groups

- Surveys (e.g., student, exit, alumni, employer) 
Based upon the quantitative data in this study, the most commonly utilized (i.e., frequent or sometimes) indirect instruments for measuring PA student learning are: classroom assessment techniques (83\%), employer surveys (75\%), entrance interviews (70\%), midpoint interviews (65\%), and exit interviews (67\%). As noted by Jones (2002), one of the strengths of the above instruments is their ability to gather feedback from students about how programs are working and can be improved.

Making Choices About the Design of Assessment

Who will be assessed?

Having decided on what types of instruments to use, Physician Assistant (PA) faculties next need to consider who will be assessed. Palomba and Banta (1999) note that "practitioners must develop clear criteria to identify individuals who will be required or invited to participate in assessment projects" (p. 110). Based upon this study, 65\% of program directors report that their faculties have developed these types of criteria.

What should be assessed?

Another choice that PA educators must consider is what needs to be measured. Faculty members at PA programs may focus specifically on a particular domain of learning (i.e., cognitive, affective, or psychomotor). A possible measurement that can prove especially useful in PA programs is ascertaining the extent of content knowledge and skill integration (Jones, 2002). Faculties at these programs have apparently considered these factors as $91 \%$ of their directors report that they have established definite criteria on what will be measured. 


\section{When will the assessments occur?}

When specific measurements of PA student learning will occur is yet another consideration for educators. Programmatically, PA faculties may wish to monitor student and graduate growth in the discipline as they move from entry through mid-point to exit and in the years that follow (Accreditation Review Commission on Education for the Physician Assistant, 2002). At the programs in this study, directors provide strong indication $(80 \%)$ that they have emplaced definitive criteria that identifies when their students will be required or invited to participate in assessments.

How will students be assessed?

Lastly, Physician Assistant (PA) educators need to make choices about how to use assessment instruments they have selected. Will the program use commercially designed instruments or will they design their own instruments? How will direct and indirect measures be integrated into the program? PA faculties are addressing this criterion since $91 \%$ of directors indicate they utilize a combination of these methods.

\section{Research Question 6:}

How do faculties use assessment results to make program improvements?

"Because the specifics of assessment vary from campus to campus, assessment practitioners need to think about the kinds of actions that will foster the use of assessment information on their own campuses" (Palomba \& Banta, 1999, p. 303).

\section{Integrating Results and Implementing Improvements}

At its very core, programmatic student learning outcomes assessment is focused using data for the purpose of continuously improving faculty teaching and student learning 
(American Association for Higher Education, 1992; Huba \& Freed, 2000; Middle States

Commission on Higher Education, 2003; Peterson \& Vaughan, 2002).

Planning and review.

In the early 1990s, scholars noted that assessment results should be "linked to comprehensive strategies for planning or program review that encourage change and improvement" (Aper \& Hinkle, 1991, p. 545). A decade later, researchers are finding that "many institutions [have] policies designed to assure the use of student performance indicators in academic planning and review" (Peterson \& Vaughan, 2002, p. 35). At the PA programs participating in this study, $96 \%$ of program directors indicate they integrate assessment results in their programmatic planning. Additionally, all of these directors report that results are also used in their program reviews. This integration is a positive indicator for these programs as research indicates that intradepartmental integration of assessment results increases the chances an assessment program will flourish (Peterson, Vaughan, \& Perorazio, 2001, p. 83).

\section{Budgeting.}

In order for a student learning outcomes assessment effort to be successful at a Physician Assistant (PA) program, or any other program, it is essential to develop a direct, formal linkage to the budgetary process (Lopez, 1999; Peterson, Vaughan, \& Perorazio, 2001). Given these research findings, it is disconcerting that $40 \%$ of the programs in this study report that this level of integration has not yet occurred at their institutions. Ideally, these institutions will eventually "link the assessment process to their internal budgeting process, [thus] setting aside a block of funds for initiatives to improve 
student learning based on recommendations from assessment activities" (Palomba \& Banta, 1999, p. 43).

\section{Teaching and learning.}

Evenbeck and Kahn (2001) note that "campus assessment efforts have been most meaningful and effective when they have been conducted within the disciplines, using processes and procedures that articulate desired outcomes and measure them in light of the department's mission" (p. 25). Additionally, researchers find that these assessment efforts provide important "insights into the type of learning occurring in the program, and we are better able to make informed decisions about needed program changes" (Huba \& Freed, 2000, p. 15). Nearly all (98\%) of the PA program directors involved in this study report using their assessment data to improve faculty teaching. Further, all of these directors indicate using their assessment results in an effort to improve student learning. This, then, seems to indicate that PA educators are using their assessment data to make program and course modifications (Banta, Lunda, Black, \& Oblander, 1996; Cottrell \& Jones, 2002; MSCHE, 2003). The strength of these responses, however, seems in conflict with the directors' earlier responses that indicate only about $50 \%$ of there assessment plans are fully developed or implemented.

\section{Curricular modification.}

Data from numerous research endeavors by assessment scholars have established the value of integrating assessment results and curricular modifications (Ewell, 2002; Huba \& Freed, 2000; Jones, 2002; Stark \& Lattuca, 1997). In this study, all of the Physician Assistant (PA) program directors report that they integrate assessment results in multiple intradepartmental areas by using assessment data in curricular modifications. 
Although not yet fully demonstrated, it appears that PA educators may use assessment results from student learning to help "keep a learner-centered perspective during curriculum development and revision" (Huba \& Freed, 2000, p. 70). Finally, these faculty members appear to be using these results to assist them in determining "whether or not the curriculum has been effective" (p. 70). As noted in the previous section, the strength of these responses seems in contention with director responses regarding the development and implementation of assessment plans.

\section{Research Question 7:}

How do faculties communicate assessment results and to what audiences?

\section{Communicating Assessment Results to Specific Audiences}

Teaching, learning, and assessment are collaborative efforts that rely on a high degree of open communication between stakeholders internal and external to academia (Angelo, 1999; Douglas \& La Voy, 2002; Suskie, 2000; Tiberious, R. G., Sackin, H. D., Slingerland, J.M., Jubas, K., Bell, M., Matlow, A., 1989).

Reporting formats.

Given the importance of clear communication, Physician Assistant (PA) faculties need to select the appropriate reporting formats for the corresponding audiences (Erwin, 1996). A myriad of differing formats for reporting assessment data are discussed in the scholarly literature. Some of the most common formats are:

- Comprehensive reports

- Annual reports

- Executive summaries

- Special reports

- Newsletters

- Presentations 
- Report cards

- Specific audience reports

- Web-based reports

(Banta, Lund, Black, \& Oblander, 1996; Jones, 2002; Lopez, 1999; Palomba \& Banta, 1999). At these programs, the most commonly (i.e., frequent or sometimes) utilized formats for reporting assessment results to the various internal and external stakeholder audiences are annual reports (77\%) and comprehensive reports (59\%). Although other formats are used less frequently, but it appears these faculties are using a wide range of formats to communicate with their stakeholders (Jones, Voorhees, \& Paulson, 2002).

\section{Internal audiences.}

Ewell (2002) notes that all phases and levels of outcomes assessment planning and implementation require an open collegiality with the goal of institutional, programmatic, pedagogical, and student learning improvement. To achieve this collegiality, scholars recommend frequent communication with internal stakeholders (Birnbaum, 1988; Terenzini, 1989). These different stakeholders are identified as such as:

- Executive level personnel

- Senior administrative leaders

- Faculty

- Students

- Committees (e.g., planning, review, budget, and curriculum

(Erwin, 1996; Banta, Lund, Black, \& Oblander, 1996; Maki, 2002). Of these internal stakeholders, this research data reveals that PA faculty are the most common (89\%) recipients of assessment reports. Other internal stakeholders receiving assessment results from PA programs include: institutional executives and senior administrators (66\%), students (45\%), and institutional committees (25\%). Considering how integral faculties are to any assessment effort, a strength of these results lies in the fact that PA educators 
are the emphasis in the distribution of assessment data. There are, however, some high priority recipients, such as the budget committee, that appear to be infrequently considered when sharing assessment results.

\section{External audiences.}

As noted above, student learning outcomes assessment is a culture of inclusion, thus communication with external stakeholders is very important. Given that these audiences are primary sources of input to the assessment process, it is logical that they also be primary recipients in any assessment data distribution plan (Allen \& Bresciani, 2003; Ewell, 2003; Maki, 2002). Assessment scholars identify some of the most common external audiences as:

- Alumni, parents, trustees, employers

- Federal and state officials

- Accrediting and professional bodies

- Philanthropic individuals and organizations

(American Association for Higher Education, 1992; Erwin, 1996; Jones, 2002; Jones, Voorhess, \& Paulson, 2002; Tam, 2001; Wiggins, 1990). As might be expected, a substantial percentage ( $86 \%$ ) of program directors report their accrediting body as the most common recipient of assessment reports. Given the importance of including external audiences in the distribution of assessment results, it is disconcerting that the following stakeholder emphasis is thus: professional bodies (25\%), employers (23\%), alumni (18\%), state government (18\%), and federal government $(16 \%)$.

\section{Dissemination plans.}

During the development of a dissemination plan for assessment results, PA faculties should consider when and to whom their results will be distributed. For example, throughout the process of reporting student learning outcomes assessment data, 
faculty members should remain cognizant that "timing can be everything" (Upcraft \& Schuh, 1996, p. 286). Based upon the quantitative data analyzed during this research, it appears that a majority (75\%) of PA program directors are providing their numerous stakeholders with assessment reports at an appropriate time. This is consistent with Palomba and Banta's findings (1999) that a "useful distribution plan considers the needs of various audiences and the appropriate sequence of report sharing" (p. 328).

Program directors remain consistent regarding the appropriate stakeholder and sequencing of assessment data dissemination in that $69 \%$ percent also indicate that their reports are initially released to those most affected by the assessment results. Lastly, $72 \%$ of the directors in this study report that their assessment results "released as decisions are being made, so that the findings and recommendations can become part of the decisionmaking process" (Palomba \& Banta, 1999, p. 286). Only $61 \%$ of the directors, however, indicate that they have a dissemination plan for reporting assessment results to their various stakeholders. This, coupled with only about $50 \%$ of directors reporting fully developed or implemented assessment plans, seems in contrast to the responses indicated here.

\section{Recommendations for Practice}

The recommendations from this study are based on the dominant themes identified during data analysis. The majority of these recommendations are focused at the program level, thus they are offered primarily to directors and faculties of Physician Assistant programs. At the conclusion of this section, however, several brief comments and suggestions of potential interest and use are offered to the Association of Physician 
Assistant Programs (APAP) and the Accreditation Review Commission on Education for the Physician Assistant (ARC-PA).

\section{Research Question 1:}

What types of institutional resources are available to conduct assessment?

Physician Assistant educators are encouraged to:

- Institute a culture of assessment.

- Initiate the development of a comprehensive, research-based assessment plan.

- Acquire adequate funding for assessment initiatives.

- Link assessment results to strategic planning and budget decisions.

- Develop guiding principles.

Institute a Culture of Assessment

Given that that only one out of the nine criteria that characterize important leadership traits identified as hallmarks of success in a culture of assessment is found to be above $50 \%$ in this study, PA educators should consider why this current relationship exists. It is therefore recommended that PA faculties examine their assessment environment to determine if there are strategies that can be developed and implemented to increase the involvement of institutional leaders in assessment activities. These strategies should focus on:

- direct leader involvement in the assessment process;

- meeting regularly with assessment personnel;

- maximizing honest, open, two-way communication;

- establishing an environment based on trust; 
- demonstrating a commitment to assessment by providing real incentives for participation and support (e.g., time, teaching loads, grants, stipends, students);

- encouraging assessment personnel to use a deliberate planning process;

- making slow, incremental changes thereby increasing chances for success; and

- approving the integration of assessment and budget. (Jones, Voorhees, and Paulson, 2002)

During the development of these strategies, PA educators may wish to consult Robert Birnbaum's (1988) research on "how colleges work" for additional insights. Initiate the Development of a Comprehensive, Research-Based Assessment Plan

The assessment of student learning outcomes is a dynamic process, thus it is recommended that PA educators seize the initiative in the development and implementation of a comprehensive, research-based assessment plan. These plans should articulate the following major components in specific detail:

- institutional and programmatic assessment philosophy;

- key terms and definitions in assessment language;

- strategies for gaining institutional resources;

- faculty development in assessment planning and implementation;

- crafting and alignment of institutional and programmatic mission statements, goals, and student learning outcomes;

- comprehensive integration of Bloom's learning domains in all student learning outcomes;

- integration of multiple instruments for measuring student learning over time;

- using assessment results to affect authentic change;

- dissemination assessment results to multiple internal and external audiences; and 
- $\quad$ assessing the assessment program. (Palomba \& Banta, 1999; Shipman, Aloi, \& Jones, in press)

Additionally, it is recommended that PA educators incorporate the following principles of good practice in their assessment plans:

- the assessment of student learning begins with educational values;

- assessment is most effective when it reflects an understanding of learning as multidimensional, integrated, and revealed in performance over time;

- assessment works best when the programs it seeks to improve have clear, explicitly stated purposes;

- assessment requires attention to outcomes but also and equally to experiences that lead to those outcomes;

- assessment works best when it is not episodic;

- assessment fosters wider improvement when representatives from across the educational community are involved;

- assessment makes a difference when it begin with issues and illuminates questions that people really care about;

- assessment is likely to lead to improvement when it is part of a larger set of conditions that promote change; and

- through assessment, educators meet responsibilities to students and to the public. (American Association for Higher Education, 1992) Acquire Adequate Funding for Assessment Initiatives

As noted by the Middle States Commission on Higher Education (2003), the planning and implementation of a student learning outcomes assessment program 
involves numerous funding considerations. Thus, it is recommended that Physician

Assistant educators develop strategies and plans to acquire funding for:

- faculty development costs

○ time (e.g., planning, preparation, attendance)

- compensation of internal and external experts

$\circ$ presentations, workshops, retreats, etc.

- faculty incentives

○ time (e.g., reduced teaching load, publication preparation)

$\circ$ use of graduate assistant / student

- travel to other institutions to examine assessment programs

0 travel to assessment conferences

- availability of stipends, small grants (less than \$2000), and large grants (more than \$2000)

- faculty resources

○ office space

$\circ$ office supplies

○ measurement instrument acquisition (e.g., develop, purchase)

○ administrative support (e.g., secretarial, postage)

$\circ$ technology support (e.g., hardware, software, expertise)

(Middle States Commission on Higher Education, 2003; Palomba \& Banta, 1999).

Additionally, it is recommended that PA faculties delineate those costs associated with "start-up" activities (e.g., office space) and those used to sustain the assessment effort (e.g., grants). Finally, embedded within the entire resource acquisition strategy and process is the ultimate goal of gaining "approved budget lines...in successive annual budgets" (Lopez, 1999, p. 29).

\section{Link Assessment Results to Strategic Planning and Budget Decisions}

Physician Assistant faculties are encouraged to learn how to link assessment results with strategic planning and budget decisions. As noted in this study, when the above linkages fail to occur an assessment program "is likely to lose its momentum, and 
disaffection will replace the satisfaction that faculty experience when they are able to propose, document, test, and evaluate the effects of a change that could increase students' learning within one academic year" (Lopez, 1999, p. 32).

Develop Guiding Principles and Best Practices Based on Previous Research

Given the paucity of guiding principles for assessment available for analysis in this study, PA educators are encouraged to develop principles that will guide their assessment endeavor. At a minimum, these guiding principles should articulate the following:

- Guiding Principle 1: Examine the Existing Culture.

Begin by acknowledging the existence of assessment throughout the program to ensure that the assessment plan is grounded in a culture of assessment.

- Guiding Principle 2: Develop a Realistic Plan with Appropriate Investment of Resources.

The Physician Assistant (PA) program assessment plan should be realistic and supported by the appropriate investment of institutional resources.

- Guiding Principle 3: Involve Faculty and Students.

Institutional and programmatic leadership is necessary in order to gain the support and involvement of PA educators, staff, and students throughout the program.

- Guiding Principle 4: Set Clear Goals.

Assessment activities should be focused by a set of clear statements of expected learning (knowledge, skills, and competencies). 
- Guiding Principle 5: Select the Appropriate Methods.

Assessment should involve the systematic and thorough collection of direct and indirect evidence of student learning, at multiple points in time and in various situations, using a variety of quantitative and qualitative methods that are embedded in lessons, courses, and the overall program.

- Guiding Principle 6: Use Data to Make Improvements.

Data gained through assessment activities should be meaningful. They should be used:

○ to enhance student learning at the program, course, and lesson levels;

$\circ$ in programmatic planning and resource allocation; and

$\circ$ to evaluate periodically the assessment process itself for its comprehensiveness and efficacy.

(Middle States Commission on Higher Education, 2003, p. 3)

\section{Research Question 2:}

How is assessment planning integrated into PA faculty development?

The following recommendation is offered to Physician Assistant (PA) educators:

- Institute a well-organized, dynamic, ongoing faculty development program that focuses on the major components of student learning outcomes assessment. Given that the assessment scholars and the Physician Assistant program directors in this study consider faculty the most integral component in the student learning outcomes assessment process, it naturally follows that these members need the greatest degree of development to fulfill the roles and expectations set forth at the institutional and programmatic levels.

Given the essentiality of equipping PA educators with the appropriate knowledge and skills to plan and implement a credible student learning outcomes assessment 
program, this same essentiality and credibility must be components of the very process that will deliver the above knowledge and skills. This said, PA program directors are strongly encouraged to institute a faculty development program that is: (a) wellorganized, (b) well-publicized, (c) dynamic, (d) ongoing, and (e) focuses on the major components of student learning outcomes assessment. To achieve this end, PA faculty development programs should incorporate the following features:

- use of internal and external experts to assist in assessment-related faculty development;

- a variety of development methods to deliver assessment training;

- discussion and application of major assessment components;

- definition of faculty roles and expectations in the assessment process; and

- the institution of an authentic incentives and rewards system for assessment participation.

Physician Assistants (PA) are accustomed to consulting with specialists during the practice of medicine, thus it is strongly recommended that PA educators routinely consult with assessment specialists internal and external to their institutions during the planning and implementation of their assessment programs. For example, there may be other departments at a PA program's institution that are further evolved in the assessment process and have faculty that can present "lessons learned" to PA educators. Also, PA faculties should make use of educational researchers, budget experts, and other assessment-related personnel to provide a greater degree of perspective and expertise for their assessment effort. Additionally, since some campuses may lack assessment-specific 
experts, PA directors should seriously consider inviting these individuals to assist them in their faculty development as well as with the entire assessment process itself.

Faculty development programs for PA educators should incorporate a variety of development methods to deliver assessment education and training. Directors should, for example, seek to integrate the following types of faculty development sessions:

(a) formal presentations; (b) hands-on, interactive, single-topic workshops; and (c) handson, interactive, multi-topic workshops. These sessions can be conducted as part of regularly scheduled faculty meetings, seminars, retreats, and even conferences. Additionally, it is imperative that the bulk of these sessions use a workshop method, thus providing PA faculty members the greatest degree of knowledge and skills integration. Lastly, insuring that PA educators receive ample opportunities to attend these development sessions is a programmatic investment in the future success of any assessment effort.

This research indicates that the Physician Assistant programs in this study appear to be in the early stages of the student learning outcomes assessment planning and implementation. It is therefore recommended that initial faculty development sessions should provide an in-depth introduction to:

- assessment history and philosophy;

- assessment language;

- assessment-related faculty development;

- incentives for participation in assessment; and

- acquisition of institutional resources. 
More evolved programs should, of course, focus on more complex assessment issues (e.g., instruments, results, etc.).

Gaining faculty "buy-in" and subsequent "ownership" of an assessment program is certainly influenced heavily by a credible faculty development process in assessment subjects. Another important influence is that of defining the faculty roles and expectations in the process. To address the articulation of specific roles and expectations, it is recommended that PA faculties clearly delineate specific roles (e.g., resource acquisition, instrument design, data analysis, etc.) and establish specific timelines for developing assessment products.

Perhaps the single most important structural item influencing the success of an assessment-related faculty development process, and indeed the entire assessment program itself, is the institution of an authentic incentive and reward system for faculty participation in assessment activities. Given that PA educators appear to have limited incentives, program leaders should consider investigating and instituting a system that provides concrete compensation for faculty participation. Explicit incentives could include the following:

- time (e.g., reduced teaching load, publication preparation);

- use of graduate assistant / student;

- travel to other institutions to examine assessment programs;

- travel to assessment conferences; and

- the availability of stipends, small grants (less than \$2000), and large grants (more than \$2000). (Jones, 2002; Middle States Commission on Higher Education, 2003; Palomba \& Banta, 1999) 
Finally, given the potential for resistance to assessment, Palomba and Banta (1999) observe that "it is important to be aware of its nature" (p. 71). It is significant that one-quarter of the directors in this study note that their assessment initiatives meet resistance from other PA educators. To address this potential issue, it is recommended that PA program directors ensure that faculty members are provided ample opportunities to learn about:

- the nature and purpose of assessing student academic achievement;

- what constitutes an assessment program, academic program review, and evaluation of programmatic effectiveness;

- the idea of "measuring" learning and the thought that assessment results can be used to actually improve students' learning; and

- the technical skills needed to plan and implement assessment. (Lopez, 1999, p. 9) Although the above factors may constitute formidable challenges for PA program directors, given the potential that these issues will arise, directors need to be vigilant for their manifestations and anticipate addressing these very real concerns on the part of the PA educators that will drive the assessment process (Rodrgues, 2002). Using the research, insights, and recommendations developed by this researcher and the assessment scholars in this study will help prevent assessment from being perceived as an "intrusive imposition by outsiders or a bureaucratic chore, rather than as a useful tool for the purpose of effectively accomplishing educational goals and intended student learning outcomes (Lopez, 1999, p. 9).

Ultimately, faculty development has the potential to be an impetus of individual and cultural transformation for PA educators and their programs. Culturally, assessment- 
based faculty development can provide the momentum for the transition from a teachercentered to student-centered learning environment (Huba \& Freed, 2000). At its very essence, this process should be considered a force for positive, non-punitive improvements at the institutional, programmatic, faculty, and student levels. To do this, however, faculty development programs need to be dynamic, meaningful learning environments that empower faculty to achieve assessment goals. Using the information discussed above, those interested in faculty development and assessment can apply these transformational elements to create the conditions that allow assessment to take root and flourish. As Angelo (1999) observes, it all begins with building a shared trust, a shared language, shared motivations, and shared guidelines.

\section{Research Question 3:}

What programmatic student learning outcomes are used by PA educators?

Many of the Physician Assistant (PA) program directors participating in this study are to be commended for the strength of their programmatic mission statements, goals, and SLOs. The following recommendations are offered to PA educators:

- Ensure that programmatic goals are developed in collaboration with other faculty members.

- Increase the integration of affective learning.

Ensure that Programmatic Goals are developed in Collaboration with Other Faculty Members.

Physician Assistant faculties should examine and ensure that, like the programmatic mission statement, the goals at the program level are crafted as part of the collaborative process that is assessment. The synergy created by this process results in a 
series of programmatic goals that are shared by faculty members across the program, thus increasing the sense of faculty ownership in the mission.

Increase the Integration of Affective Learning

All of the programmatic goals examined in this study exhibit the integration of cognitive and psychomotor learning domains. Affective learning integration, however, is not present in $29 \%$ of the programmatic goals examined. It is therefore recommended that PA educators determine if the affective learning domain can be incorporated into existing programmatic goals. If this not feasible, it is further recommended that faculty members consider crafting a goal(s) to capture this type of learning in their programs.

\section{Research Question 4:}

How are student learning outcomes integrated into PA program courses?

The following recommendations are offered to Physician Assistant (PA) faculty:

- Acquisition, immersion, and application of previous assessment research.

- Achieve a deeper integration of cognitive, affect, and psychomotor domains of learning.

As in the discussion regarding programmatic student learning outcomes (SLOs) (see above), the strength of course-level SLOs demonstrated in the quantitative and qualitative data is commendable. The following comments are offered in an effort to provide further points of consideration to faculties and as a source of insight for programs in need of additional assistance with these topics. Acquisition, Immersion, and Application of Previous Assessment Research 
Physician Assistant faculty members should develop evidence-based SLOs. Thus, the single strongest recommendation that can be offered to fellow PA educators is that of acquisition, immersion, and application of the assessment evidence provided in:

- Assessment Essentials: Planning, Implementing, and Improving Assessment in Higher Education (Palomba \& Banta, 1999).

- Assessment in Practice: Putting Principles to Work on College Campuses (Banta, Lund, Black, \& Oblander, 1996);

- Building a Scholarship of Assessment (Banta \& Associates, 2002);

- Defining and Assessing Learning: Exploring Competency-Based Initiatives (Jones, Voorhees, \& Paulson, 2002

- Learner-Centered Assessment on College Campuses: Shifting the Focus from Teaching to Learning (Huba \& Freed, 2000);

- Principles of Good Practice for Assessing Student Learning (American Association for Higher Education, 1992);

- Student Learning Assessment: Options and Resources (Middle States Commission on Higher Education, 2003); and

- Transforming the Curriculum: Preparing Students for a Changing World (Jones, 2002).

Although listed in this study's bibliography, the above references are offered here to highlight their importance in any assessment endeavor; regardless of experience level or maturation of program. Quite simply, these references are reflective of the best thinking on student learning assessment today. For those new to assessment, the researcher especially recommends Palomba and Banta (1999). For those specifically 
interested in learning more about a student-centered learning environment or writing student learning outcomes, Huba and Freed (2000) is recommended.

A related recommendation is that of establishing a small assessment reference section to a PA program's existing medical references. Although some of the texts above may be found in an institution's library, it is suggested that PA educators acquire these works for permanent placement at the program level. Like medical references that are often used by medical practitioners, assessment practitioners will find that having these sources close at hand increases the propensity for use and application.

Achieve a Deeper Integration of Cognitive, Affect, and Psychomotor Domains of

\section{Learning}

At this juncture, the discussion turns to recommendations regarding Bloom's Taxonomy (1956). The importance of Bloom's work cannot be overstated; it is, to use medical jargon, "The Gold Standard” for understanding how human beings learn. Thus, it is essential that all Physician Assistant (PA) educators learn, apply, and integrate the cognitive, affective, and psychomotor domains (and sub-domains) while developing their student learning outcomes (SLOs). These are as follows:

- Cognitive domain:

○ Knowledge

- Comprehension

- Application

- Analysis

○ Synthesis

- Evaluation

- Affective domain:

○ Receiving

o Responding

- Valuing

- Organization

- Characterization by a Value 
- Psychomotor domain:

○ Imitation

- Manipulation

○ Precision

- Articulation

○ Naturalization

(Bloom, 1956; Bloom, Mesia, \& Krathwohl, 1964; The University of Mississippi, 2003a) It is further recommended that PA educators actively seek additional methods for achieving deeper integration of the above learning domains at the programmatic, course, and lesson levels. For example, PA faculties should:

- view the different learning domains as inseparable components of the same process;

- build a foundation of lower-order thinking skills (e.g., knowledge, comprehension) with the intent of achieving proficiencies in higher-order thinking (e.g., application, analysis, synthesis, and evaluation);

- recognize affective learning as a vital component of the PA student learning experience;

- use the full spectrum of affective descriptors (e.g., receiving, responding, valuing, organization, and internalization) when formulating SLOs; and

- design active learning experiences that maximize the full range of psychomotor sub-domains. 


\section{Research Question 5:}

What measurement instruments do PA educators use in the assessment of their

$$
\text { programs? }
$$

It is recommended that Physician Assistant (PA) educators examine and ensure that their programs use multiple methods for measuring student learning. To achieve this, it is further suggested that educators:

- increase individual and collective knowledge and application of various instruments for measuring student learning outcomes (SLOs);

- use course-embedded instruments; and

- develop clear criteria about who, what, when, and how students and other stakeholders will be assessed.

Increase Individual and Collective Knowledge and Application of Various Instruments for Measuring SLOS

Although some faculty members in higher education may have reservations about measuring learning, numerous scholars recognize the need for instruments that gauge what students learn during their collegiate experience (AAHE, 1992; Aper \& Hinkle, 1991; Lopez, 1999; Maki, 2002; Stark \& Lattuca, 1997; Steutzer, 1999). Thus, where applicable, PA faculty members are advised to increase their individual and collective knowledge and application of various instruments available for measuring student learning outcomes (e.g., definitions, types, strength and limitations, and integration). Although a comprehensive treatment of instruments for measuring students learning is beyond the scope of this heading, readers are encouraged to examine Chapter Two of this research as well as the cited scholars therein for more in-depth information. 
Having gained an understanding of measurement instruments in general, it strongly recommended that PA educators use as many different types of instruments as possible as frequently as possible throughout individual courses and the PA program in general. Some of these instruments are as follows:

- Direct (or performance) instruments:

- Written examinations

- Presentations

○ Essays

- Case studies and simulations

- Products

- Poster presentations

- Problem sets

- Oral examinations

- Portfolios

- Capstones, practicums, and internships

- Indirect (or reflective) instruments:

- Classroom assessment techniques

$\circ$ Reflective papers and journals

$\circ$ Entrance interviews

- Mid-point interviews

- Exit interviews

$\bigcirc$ Focus groups

- Employer surveys

- Patient surveys

The rationale here is that these instruments provide PA educators a multidimensional picture of student learning in a longitudinal pattern.

Use Course-Embedded Instruments

An additional recommendation for PA educators is to embed student learning measurements in their individual courses (Erwin, 2000a; Jones, Voorhees, \& Paulson, 2002; Suskie, 1996). As noted by Huba and Freed (2000), embedded assessments are:

- the most efficient means of gathering data about student learning; 
- more cost-effective than other means of data collection; and

- enhance student motivation to participate in the assessment process (p. 82).

Develop Clear Criteria about Who, What, When, and How Students and Other

Stakeholders will be Assessed

A final recommendation to PA educators concerns the process of measuring student learning. As indicated in Chapters 2, 4, and earlier in this chapter, faculty members need to develop clear criteria about:

- who (e.g., prospective student, alumni, employers),

- what (e.g., critical thinking, skills integration),

- when (e.g., entrance, exit, 3-years post-graduation),

- how (e.g., exams, journals, focus groups),

students and other stakeholders will be assessed (Palomba and Banta, 1999, p. 110). The formalization of this process provides a structure that allows faculty members to gather measures of learning in a consistent, methodical manner. In essence, this process is the primary component of the assessment data collection effort and the subsequent database that is used to affect changes in operations, pedagogy, and learning.

In closing this section of the chapter, a few general insights are offered or reiterated. First, there are obviously a multitude of measurements that educators can undertake and while the thought of this may be overwhelming to some faculty, it certainly reinforces the need for well-crafted mission statements, goals, and student learning outcomes (Banta, Lund, Black, \& Oblander, 1996; Jones, 2002). Secondly, embedded multi-instrument, longitudinal studies will provide PA educators with the greatest degree of reliable information about what their students know and can do as a 
result of their collegiate experience (Jones, Voorhees, \& Paulson, 2002; Upcraft \& Schuh, 1996). Thirdly, "the issue is not really whether 'assessments' should be made, but rather what is to be the nature, sources, and quality of the evidence on which those judgments are based" (as Terenzini, 1989, p. 651).

\section{Research Question 6:}

How do faculties use assessment results to make program improvements?

Physician Assistant (PA) educators should examine their assessment process and ensure that they:

- Use assessment results to affect constructive changes.

Use Assessment Results to Affect Constructive Changes

As a general recommendation, Physician Assistant (PA) educators, like other faculty members in higher education, "need to think about the kinds of actions that will foster the use of assessment information on their own campuses" (Palomba \& Banta, 1999, p. 303). Additionally, faculty, having considered these actions, must then affect genuine, concrete, evidence-based changes. Depending on the type of data revealed during assessment activities, faculty members at the various PA programs will likely be challenged to affect these changes in some of the following areas:

- programmatic planning and review;

- programmatic budget;

- curriculum development and modification; and

- faculty teaching and student learning.

The use of this data to affect constructive changes will result in assessment being viewed as an authentic tool for programmatic improvement. 


\section{Research Question 7:}

How do faculties communicate assessment results and to what audiences?

Generally, educators should ensure that their programs develop a comprehensive, detailed dissemination plan for distributing assessment results to their various internal and external audiences. To achieve this, it is also recommended that educators consider:

- Increasing the use of various reporting formats.

- Expanding the distribution of assessment results.

Increasing the Use of Various Reporting Formats

Physician Assistant educators, as assessment practitioners, need to select appropriate reporting formats for the corresponding audiences (Erwin, 1996). It is thus recommended that PA educators examine these differing types of reports and consider adopting additional formats with the intent of reaching the wide variety of stakeholders that require differing degrees of assessment information. For example, an annual or comprehensive report is obviously better suited for an accrediting body or institutional administrators than for employers or clinical preceptors. Likewise, small web-based reports or assessment newsletters are excellent formats for increasing public and institutional access to a program's assessment results. To illustrate, an assessment newsletter, even if only circulated along the students, increases that audience's access to how they have contributed to the student learning outcomes assessment effort.

The increased access to a program's assessment efforts has numerous potential direct and indirect benefits. The most obvious of these benefits is the public demonstration that PA educators are simultaneously engaged in satisfying the demands of programmatic accountability and programmatic improvements. Like multiple 
measurements of student learning, efficient multidimensional dissemination of assessment information provides audiences with the most accurate portrayal of this engagement (American Association for Higher Education, 1992; Jonson \& Calhoun, 2000; Pike, 2002).

Expanding the Distribution of Assessment Results

It is further recommended that PA educators consider expanding their distribution of assessment results to include additional valued stakeholders. As noted in the North Central Association of Colleges and Schools' longitudinal study of institutional assessment activities, consistent, timely and accurate reporting on the progress and results of the assessment effort creates and maintains vital feedback loops (Lopez, 1999). In addition to the executives and faculty that are currently receiving assessment data, the following internal stakeholders should be considered for more frequent inclusion in assessment feedback loops:

- students; and

- institutional committees.

As noted in the early part of this chapter, only $45 \%$ of PA program directors report including students in these assessment feedback loops. Given the centrality of students in the assessment effort, it is suggested that this level be increased. Further, a low percentage (25\%) of directors report distributing assessment results to institutional committees. Considering how vital these committees can be in providing essential resources to programmatic assessment efforts, it is highly recommended that faculty interactions, communications, and dissemination of assessment results be expanded. 
In addition to the accrediting bodies currently receiving assessment data from PA educators, several other external audiences also need greater inclusion in PA assessment feedback loops. Some of these stakeholders include:

- professional bodies;

- employers;

- alumni; and

- governmental agencies.

Given the level and importance of support that the above stakeholders can potentially provide PA programs (i.e., guidance, assessment data, funding, etc.), PA faculties should consider increasing their communication with these audiences.

Ultimately, teaching, learning, and assessment are collaborative efforts that rely on a high degree of open communication between stakeholders internal and external to academia (Angelo, 1999; Douglas \& La Voy, 2002; Suskie, 2000; Tiberious, R. G., Sackin, H. D., Slingerland, J.M., Jubas, K., Bell, M., Matlow, A., 1989). Thus, it is imperative that educators share their assessment information in frequent, meaningful ways (Jones, Voorhess, \& Paulson, 2002; Pike, 2002). At their essence, then, these reports are meant to inform stakeholders about the status of student learning in some form; hence these communications should be clear and concise with a solution-oriented approach (Brinko, 1993; Lopez, 1999).

\section{Professional Bodies and Accreditation}

In closing this section of the chapter, important recommendations are offered to the Association of Physician Assistant Programs (APAP) and the Accreditation Review Commission on Education for the Physician Assistant (ARC-PA). These are: 
- Increase faculty development in programmatic assessment.

- Increase programmatic assessment criteria in accreditation process.

Increase Faculty Development in Programmatic Assessment

Given the centrality of Physician Assistant (PA) educators in any programmatic assessment endeavor, it is essential that these faculty members receive the caliber of faculty development discussed throughout this study. In general, it is recommended that this development be emphasized and facilitated by APAP, ARC-PA, and the respective PA programs. In regard to APAPs contribution specifically, it is suggested that the organization consider providing on-going regional assessment workshops. Given that some assessment topics are already offered at workshops during the annual APAP Forum, this recommendation is merely an expansion of an existing theme. These workshops can provide:

- increased access by a greater number of PA faculty members to assessment education and skills development;

- decreased costs associated with travel to other institutions or conferences for assessment education; and

- an indication of how assessment is valued by the professional body that represents PA educators nationwide.

Increase Programmatic Assessment Criteria in Accreditation Process

One of the most important recommendations to emerge as a result of this study is that of recommending that the collective attention to programmatic student learning outcomes assessment needs to evolve further in PA education. To achieve this end, the ARC-PA can play a dominant role in moving the discipline forward. Hence, the ARC- 
PA, in collaboration with the leaders in PA education, should consider increasing the emphasis of programmatic assessment activities in accreditation criteria. It is therefore recommended that criteria be added or modified to clearly articulate the important dimensions of programmatic assessment planning and implementation. These include:

- a formalized assessment program that incorporates guidelines and best practices;

- assessment history, language, culture, and structure;

- on-going faculty development in assessment topics;

- resource acquisition for assessment activities;

- programmatic mission statements, goals, and student learning outcomes (SLOs);

- course-level goals and SLOs;

- comprehensive integration of all learning domains;

- multi-dimensional, longitudinal measures of student learning;

- use of assessment data to affect constructive programmatic improvements;

- inclusive, comprehensive dissemination of assessment results to numerous internal and external stakeholders; and

- an assessment mechanism for improving the programmatic assessment process itself.

These criteria, then, will provide the motivation and potential for PA education to evolve as a result of dynamic leadership, clear guidance, faculty education, and evidence-based decision making about how best to improve PA programs.

\section{Suggestions for Additional Research}

Under this heading, the focus remains on the seven research questions and suggestions are offered as quantitative, qualitative, or mixed-method studies. 


\section{Research Question 1:}

What types of institutional resources are available to conduct assessment?

\section{Quantitative}

Funding assessment costs.

As discussed under Interpretation of Findings and Relationship to Previous Research, this study does not reveal the nature of initial assessment costs at Physician Assistant (PA) programs nor does it disclose the degree to which these costs were funded. Given this circumstance, future researchers may wish to focus on how these initial funds are used by PA program faculties to facilitate the early assessment process. The areas identified in the study conducted by the Middle States Commission on Higher Education (2003) can provide points of focus in an initial investigation of this topic.

There also appears to be a gap between the initial and sustained funding of PA assessment activities. Given that $60 \%$ of survey respondents report receiving "start-up" funding for their assessment efforts, it is curious that $66 \%$ of the PA program directors also report that they are not currently forecasting future assessment costs by line-item in successive budgets. There is, of course, any number of possible explanations for this apparent gap, thus future researchers are encouraged to explore this area. Considering how especially important sustained funding is to the success of any assessment program, this is an issue that should be investigated in the near future.

\section{Qualitative}

Examining leadership and a culture of assessment.

Although this study describes a certain level of executive and senior leader support for assessment activities at Physician Assistant (PA) programs, future research is 
needed to determine the depth and characteristics of this support and how it affects the adoption, planning, and implementation of assessment programs (Lopez, 1999; Maki, 2002).

Additional research is also needed to determine why a culture of assessment seems to exist at only one-third to one-half of the institutions providing data for this study. Future researchers may wish to conduct a qualitative study of those institutional leaders who provide strong support to PA programs. Conversely, researchers may consider focusing on those PA program directors who have gained consistent, long-term executive-level support of their assessment programs. Conducting these investigations can potentially lead to the development of strategies that will assist educators in procuring additional and sustained institutional sponsorship for programmatic assessment activities.

Researchers may also wish to consider exploring the similarities, differences, strengths and limitations between those PA programs that rely on "top-down" and "bottom-up" approaches as they apply to the embracement, planning, and implementation of student learning outcomes assessment at PA programs. Additionally, an exploration of the organizational climate as it pertains to assessment funding may affect whether PA faculties choose active or passive roles in articulating resource requirements for assessment activities. 


\section{Research Question 2:}

How is assessment planning integrated into PA faculty development?

\section{Quantitative}

Future researchers should investigate why the use of internal and external assessment practitioners, experts, and consultants are not a more integral part of assisting Physician Assistant (PA) faculties in their assessment activities. Given the wide range of assessment and assessment-related expertise that exists on and off campus, it is curious that these resources are not being utilized more extensively in assessment-related faculty development at PA program.

An additional opportunity for research exists for investigators who wish to examine the disparities between the differing types of faculty development sessions (i.e., presentation, single- and multi-topic workshops) at PA programs. For example, the PA program directors in this study indicate that short assessment-related presentations are the most common form of development. This, however, leads scholars to ponder if PA educators are being provided sufficient opportunities to apply newly-learned assessment concepts. Future researchers, then, may wish to investigate the differences in assessment program development and implementation levels between those PA programs making extensive, frequent use of workshops for skills integration and those PA programs that rely primarily on presentations.

\section{Qualitative}

A qualitative study between those institutions that provide authentic incentives and rewards systems for faculty involvement in assessment activities and those institutions where these systems are absent should be considered for exploration in the 
near future. Considering the prominence accorded these systems in the literature (Borden, 2002; Jones, 2002; Lopez, 1999; Palomba \& Banta, 1999), researchers may wish to determine if there are successful strategies that PA directors can pursue to acquire these systems for their faculties.

\section{Research Question 3:}

What programmatic student learning outcomes are used by PA educators?

\section{Mixed-Method}

The research data reveals that nearly a quarter of the Physician Assistant (PA) programs in this study do not have fully implemented programmatic goals. What factors are preventing implementation? What affect is this having on programmatic and courselevel student learning outcomes? To explore these and other related questions, future researchers should consider using a mixed-method study design featuring a survey instrument, interviews, and document analysis to determine cause, effect, and recommendations.

\section{Research Question 4:}

How are student learning outcomes integrated into PA program courses?

\section{Mixed-Method}

Future research is needed to investigate the relationships between regional accrediting bodies (e.g., North Central Association of Colleges and Schools), the professional accrediting body (i.e., Accreditation Review Commission on Education for the Physician Assistant [ARC-PA]), the professional education organization (i.e., Association of Physician Assistant Programs [APAP]), and the respective institutions as they apply to the successful implementation of effective student learning outcomes at 
individual Physician Assistant (PA) programs. An investigation of these forces and their individual and collective affects on PA faculties may provide valuable insights on how these same forces can be harnessed to achieve successes in the planning and implementation of other assessment program components (e.g., reporting results, gaining resources). Investigators may wish to utilize surveys, interviews, and sample analysis to explore these forces.

\section{Quantitative}

Additional research is also suggested regarding PA program integration of learning domains in student learning outcomes (SLOs). For example, what is the collective knowledge-base of PA educators in regard to Bloom's Taxonomy (1956) and its subsequent application in crafting SLOs. What faculty development occurs to facilitate this PA faculty knowledge acquisition and skill integration? Additionally, it is important that researchers examine the prevalence and depth of understanding and application of Bloom's sub-domains (e.g., Knowledge: analysis; Affective: responding; Psychomotor: manipulation) in the formulation of PA program SLOs. Lastly, do educators integrate these domains across the entire curriculum throughout the course to achieve progressively higher levels of learning?

\section{Research Question 5:}

What measurement instruments do PA educators use in the assessment of their

$$
\text { programs? }
$$

\section{Mixed-Method}

In this study, $88 \%$ of Physician Assistant (PA) program directors indicate that they seldom or never use portfolios to measure learning in their programs. They also 
report that they seldom or never use products $(64 \%)$, poster presentations $(55 \%)$, and problem sets $(52 \%)$. Given the importance of developing a multi-dimensional picture of student learning through the utilization of numerous direct and indirect instruments over time, researchers should examine why more of these instruments are not being used more frequently at PA programs.

\section{Research Question 6:}

How do faculties use assessment results to make program improvements?

Mixed-Method

Forty percent of Physician Assistant (PA) program directors report that assessment results are not yet used to justify the acquisition of increased budgets. Given the sine qua non of resource acquisition in the successful planning, implementation, and sustaining efforts of student learning assessment programs, an investigation is needed to examine those factors that are affecting why directors are not using results to gain budget increases.

\section{Research Question 7:}

How do faculties communicate assessment results and to what audiences?

\section{Quantitative}

Research is needed to explore why only about one-third of Physician Assistant (PA) program directors are using reporting formats other than comprehensive and annual reports. Additionally, is there any correlation between the use of these formats and the internal and external audiences communicated with most frequently? Lastly, with the lone exception of accrediting bodies, many PA program directors are not communicating assessment results to most of the stakeholders identified in this study. Researchers need to examine this trend. 


\section{Conclusion}

Today's assessment movement in higher education has been evolving since the mid-1980s (Evenbeck \& Kahn, 2001; Ewell, 2002). Throughout this time period, numerous educators and researchers in a variety of disciplines have examined multiple aspects of student learning outcomes assessment and related topics. As a result of these efforts, the assessment movement and its affects at institutions of higher education have evolved at varying rates in numerous directions.

Some faculties, like the one at Alverno College, created a culture of assessment early in the movement (Alverno College, 2003a). Today, assessment activities are pervasive and thriving at this institution (Alverno College, 2003b, 2003c; Palomba \& Banta, 1999). Additionally, some disciplines, like business and nursing, have been quick to use assessment practices in their programmatic improvement, faculty teaching and student learning (Elon University, 2003; Jones, 2002).

The affects of these assessment research efforts and applications continue to influence numerous levels of education, educators, and students. The examination, analysis, and synthesis of where Physician Assistant (PA) education lies along the assessment continuum seems to indicate that this discipline is early in its evolution. There is, however, considerable promise associated with this stage of development. The leadership within the discipline and at the respective PA programs has the opportunity to capitalize on the experiences and research of assessment practitioners and scholars to date.

The examination of assessment-related publications by PA researchers during this study indicates that certain aspects of assessment, such as student learning outcomes, 
have received considerable attention from PA leaders and educators (Glicken, 2002; Glicken \& Blessing, 1998; Stuetzer, 1999). Additionally, this study illustrates that individual PA programs are demonstrating assessment strengths in other areas of assessment such as faculty development and using results to affect programmatic improvements.

There remain, however, a number of assessment challenges to address in higher education and in PA education as well (Shipman, Aloi, \& Jones, in press). For example, PA educators need to more fully develop and implement their assessment plans and programs. When this occurs, the benefits of the added assessment components such as increased funding, stakeholder integration, and multidimensional learning will provide programmatic improvements at all levels.

At the outset of this research endeavor, the investigator's purpose was to: (a) add additional assessment-related knowledge to the field of education and most specifically to PA education; (b) provide synthesized feedback to PA educators nationwide on the current assessment practices of their peers; and (c) establish a baseline for the profession by identifying where PA education is currently located along the programmatic assessment continuum in higher education. Physician Assistant educators nationwide can use the recommendations from this study for the betterment of their programs, themselves, and their students.

At its very core, programmatic student learning outcomes assessment is about using data for the purpose of continuously improving faculty teaching and student learning (American Association for Higher Education, 1992; Huba \& Freed, 2000; Middle States Commission on Higher Education, 2003; Peterson \& Vaughan, 2002). 
Ultimately, this researcher has heard and humbly submits this study for the following Physician Assistant directors and others like them:

- "The assessment plan is in place, but is inconsistently used."

- "We don’t do a very good job of assessment."

- "We put a lot effort into assessing and would like to make more progress in how to apply assessment results."

- "Our assessment process is an ongoing process - always evolving and hoping for perfection." 


\section{REFERENCES}

Accreditation Review Commission on Education for the Physician Assistant. (2002). Accreditation standards for Physician Assistant education. Retrieved August 13, 2003, from http://www.arc-pa.org/General/standards/standards01.pdf

Accreditation Review Commission on Education for the Physician Assistant. (2003). Accredited Programs. Retrieved October 11, 2003, from http://www.arcpa.org/General/AccreditedPrograms.html

Alderson-Broaddus College Physician Assistant Program. (2003). Assessment plan. Philippi, WV: Alderson-Broaddus College.

Allen, J., \& Bresciani, M. J. (2003). Public institutions, public challenges. Change, 35(1), 20-24.

Alstete, J. (2000). Post tenure faculty development: Building a system of faculty improvement and appreciation. Washington, DC: George Washington University, Graduate School of Education and Human Development (ERIC Identifier: ED440603).

Altbach, P. A. (1994). Problems and possibilities: The American academic profession. In P. G. Altbach, R. O. Berdahl, \& P. A. Gumport, (Eds.), Higher education in American society (3rd ed., pp. 225-247). Amherst, NY: Prometheus Books.

Alverno College. (2003a). For educators. Retrieved March 26, 2004, from Alverno College Web site, http://www.alverno.edu/for_educators.html

Alverno College. (2003b). Learning outcomes studies educational research and evaluation. Retrieved March 26, 2004, from Alverno College Web site: http://www.alverno.edu/for_educators/ere_research.html 
Alverno College. (2003c). Student Assessment-as-Learning. Retrieved March 26, 2004, from Alverno College Web site: http://www.alverno.edu/for_educators/student_as_learn.html

American Academy of Physician Assistants. (2003). Physician Assistant programs. Retrieved October 3, 2003, from http://www.aapa.org/pgmview.php3?

American Association for Higher Education. (1992). Principles of good practice for assessing student learning. Washington, DC: Author.

Angeles, P. A. (1981). Dictionary of philosophy. New York: Barnes \& Noble.

Angelo, T. A. (1999, May). Doing assessment as if learning matters most. AAHE Bulletin, 51(9), 3-6.

Aper, J. P., \& Hinkle, D. E. (1991). State policies for assessing student outcomes: A case study with implications for state and institutional authorities. Journal of Higher Education, 62(5), 539-555.

Association of Physician Assistant Programs. (2002). APAP faculty directory 2002: Membership listing and resource manual. Alexandria, VA: Author.

Association of Physician Assistant Programs. (2003). APAP 2003 Educational Forum and Exhibition. Retrieved August 13, 2003, from http://www.apap.org/

Association of Physician Assistant Programs Research Institute. (2003, May). APAP Research Institute announces 2003 APAP Small Grants Program. Retrieved June 1, 2003 from http://www.apap.org/0503docs/0503smallgrants.htm Astin, A. W. (1991). Assessment for excellence: The philosophy and practice of assessment and evaluation in higher education. New York: MacMillian. 
Banta, T. W. (2002). Characteristics of effective outcomes assessment: Foundations and examples. In T.W. Banta \& Associates, Building a scholarship of assessment (pp. 261-283). San Francisco: Jossey-Bass.

Banta, T. W., \& Kuh, G. D. (1998). A missing link in assessment. Change, 30(2), 40-47.

Banta, T. W., Lund, J. P., Black, K. E., \& Oblander, F. W. (1996). Assessment in practice: Putting principles to work on college campuses. San Francisco: JosseyBass.

Bennion, D. H. (2002). When discussing assessment, we need to define our terms. Assessment Update, 14(3), 5, 15.

Birnbaum, R. (1988). How colleges work: The cybernetics of academic organization and leadership. San Francisco: Jossey-Bass.

Blessing, J. D. (1999). Looking back at looking forward. Perspectives on Physician Assistant Education, 10(3), 144-148.

Bloom, B. S. (Ed.). (1956a). Taxonomy of educational objectives: The classification of educational goals. Handbook I, Cognitive domain. New York: David McKay.

Bloom, B. S. (Ed.). (1956b). Taxonomy of educational objectives: The classification of educational goals. Handbook II, Affective domain. New York: David McKay.

Bloom, B. S., Mesia, B. B., \& Krathwohl, D. R. (1964). Taxonomy of educational objectives (Vols. 1-2). New York: David McKay.

Boland, D. L., \& Laidig, J. (2001). Assessment of student learning in the discipline of nursing. In C. A. Palomba \& T. W. Banta (Eds.), Assessing student competence in accredited disciplines: Pioneering approaches to assessment in higher education (pp. 71-94). Sterling, VA: Stylus. 
Borden, V. M. H. (2002). Information support for assessment. In T. W. Banta \& Associates, Building a scholarship of assessment (pp. 167-181). San Francisco: Jossey-Bass.

Borg, W. R., Gall, J. P., \& Gall, M. D. (1993). Applying educational research: A practical guide. White Plains, NY: Longman.

Brinko, K. T. (1993). The practice of giving feedback to improve teaching: What is effective? Journal of Higher Education, 64(5), 574-593.

Callan, P. M., \& Finney, J. E. (2002). Assessing educational capital. Change, 34(4), 2431.

Carnegie Foundation for the Advancement of Teaching. (2000). List of institutions by Carnegie classification, control, and state. Retrieved October 13, 2003, from http://www.carnegiefoundation.org/Classification/CIHE2000/PartIfiles/partI.htm

Carrington, P. H. (1998). The academic medicine elective rotation: One potential method to meet Physician Assistant faculty development and recruitment demands. Perspectives on Physician Assistant Education, 9(2), 103-106.

Cherry, R. D., \& Meyer, P. R. (1993). Reliability issues in holistic assessment. In M. M. Williamson and B. A. Hout (Eds.), Validating holistic scoring for writing assessment: Theoretical and empirical foundations (pp. 109-141). Cresskill, NJ: Hampton Press.

Cottrell, S. A., \& Jones, E. A. (2002). A snapshot of scholarship of teaching and learning initiatives: Using assessment results to improve student learning and development. Assessment Update, 14(3), 6-7. 
Creswell, J. W., Plano Clark, V. L., Gutmann, M. L., \& Hanson, W. E. (2003). Advanced mixed methods research designs. In A. Tashakkori and C. Teddlie (Eds.), Handbook of mixed methods in social \& behavioral research. Thousand Oaks, CA: Sage.

Cross, K. P., \& Steadman, M. H. (1996). Classroom research: Implementing the scholarship of teaching. San Francisco: Jossey-Bass.

Cunningham, P. (2002, April 15). Assessment at Rivier College: Administrative and educational support. Retrieved August 24, 2003, from Rivier College, Administrative and Educational Support Assessment Web site: http://www.rivier.edu/departments/assessment/AES.htm

Douglas, K., \& La Voy, S. A. (2002). The campus assessment working group: A collaborative approach to meeting escalating assessment needs in higher education. Assessment Update, 14(3), 1-2, 10-11.

Denzin, N. K. (1978). The research act: A theoretical act: A theoretical introduction to sociological methods (2nd ed.). New York: McGraw-Hill.

Eble, K. E., \& McKeachie, W. J. (1985). Improving undergraduate education through faculty development: An analysis of effective programs and practices. San Francisco: Jossey-Bass.

Educational Testing Service. (2003). What we do. Retrieved October 11, 2003, from http://www.ets.org/aboutets/wedo.html

El-Khawas, E. (1995). Campus Trends (Higher Education Panel Report No. 85). Washington, DC: American Council on Education. 
Elon University. (2003). Self-evaluation report. Elon, North Carolina: Elon University, Martha and Spencer Love School of Business.

Erwin, T. D. (1996). Assessment, evaluation, and research. In S. R. Komives, D. B. Woodard, and Associates, Student services: A handbook for the profession (3rd ed.), pp. 415-431. San Francisco: Jossey-Bass.

Erwin, T. D. (2000a). The NPEC sourcebook on assessment (Vol. 1), (NCES 2000-172). Washington, DC: U.S. Department of Education, National Center for Education Statistics.

Erwin, T. D. (2000b). The NPEC sourcebook on assessment (Vol. 2), (NCES 2000-172). Washington, DC: U.S. Department of Education, National Center for Education Statistics.

Evenbeck, S., \& Kahn, S. (2001). Enhancing learning assessment and accountability through communities of practice. Change, 33(3), 24-34.

Ewell, P. T. (1987). Assessment: Where are we now? Change, 19, $23-28$.

Ewell, P. T. (1991). To capture the ineffable: New forms of assessment in higher education. In G. Grant (Ed.), Review of research in education (No. 17). Washington, DC: American Educational Research Association.

Ewell, P. T. (1997). Organizing for learning: A new imperative. AAHE Bulletin, 50(4), 36.

Ewell, P. T. (2002). An emerging scholarship: A brief history of assessment. In T. W. Banta \& Associates, Building a scholarship of assessment (pp. 3-25). San Francisco: Jossey-Bass.

Ewell, P. T. (2003). Assessment (again). Change, 35(1), 4-6. 
Fasser, C. M., \& Matelli, G. (1999). Conceptualization and design of a comprehensive protocol for program performance evaluation. Perspective on Physician Assistant Edcuation, 10(1), 17-22.

Fraenkel, J. R., \& Wallen, N. E. (2003). How to design and evaluate research in education (5th ed.). New York: McGraw-Hill.

Friedman, D., \& Hoffman, P. H. (2001). The politics of information. Change, 33(3), 5058.

Gaff, J.G.. Ratcliff, J.L., and Associates. (1996 ). Handbook of the undergraduate curriculum. San Francisco: Jossey-Bass.

Gardner, J. N., Van der Veer, G., \& Assoc. (1998). The senior year experience: Facilitating integration, reflection, closure, and transition. San Francisco: JosseyBass.

Garrison, B. (2000, August 10). Educators learn all about faculty development. Update, 19(37), p. 1.

Glatthorn, A. A. (1998). Writing the winning dissertation: A step-by-step guide. Thousand Oaks, CA: Corwin Press.

Glicken, A. (2002). PA education in an evolving health care system. JAAPA: The Official Journal of the American Academy of Physician Assistants, 15(10), 16-26.

Glicken, A. D., \& Blessing, D. (1998). Faculty development needs assessment. Perspectives on Physician Assistant Education, 9(2), 97-99.

Gray, P. J. (2002). The roots of assessment. In T. W. Banta \& Associates, Building a scholarship of assessment (pp. 49-66). San Francisco: Jossey-Bass. 
Gronland, N. E. (1999). How to Write and Use Instructional Objectives (6th Edition). Englewood Cliffs, NJ: Prentice Hall

Huba, M. E., \& Freed, J. E. (2000). Learner-centered assessment on college campuses: Shifting the focus from teaching to learning. Boston: Allyn and Bacon.

Hutchings, P., \& Marchese, T. (1990). Watching assessment: Questions, stories, prospects. Change, 22(5), 12-38.

Jacobs, L. C. \& Chase, C. I. (1992). Developing and using tests effectively. San Francisco: Jossey-Bass.

Johnson, B., \& Turner, L. A. (2003). Data collection strategies in mixed methods research. . In A. Tashakkori and C. Teddlie (Eds.), Handbook of mixed methods in social \& behavioral research. Thousand Oaks, CA: Sage.

Jones, E. A. (2002). Transforming the curriculum: Preparing students for a changing world [Monograph]. ASHE-ERIC Higher Education Report, 29(3).

Jones, E. A., Voorhees, R. A., \& Paulson, K. (2002). Defining and assessing learning: Exploring competency-based initiatives (NCES 2002-159). Washington, DC: U.S. Department of Education, National Center for Education Statistics.

Jonson, J. L., \& Calhoun, T. C. (2000). Making outcomes assessment work for UNL. Retrieved August 16, 2003, from University of Nebraska, Universitywide Assessment Office Web site: http://www.unl.edy/svcaa/priorities/assessment/outcomes/sld001.htm Kent State University, Office of Academic Assessment. (n.d.). Six steps to continuous improvement of student learning: A guide to support the assessment process. 
Retrieved August 16, 2003, from Kent State University, Office of Academic Assessment Web site: http://www.us.kent.edu/aa/guide/default.html

Kuh, G. D., Gonyea, R. M., \& Rodriguez, D. P. (2002). The scholarly assessment of student development. In T. W. Banta and Associates, Building a scholarship of assessment (pp. 100-127). San Francisco: Jossey-Bass.

Licklider, B. L., Schnelker, D. L., \& Fulton, C. (1997). Revisioning faculty development for changing times: The foundation and framework. Journal of Staff, Program, and Organizational Development, 9(1), 121-133.

Lopez, C. L. (2000). A decade of assessing student learning: What we have learned; What's next? Chicago: North Central Association of Colleges and Schools.

Major, C. L., \& Jones, E. A. (2001). Using course evaluations to improve a problembased learning program. Journal of Faculty Development, 18(3), 83-90.

Maki, P. (2002, January 15). Using multiple assessment methods to explore student learning and development inside and outside of the classroom. NASPA NetResults. Retrieved March 28, 2003, from http://www.naspa.org/NetResults/article.cfm?ID=558

Maki, P. L. (in press). Developing an assessment plan to learn about student learning. Journal of Academic Librarianship.

Maxwell, J. A. (1996). Qualitative research design. Thousand Oaks, CA: Sage.

McCarty, J. E., Stuetzer, L. J., \& Somers, J. E. (2001). Physician Assistant program accreditation. Perspectives on Physician Assistant Education, 12(1), 24-38.

Middle States Commission on Higher Education. (2003). Student learning assessment: Options and resources. Philadelphia: Author. 
Miller, M. A. (2001a). How are we doing? Change, 33(2), 4.

Miller, M. A. (2001b). Measuring up on college-level learning (National Forum on College-Level Learning). Purchase, NY: National Forum on College-Level Learning.

Morgan, D. L. (1997). Practical strategies for combining qualitative and quantitative methods. Portland, OR: Portland State University.

Morse, J. M. (2003). Principles of mixed methods and multimethod research design. In

A. Tashakkori and C. Teddlie (Eds.), Handbook of mixed methods in social \& behavioral research. Thousand Oaks, CA: Sage.

National Center for Postsecondary Improvement. (1998). Tracking a subtle storm: Assessment policies in higher education. Change, 2(2), 47-50.

National Center for Postsecondary Improvement. (1999). Revolution or evolution? Gauging the impact of institutional student assessment strategies. Change, 31(5), $53-56$.

National Center for Public Policy and Higher Education. (2000). Measuring up 2000: The state-by-state report card for higher education. Washington, DC: Author.

National Center for Public Policy and Higher Education. (2002). Measuring up 2002: The state-by-state report card for higher education. Washington, DC: Author.

Nichols, J. O. (1995). A practitioner's handbookfor institutional effectiveness and student outcomes assessment implementation (3rd ed.). New York: Agathon Press, 1995. 
Palomba, C. A. (2002). Scholarly assessment of student learning in the major and general education. In T. W. Banta \& Associates, Building a scholarship of assessment (pp. 201-222). San Francisco: Jossey-Bass.

Palomba, C. A., \& Banta, T. W. (1999). Assessment essentials: Planning, implementing, and improving assessment in higher education. San Francisco: Jossey-Bass.

Patton, M. Q. (2003). Qualitative research \& evaluation methods (3rd ed.). London: Sage Publications.

Peterson, J. (1996). The big picture - A four-year cycle for institutional effectiveness at Dixie College. Retrieved August 24, 2003, from Dixie College, Office of Institutional Effectiveness Web Site: http://www.dixie.edu/effective/fouryear.htm

Peterson, M. W., \& Vaughan, D. S. (2002). Promoting academic improvement: Organization and administrative dynamics that support student assessment. In T. W. Banta \& Associates, Building a scholarship of assessment (pp. 26-46). San Francisco: Jossey-Bass.

Peterson, M. W., Vaughan, D. S., \& Perorazio, T. E. (2001). Student assessment in higher education: A comparative study of seven institutions. Ann Arbor, MI: University of Michigan, National Center for Postsecondary Improvement.

Pike, G. R. (2002). Measurement issues in outcomes assessment. In T. W. Banta \& Associates, Building a scholarship of assessment (pp. 131-147). San Francisco: Jossey-Bass.

Professional and Organizational Development Network in Higher Education. (2002). What is faculty development? Retrieved August 13, 2003, from http://www.podnetwork.org/development/definitions.htm 
Professional and Organizational Development Network in Higher Education. (2004). Call for proposals. Retrieved March 22, 2004, from http://atech2.wku.edu/skuhlens/podsubmit/callforproposals2004.html\#qualities

Rodrigues, R. J. (2002, September). Want campus buy-in for your assessment efforts? AAHE Bulletin.com. Retrieved April 3, 2003, from American Association for Higher Education Web site: http://aahebulletin.com/member/articles/2002-10feature02_pf.asp?pf=1

Schulman, E. D., Fabringer, D. A., \& Skaff, K. O. (1999). Systematic practicum evaluation for program improvement. Perspective on Physician Assistant Education, 10(4), 194-198.

Shipman, D. G., Aloi, S. L., \& Jones, E. A. (in press). Addressing key challenges in higher education assessment. Journal of General Education.

Spady, W. G. (1995). Outcome-based education: Critical issues and answers. Arlington, VA: The American Association of School Administrators.

Stake, R. E. (1973, October). Program evaluation particularly responsive evaluation. Paper presented at the New Trends In Evaluation symposium, Goteborg, Sweden. Retrieved November 21, 2003, from http://www.wmich.edu/evalctr/pubs/ops/ops05.pdf

Stark, J. S., \& Lattuca, L. R. (1997). Shaping the college curriculum: Academic plans in action. Boston: Allyn \& Bacon.

Stroup, K. (2002). Missouri: An assessment consortium. SHEEO Network News, 21(1), 6-7. 
Stuetzer, L. (1999). Instructional objectives to guide student learning. Perspective on Physician Assistant Education, 10(4), 223-224.

Suskie, L. A. (1996). Questionnaire survey research: What works (2nd ed.). Tallahassee, FL: Association of Institutional Research.

Suskie, L. (2000). Fair assessment practices: Giving students equitable opportunities to demonstrate learning. AAHE Bulletin, 52(9), 7-10.

Tam, M. (2001). Measuring quality and performance in higher education. Quality in Higher Education, 7(1), 47-54.

Tashakkori, A., \& Teddlie, C. (Eds.). (2003). Handbook of mixed methods in social \& behavioral research. Thousand Oaks, CA: Sage.

Terenzini, P. T. (1989). Assessment with open eyes: Pitfalls in studying student outcomes. Journal of Higher Education, 60(6), 644-664.

The University of Mississippi. (2003a). Bloom's taxonomy: Affective domain. Retrieved September 9, 2003, from The University of Mississippi, School of Education Web site: http://www.olemiss.edu/depts/educ_school2/docs/stai_manual/manual9.htm

The University of Mississippi. (2003b). Bloom's taxonomy: Psychomotor domain. Retrieved September 9, 2003, from The University of Mississippi, School of Education Web site: http://www.olemiss.edu/depts/educ_school2/docs/stai_manual/manual10.htm

Tiberious, R. G., Sackin, H. D., Slingerland, J.M., Jubas, K., Bell, M., Matlow, A. (1989). The influence of student evaluative feedback on the improvement of clinical teaching. Journal of higher education, 60(6), 665-681.

Tuckman, B. W. (1999). Conducting educational research. New York: Harcourt Brace College. 
Upcraft, M. L., \& Schuh, J. H. (1996). Assessment in student affairs: A guide for practitioners. San Francisco: Jossey-Bass.

Wiersma, W. (1995). Research methods in education (6th ed.). Boston: Allyn \& Bacon. Wiggins, G. (1990). The case for authentic assessment. ERIC Clearinghouse on Tests Measurement and Evaluation. Washington, DC: American Institutes for Research. (ERIC Document Reproduction Service No. ED328611)

Zusman, A. (1994). Current and emerging issues facing higher education in the United States. In P. G. Altbach, P. O. Berdahl, \& P. A. Gumport, (Eds.), Higher education in American society (pp. 335-364). Amherst, NY: Prometheus Books. 


\section{APPENDIX A}

Survey Instrument:

A Survey of Internal Programmatic Assessments Implemented by

Physician Assistant Educators 


\section{A Survey of Internal Programmatic Assessments Implemented by}

Survey \#

\section{Physician Assistant Educators}

This survey is designed to elicit information about the assessment process at your program. In this survey, assessment is defined by Huba and Freed (2000) as "the process of gathering and discussing information from multiple and diverse sources in order to develop a deep understanding of what students know, understand, and can do with their knowledge as a result of their educational experiences; the process culminates when assessment results are used to improve subsequent learning” (p. 80).

\section{Demographic Information}

- Number of full-time faculty:

Number of part-time faculty:

- Number of students currently enrolled in your program:

- Average number of students that graduate from your program annually:

- How long has your program been accredited?

- When did your program receive its last accreditation from ARC-PA?

\section{Survey Questions}

Please review each statement below and indicate your responses. Please mark only one response per statement.

Gaining Institutional Resources for Assessment.

1. Our assessment effort has executive-level support.....
Strongly

Agree Agree

$\mathrm{O}$

$\mathrm{O} \quad \mathrm{O}$

$\mathrm{O}$
Strongly

Disagree

2. Our institutional leaders provide an assessment culture characterized by the following: (Please mark all that apply)

O Direct involvement in the assessment process

O Meeting regularly with assessment personnel

O Maximizing honest, open, two-way communication

O Establishing an environment based on trust

O Treating faculty, staff, and administrators as collaborators in a team effort

O Demonstrating a commitment to assessment by providing real incentives for participation and support (e.g., time, teaching loads, grants, stipends, students)

$\mathrm{O}$ Encouraging assessment personnel use a deliberate planning process

$\mathrm{O}$ Encouraging slow, incremental changes thereby increasing chances for success

$\mathrm{O}$ Approving the integration of assessment and budget 
3. Our program has articulated projected resource

expenditures for assessment at senior levels

$\begin{array}{lll}\text { Strongly } & \text { Strongly } \\ \text { Agree Agree } & \text { Disagree } & \text { Disagree }\end{array}$

4. Our leaders have allocated resources for initial

assessment costs...

5. Our continuing assessment costs are forecasted by lineitem in successive budgeting cycles....

$\mathrm{O} \quad \mathrm{O} \quad \mathrm{O} \quad \mathrm{O}$

$\mathrm{O}=\mathrm{O} \quad \mathrm{O} \quad \mathrm{O}$

6. Our program has a set of guiding principles that address the budgeting for our assessment process

$\mathrm{O}-\mathrm{O}-\mathrm{O}$

$\mathrm{O}$

If possible, please include a sample of these guiding principles when you return your survey.

\section{Faculty Development in Assessment.}

7. Our faculty are the essential human resource in our assessment effort

8. On-campus experts teach our assessment sessions.......

9. Off-campus experts teach our assessment sessions......

$\begin{array}{lll}\text { Strongly } & \text { Strongly } \\ \text { Agree Agree Disagree } & \text { Disagree }\end{array}$

$\mathrm{O} \quad \mathrm{O} \quad \mathrm{O} \quad \mathrm{O}$

Monthly Quarterly Bi-annually Annually Never

10. During the last academic year, how often have these types of assessment sessions been offered:

(Please mark all that apply)

- Formal presentations

- Hands-on, interactive, single topic workshops...

- Hands-on, interactive, multi-topic workshops...

- Other:
1

$\mathrm{O}$

$\mathrm{O}$

$\mathrm{O}$

$\mathrm{O}$
$2-3$

O

O

$\mathrm{O}$

O
4-5

O

$\mathrm{O}$

O

O
$5+$

O

O

$\mathrm{O}$

$\mathrm{O}$
Never

O

O

$\mathrm{O}$

11. Our faculty development sessions have addressed: (Please mark all that apply)
O Assessment philosophy
O Assessment language
O Gaining institutional resources
O Faculty development \& assessment
O Student learning outcomes
O Instruments for measuring learning
O Using assessment results to affect change
O Reporting assessment results
O Other:

12. During the last academic year, how many of your faculty have attended faculty development sessions on assessment? 


\begin{tabular}{|c|c|c|c|c|}
\hline & \multicolumn{3}{|l|}{ Strongly } & Strongly \\
\hline & Agree & Agree & Disagree & Disagree \\
\hline 3. Our faculty roles in assessment are well-defined...... & $\mathrm{O}$ & $\mathrm{O}$ & $\mathrm{O}$ & $\mathrm{O}$ \\
\hline Our faculty expectations in assessment are $\mathrm{v}$ & $\mathrm{O}$ & $\mathrm{O}$ & $\mathrm{O}$ & $\mathrm{O}$ \\
\hline
\end{tabular}

15. The following are often used as incentives to increase faculty participation in the assessment effort: (Please mark all that apply)
O Small grants (less than $\$ 2000$ )
O Large grants (more than $\$ 2000$ )
O Stipends
O Time
O Travel to assessment conferences

O Travel to other institutions

O Graduate assistant / student

O Other:

O None (If none, please proceed to question 18)

16. In the past year, how many of your faculty have received these incentives?

If possible, please include a sample of materials that describe your faculty incentives for participation in assessment activities when you return your survey.

17. Our faculty members are rewarded for their assessment efforts through a system that includes:

(Please mark all that apply)

Intrinsic-

$\mathrm{O}$ Increased interaction with other faculty members

$\mathrm{O}$ Increased interaction with faculty members from other institutions

$\mathrm{O}$ Increased understanding of institutional linkages

$\mathrm{O}$ Knowing that assessment results will not be used against them

O Other:

Extrinsic-

O Personal expressions of gratitude from institutional leaders

O Public expressions of gratitude from institutional leaders

O Letters of commendation for personal files

$\mathrm{O}$ Inclusion of participation in the promotion and tenure process

$\mathrm{O}$ Publication of assessment results in journals and books

O Presentations at national conferences

O Other:

18. Faculty resistance to assessment is an issue in our program... $\mathrm{O} \quad \mathrm{O} \quad \mathrm{O} \quad \mathrm{O}$ 


\section{Programmatic Student Learning Outcomes (SLOs).}

19. Our programmatic mission statement is in alignment with our institutional mission statement.

$$
\begin{array}{lll}
\text { Strongly } & \text { Strongly } \\
\text { Agree Agree } & \text { Disagree } & \text { Disagree }
\end{array}
$$

$\mathrm{O} \quad \mathrm{O} \quad \mathrm{O} \quad \mathrm{O}$

- Goals communicate intended educational results in general terms. For example, Palomba and Banta (1999) describe goals as "broad learning concepts such as clear communication, problem solving, and ethical awareness" (p. 26).

$\begin{array}{lll}\text { Strongly } & \text { Strongly } \\ \text { Agree Agree Disagree } & \text { Disagree }\end{array}$

20. Our programmatic goals are developed in accordance with our mission statement

21. Our programmatic goals are clear

22. Our programmatic goals are shared

23. Our programmatic goals are fully implemented.........

- Huba and Freed (2000) define student learning outcomes as the kinds of things that students know or can do after instruction that they did not know or could not do before the instruction. There are three major foci in regard to these outcomes: cognitive, affective, and psychomotor.

24. Our programmatic student learning outcomes express intended outcomes in precise terms.

25. Our programmatic student learning outcomes are developed in collaboration with other faculty members...

26. Our programmatic student learning outcomes manifest the vision identified in the mission statement

$\mathrm{O} \quad \mathrm{O} \quad \mathrm{O}$

If possible, please include a sample of your programmatic goals and student learning outcomes when you return your survey.

\section{Student Learning Outcome Integration}

27. Our course learning outcomes are student-focused rather than professor-focused

$\mathrm{O}$

28. Our course learning outcomes focus on the learning resulting from an activity rather than on the activity itself

29. Our course learning outcomes reflect the institution's mission and the values it represents.
Strongly

Agree Agree Disagree

Strongly

$\mathrm{O}$

$\begin{array}{lll}\text { Strongly } & & \text { Strongly } \\ \text { Agree Agree } & \text { Disagree } & \text { Disagree }\end{array}$

O $\quad \mathrm{O} \quad \mathrm{O}$

O $\quad \mathrm{O} \quad \mathrm{O} \quad \mathrm{O}$

$\begin{array}{llll}\mathrm{O} & \mathrm{O} & \mathrm{O} & \mathrm{O}\end{array}$

O $\mathrm{O} \quad \mathrm{O}$

$\mathrm{O} \quad \mathrm{O} \quad \mathrm{O} \quad \mathrm{O}$ 
30. Our learning outcomes are in alignment at the course, academic program, and institutional levels.

Strongly

Agree Agree

$\mathrm{O} \quad \mathrm{O} \quad \mathrm{O}$

$\mathrm{O} \quad \mathrm{O} \quad \mathrm{O}$

$\mathrm{O}$

non-trivial aspects of learning that are credible to the public

32. Our course learning outcomes focus on skills/abilities central to the discipline.

33. Our course learning outcomes are general enough to capture important learning but clear and specific enough to be measurable.

34. Our course learning outcomes focus on aspects of learning that will develop and endure but that can be assessed in some form now...

35. Our course learning outcomes focus on cognitive dimensions (e.g., knowledge, analysis, synthesis).

36. Our course learning outcomes focus on affective dimensions (e.g., attitudes, values, emotions).

37. Our course learning outcomes focus on psychomotor dimensions (e.g., coordination, performance abilities)....

$\begin{array}{llll}\mathrm{O} & \mathrm{O} & \mathrm{O} & \mathrm{O}\end{array}$

$\mathrm{O} \quad \mathrm{O} \quad \mathrm{O} \quad \mathrm{O}$

$\mathrm{O} \quad \mathrm{O} \quad \mathrm{O} \quad \mathrm{O}$

$\mathrm{O} \quad \mathrm{O} \quad \mathrm{O} \quad \mathrm{O}$

$\mathrm{O} \quad \mathrm{O} \quad \mathrm{O} \quad \mathrm{O}$

$\begin{array}{llll}\mathrm{O} & \mathrm{O} & \mathrm{O} & \mathrm{O}\end{array}$

If possible, please include a sample of your course student learning outcomes when you return your survey.

\section{Measuring Student Learning.}

38. Our program uses commercially-developed instruments

39. Our program uses locally-developed instruments

$\begin{array}{llll}\text { Frequently } & \text { Sometimes } & \text { Seldom } & \text { Never } \\ \mathrm{O} & \mathrm{O} & \mathrm{O} & \mathrm{O} \\ \mathrm{O} & \mathrm{O} & \mathrm{O} & \mathrm{O}\end{array}$

40. During the past year, our program has used the following direct, course-embedded assessment techniques. (Please mark all that apply.)

- Written examinations...............................

- Presentations.....................................

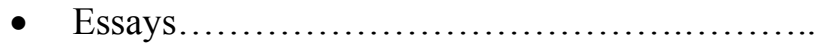

- Case studies and simulations......................

- Products.... Frequently Sometimes Seldom Never

- Poster presentations.................................

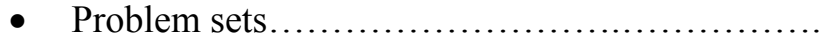

- Oral examinations................................

- Portfolios.

$\mathrm{O}$

$\mathrm{O}$

$\mathrm{O}$

$\mathrm{O}$

$\mathrm{O}$

$\mathrm{O}$

$\mathrm{O}$

$\mathrm{O}$

O

$\mathrm{O}$

$\mathrm{O}$

$\mathrm{O}$

$\mathrm{O}$

0

O

O

O

O

$\mathrm{O}$

O

$\mathrm{O}$

$\mathrm{O}$

$\mathrm{O}$

O

$\mathrm{O}$

$\mathrm{O}$

$\mathrm{O}$

O

$\mathrm{O}$

$\mathrm{O}$

$\mathrm{O}$

$\mathrm{O}$

$\mathrm{O}$

$\mathrm{O}$

O

- Capstones, practicums, and internships....

$\mathrm{O}$

$\mathrm{O}$

$\mathrm{O}$

O

- Other

$\mathrm{O}$

O

$\mathrm{O}$ 
41. During the past year, our program has used the following indirect assessment techniques. (Please mark all that apply.)

\begin{tabular}{|c|c|c|c|}
\hline (2) & Frequently & Sometimes & Seldom \\
\hline - Classroom assessment techniques............... & $\mathrm{O}$ & $\mathrm{O}$ & $\mathrm{O}$ \\
\hline - Reflective papers and journals................ & $\mathrm{O}$ & $\mathrm{O}$ & $\mathrm{O}$ \\
\hline - Entrance interviews.............................. & $\mathrm{O}$ & $\mathrm{O}$ & $\mathrm{O}$ \\
\hline - Mid-point interviews.... & $\mathrm{O}$ & $\mathrm{O}$ & $\mathrm{O}$ \\
\hline • Exit interviews............................... & $\mathrm{O}$ & $\mathrm{O}$ & $\mathrm{O}$ \\
\hline • Focus groups............................... & $\mathrm{O}$ & $\mathrm{O}$ & $\mathrm{O}$ \\
\hline - Employer surveys..... & $\mathrm{O}$ & $\mathrm{O}$ & $\mathrm{O}$ \\
\hline - Patient surveys........ & $\mathrm{O}$ & $\mathrm{O}$ & $\mathrm{O}$ \\
\hline - Other & $\mathrm{O}$ & $\mathrm{O}$ & $\mathrm{O}$ \\
\hline
\end{tabular}

If possible, please include a sample of your commercially- and locally-developed instruments when you return your survey.

42. Our program has developed clear criteria to identify who will be required or invited to participate in specific assessment activities (e.g., prospective student, alumni)

43. Our program has developed clear criteria to identify when students will be required or invited to participate in assessment activities (e.g., entrance, exit, etc.)........

44. Our program has developed clear criteria to identify what will be assessed (e.g., critical thinking, etc.).........

45. Our program has developed clear criteria to identify how assessment will take place (e.g., exam, journals, etc.)
Strongly

Agree Agree Disagree Disagree

$\mathrm{O} \quad \mathrm{O} \quad \mathrm{O} \quad \mathrm{O}$

$\mathrm{O} \quad \mathrm{O} \quad \mathrm{O} \quad \mathrm{O}$

$\mathrm{O} \quad \mathrm{O} \quad \mathrm{O} \quad \mathrm{O}$

$\mathrm{O} \quad \mathrm{O} \quad \mathrm{O} \quad \mathrm{O}$

Using Assessment Results to Make Program Improvements.

46. Programmatic accountability is the focus of our assessment process

47. Programmatic improvement is the focus of our assessment process

48. Our program conducts planning based on assessment results.

49. Our program incorporates assessment results in our program review

50. Our program uses assessment results to acquire budget increases....
$\mathrm{O} \quad \mathrm{O} \quad \mathrm{O} \quad \mathrm{O}$

$\mathrm{O} \quad \mathrm{O} \quad \mathrm{O} \quad \mathrm{O}$

$\mathrm{O} \quad \mathrm{O} \quad \mathrm{O} \quad \mathrm{O}$

$\begin{array}{llll}\mathrm{O} & \mathrm{O} & \mathrm{O} & \mathrm{O}\end{array}$

$\begin{array}{llll}\mathrm{O} & \mathrm{O} & \mathrm{O} & \mathrm{O}\end{array}$ 
51. Our program makes curricular modifications based on assessment results.

52. Our program uses assessment results to improve teaching....

53. Our program uses assessment results to improve student learning....
Strongly

Agree Agree Disagree Disagree

$\mathrm{O} \quad \mathrm{O} \quad \mathrm{O} \quad \mathrm{O}$

$\mathrm{O} \quad \mathrm{O} \quad \mathrm{O}$

$\mathrm{O}$

$\mathrm{O} \quad \mathrm{O} \quad \mathrm{O} \quad \mathrm{O}$

Communicating Assessment Results to Specific Audiences.

54. Our program uses the following formats to report assessment results: (Please mark all that apply)
O Comprehensive reports
O Presentations
O Annual reports
O Programmatic report cards
O Executive summaries
O Specific audience reports
O Special reports
O Newsletters
O Web-based reports
O Other:

55. We report assessment results to: (Please mark all that apply)

Internal Audiences-
O Institutional executives
O Faculty
O Senior administrators
O Students
O Institutional committees (e.g., budget)
O Other:

External Audiences-
O Parents
O Professional bodies
O Alumni
O State government
O Employers
O Accrediting bodies
O Federal government
O Other:

56. Our reports are initially released to those most affected by the results.

\begin{tabular}{|c|c|c|c|}
\hline \multicolumn{3}{|c|}{ Strongly } & Strongly \\
\hline Agree & Agree & Disagree & Disagree \\
\hline $\mathrm{O}$ & $\mathrm{O}$ & $\mathrm{O}$ & $\mathrm{O}$ \\
\hline
\end{tabular}

57. Our reports are released prior to decisions being made, so that the findings and recommendations can become part of the decision-making process....................

$\mathrm{O} \quad \mathrm{O} \quad \mathrm{O} \quad \mathrm{O}$

58. Our reporting process considers the needs of various audiences and the appropriate sequence of report sharing

$\mathrm{O} \quad \mathrm{O} \quad \mathrm{O} \quad \mathrm{O}$

59. Our program has a dissemination plan for reporting assessment results. $\begin{array}{llll}\mathrm{O} & \mathrm{O} & \mathrm{O} & \mathrm{O}\end{array}$

If possible, please include a sample of one of your assessment reports when you return your survey. 
60. Our assessment plan is fully developed.....

61. Our assessment plan is fully implemented.....
Strongly

Agree Agree Disagree Disagree

$\mathrm{O} \quad \mathrm{O} \quad \mathrm{O} \quad \mathrm{O}$

$\mathrm{O} \quad \mathrm{O} \quad \mathrm{O} \quad \mathrm{O}$

Additional comments:

\section{Please return this survey by January 21, 2004.}

If you would like to receive the results of this survey, please fill in this bubble: $\mathrm{O}$

Please send a copy of your program's assessment plan to: NSlopeExpd@,3wlogic.net

or

Don Shipman, MPAS, PA-C

1 Deerwood Lane

Buckhannon, WV 26201

Please be assured that anonymity and confidentiality will be maintained during all phases of the research.

Please send additional questions and comments to the researcher at: NSlopeExpd@3wlogic.net Thank you for your time and attention.

Donald G. Shipman, MPAS, PA-C

Doctoral Candidate

West Virginia University 


\section{APPENDIX B}

\section{Carnegie Classification of Physician Assistant Programs}




\section{Institutions by Carnegie Classification, Control, and State}

The 133 PA programs listed below are taken from the Association of Physician Assistant Programs' 2002 faculty directory (APAP, 2002) and the Accreditation Review Commission on Education for the Physician Assistant 2003 listing (ARC-PA, 2003). The programs are matched with their home institutions and their respective Carnegie classifications are thus established. In regard to these classifications, the Carnegie Foundation for the Advancement of Teaching (2000) states that:

The 2000 Carnegie Classification groups institutions according to their degree-granting activity from 1995-96 through 1997-98. The use of a consistent time referent is an important element of the Classification. Users of the Classification should bear in mind that an institution might be classified differently using more recent data.

Doctoral/Research Universities-Extensive

Public institutions, by state.

$\begin{array}{ll}\text { Alabama } & \text { University of Alabama-Birmingham } \\ \text { California } & \text { University of California-Davis } \\ \text { Florida } & \text { University of Florida } \\ \text { Illinois } & \text { Southern Illinois University-Carbondale } \\ \text { Iowa } & \text { University of Iowa } \\ \text { Kentucky } & \text { University of Kentucky } \\ \text { Michigan } & \text { Wayne State University } \\ & \text { Western Michigan University } \\ \text { New York } & \text { State University of New York-Stony Brook } \\ \text { New Mexico } & \text { University of New Mexico } \\ \text { Oklahoma } & \text { University of Oklahoma } \\ \text { Utah } & \text { University of Utah } \\ \text { Washington } & \text { University of Washington } \\ \text { Wisconsin } & \text { University of Wisconsin-Madison }\end{array}$


Private not-for-profit institutions, by state.

$\begin{array}{ll}\text { California } & \begin{array}{l}\text { Stanford University } \\ \text { University of Southern California }\end{array} \\ \text { Connecticut } & \text { Yale University } \\ \text { District of Columbia } & \text { George Washington University } \\ & \text { Howard University } \\ \text { Georgia } & \text { Emory University } \\ \text { Massachusetts } & \text { Northeastern University } \\ \text { Missouri } & \text { Saint Louis University } \\ \text { North Carolina } & \text { Duke University } \\ \text { Wisconsin } & \text { Marquette University }\end{array}$

Doctoral/Research Universities-Intensive

Public institutions, by state.

\begin{tabular}{|c|c|}
\hline Alabama & University of South Alabama \\
\hline Idaho & Idaho State University \\
\hline Kansas & Wichita State University \\
\hline Michigan & Central Michigan University \\
\hline North Carolina & East Carolina University \\
\hline North Dakota & University of North Dakota \\
\hline South Dakota & University of South Dakota \\
\hline \multicolumn{2}{|c|}{ Private not-for-profit institutions, by state. } \\
\hline California & Loma Linda University \\
\hline Florida & Nova Southeastern University \\
\hline New Jersey & Seton Hall University \\
\hline \multirow[t]{2}{*}{ New York } & Hofstra University \\
\hline & Pace University \\
\hline North Carolina & Wake Forest University \\
\hline \multirow[t]{3}{*}{ Pennsylvania } & Drexel University \\
\hline & Duquesne University \\
\hline & MCP Hahnemann University \\
\hline
\end{tabular}

Master's Colleges and Universities I

Public institutions, by state.

Maryland Towson University

University of Maryland Eastern Shore

Michigan Grand Valley State University

Missouri Southwest Missouri State University

Texas University of Texas - Pan American 


\begin{tabular}{ll} 
Virginia & James Madison University \\
Wisconsin & University of Wisconsin-La Crosse \\
\multicolumn{1}{c}{ Private not-for-profit institutions, by state. } \\
Connecticut & Quinnipiac University \\
Florida & Barry University \\
Indiana & Butler University \\
Massachusetts & University of Saint Francis \\
Michigan & Springfield College \\
New Hampshire & University of Detroit Mercy \\
New York & Notre Dame College \\
& Long Island University-Brooklyn \\
& Mercy College \\
& New York Institute of Technology \\
& Rochester Institute of Technology \\
& Touro College-Bayshore \\
Touro College-Manhattan
\end{tabular}

Public institutions, by state.

Pennsylvania Lock Haven University of Pennsylvania

Private not-for-profit institutions, by state.

Maine University of New England

Minnesota Augsburg College

New York Le Moyne College

Pennsylvania King's College 
Baccalaureate Colleges-Liberal Arts

Private not-for-profit institutions, by state.

Pennsylvania Chatham College

Tennessee Bethel College

Baccalaureate Colleges-General

Private not-for-profit institutions, by state.

Montana $\quad$ Rocky Mountain College

Nebraska Union College

New York Daemen College

North Carolina Methodist College

Ohio Marietta College

Baccalaureate/Associate's Colleges

Public institutions, by state.

Pennsylvania Pennsylvania College of Technology

Private not-for-profit institutions, by state.

West Virginia Mountain State University

Associate's Colleges

Public institutions, by state.

California $\quad$ Riverside Community College

Colorado Red Rocks Community College

Florida Miami-Dade Community College

Illinois City College of Chicago-Malcolm X College

Maryland Anne Arundel Community College

Ohio Cuyahoga Community College

Private for-profit institutions, by state.

California San Joaquin Valley College

Georgia South University 


\section{Medical Schools and Medical Centers}

Public institutions, by state.

$\begin{array}{ll}\begin{array}{ll}\text { Colorado } \\ \text { Georgia }\end{array} & \text { University of Colorado Health Sciences Center } \\ \text { Louisiana } & \text { Medical College of Georgia } \\ \text { Nebraska } & \text { Louisiana State University Health Sciences Center } \\ & \text { University of Nebraska Medical Center } \\ \text { New Jersey } & \text { University of Nebraska Medical Center-Interservice (San Antonio, TX) } \\ \text { New York } & \text { University of Medicine and Dentistry of New Jersey-Piscataway } \\ & \text { Albany Medical College } \\ & \text { Cornell University Medical Campus } \\ & \text { State University of New York Health Science Center-Brooklyn } \\ \text { Ohio } & \text { State University of New York Health Science Center-Stony Brook } \\ \text { Oregon } & \text { Medical College of Ohio } \\ \text { South Carolina } & \text { Oregon Health Sciences University } \\ \text { Texas } & \text { Medical University of South Carolina } \\ & \text { Texas Tech University Health Sciences Center } \\ & \text { University of North Texas Health Sciences Center } \\ & \text { University of Texas Health Science Center-San Antonio } \\ & \text { University of Texas Medical Branch-Galveston } \\ & \text { University of Texas Southwestern Medical Center-Dallas }\end{array}$

Private not-for-profit institutions, by state.

California Western University of Health Sciences

Touro University at Mare Island College of Health Science

Illinois $\quad$ Finch University of Health Sciences-Chicago Medical School

Midwestern University (Glendale, AZ)

Iowa Des Moines University Osteopathic Medical Center

Pennsylvania Philadelphia College of Osteopathic Medicine

Texas Baylor College of Medicine

Virginia $\quad$ Eastern Virginia Medical School

Other Separate Health Profession Schools

Private not-for-profit institutions, by state.

California Charles R. Drew University of Medicine \& Science

Samuel Merritt College

Massachusetts Massachusetts College of Pharmacy and Allied Health Sciences

New York D'Youville College

Ohio Kettering College of Medical Arts

Virginia College of Health Sciences-Community Hospital of Roanoke Valley

West Virginia Alderson Broaddus College 
Not Classed

Arizona

Arizona School of Health Science

New York

Bronx-Lebanon Hospital Center

City University of New York-Harlem

St. Vincent Catholic Medical Center-Fresh Meadows

St. Vincent Catholic Medical Center-Staten Island 


\section{APPENDIX C}

Pilot Study Advanced Mailing 


\section{Sample Electronic Mail Message}

To:

From: dshipman@mix.wvu.edu

Subject: Pilot Study (PA education research)

Dr.

This is an advanced mailing on behalf of West Virginia University and the Association of Physician Assistant Programs inviting you to participate in a pilot survey of ten Physician Assistant (PA) program directors. This survey is part of a doctoral dissertation in Advanced Educational Leadership. The research intent is to survey all PA program directors to determine the extent of assessment activities within their programs.

In the next week, you will be receiving a survey and cover letter further explaining the pilot. Please be assured that your feedback is vital to this research and will be used in an anonymous and confidential manner.

We realize that you are quite busy and we wish to express our sincere appreciation for taking your time to assist us in this pilot.

Regards,

Donald G. Shipman, MPAS, PA-C

Doctoral Candidate

West Virginia University

(304) 472-1150 / dshipman@mix.wvu.edu 


\section{APPENDIX D}

\section{Pilot Study Cover Letter}


(West Virginia University Letterhead)

December 1, 2003

, PA-C
Program Director, PA Program
University
WVU-IRB Approval: 12-01-03

APAP Approval: 11-25-03

\section{Dear}

On behalf of West Virginia University and the Association of Physician Assistant Programs, I would like to invite you to participate in a pilot survey of ten Physician Assistant (PA) program directors. This survey is part of a doctoral dissertation in Advanced Educational Leadership. The research intent is to survey all PA program directors to determine the extent of assessment activities within their programs.

The data collected from this survey will provide a baseline measurement of where PAs as a profession lie along the assessment continuum in higher education. This data will provide PA educators an indication of our strengths and limitations in programmatic assessment. Most importantly, the results may suggest improvements in faculty development, student learning, and programmatic growth. Your input is vitally important to this research. Please be assured that your input will be used in an anonymous, confidential manner.

As a pilot study participant, I would like to call you and discuss the survey before you return it. During the conversation, I would like to discuss survey items that may be unclear or unfamiliar terminology. Your insights and suggestions will make the instrument stronger and clearer for the remaining PA program directors. Lastly, I will email / call you within the next two weeks to arrange this conversation.

In addition to the survey, please enclose the following qualitative samples for analysis:

- Guiding principles for assessment (institutional or programmatic)

- Materials that describe incentives for faculty participation in assessment

- Examples of programmatic goals and student learning outcomes

- Examples of student learning outcomes at the course-level

- Commercially- and locally-developed instruments (e.g., direct, indirect)

- An assessment report

- Your assessment plan 
West Virginia University, the Association of Physician Assistant Programs, and I realize that you are quite busy and we wish to express our sincere appreciation for taking your time to assist us in this pilot. Please return the survey in the enclosed stamped, selfaddressed enveloped by December , 2003.

I look forward to speaking with you. Thank you for your time and attention.

Regards,

Donald G. Shipman, MPAS, PA-C

Doctoral Candidate

West Virginia University

(304) 472-1150 / dshipman@mix.wvu.edu 


\section{APPENDIX E}

Survey Cover Letter 
January 1,2004

, PA-C

Director, PA Program
WVU-IRB Approval: 12-01-03

APAP Approval: $11-25-03$

\section{University}

\section{Dear}

On behalf of West Virginia University (WVU) and the Association of Physician Assistant Programs (APAP), I would like to invite you to participate in a census of all the Physician Assistant (PA) program directors in the nation. This survey is part of a doctoral dissertation in Advanced Educational Leadership. The intent of this census is to determine the extent of assessment activities within PA programs.

The data collected from this survey will provide a baseline measurement of where PAs as a profession lie along the assessment continuum in higher education. This data will provide PA educators an indication of our strengths and limitations in programmatic assessment. Most importantly, the results may suggest improvements in faculty development, student learning, and programmatic growth. Your input is vitally important to this research. Please be assured that your input will be used in an anonymous, confidential manner. Participation in the survey is voluntary and questions may be left unanswered if you desire. Completing this survey should take about 30 minutes.

Once completed with the survey, return it in the enclosed stamped, self-addressed envelope by January 21, 2004.

If possible, please include the samples listed below when you return your survey. The rich qualitative data gleaned from your samples will provide a greater degree of triangulation and depth to the research results. I realize that providing these samples may take you extra time and I sincerely appreciate your willingness to assist me in this study. The requested samples are:

- Guiding principles for assessment (institutional or programmatic)

- Materials that describe incentives for faculty participation in assessment

- Examples of programmatic goals and student learning outcomes

- Examples of student learning outcomes at the course-level

- Commercially- and locally-developed instruments (e.g., direct, indirect)

- An assessment report

- Your assessment plan 
This survey was approved by APAP for distribution to PA program directors on November 25, 2003. For verification, see:

http://paprogam.medicine.uiowa.edu/randr/RR_surveys.htm

West Virginia University, the Association of Physician Assistant Programs, and I realize that you are quite busy and we wish to express our sincere appreciation for taking your time to assist us in this census of your fellow program directors.

Regards,

Donald G. Shipman, MPAS, PA-C

Doctoral Candidate

West Virginia University

(304) 472-1150 / NSlopeExpd@3wlogic.net 


\section{APPENDIX F}

Program Documents Protocol 


\section{Program Documents Protocol}

\section{Date}

Director

Institution

1. Documents reflect executive-level support for assessment activities. (describe)

2. Documents reflect faculty development in assessment activities. (describe)

3. Documents reflect programmatic student learning outcomes. (describe) 
4. Documents reflect student learning outcome integration at the course level. (describe)

5. Documents reflect measurements of student learning. (describe)

6. Documents reflect the use of assessment results to make programmatic improvements. (describe)

7. Documents reflect the dissemination of assessment results to specific audiences. (describe) 